(Aus dem physiologischen Institut zu Breslau.)

\title{
Versuche über den zeitlichen Verlauf des Muskelstroms im Tetanus.
}

Von

\section{Dr. K. Sehoenlein,}

Privatdocent und Assistent am physiologischen Institut zu Würzburg.

Hierzu Tafel III u. IV und 5 Figuren.

Die im Nachfolgenden mitgetheilten Untersuchungen sind in der Absicht angestellt, über den Verlauf der negativen Schwankung im Tetanus detaillirtere Aufschlïsse zu gewinnen.

Aus einer in $\mathrm{Du}$ Bois Arehiv von mir mitgetheilten Untersuchung ${ }^{1}$ ) iiber die Summation der negativen Schwankungen bat sich ergeben, dass in gleich langen Tetanis die tetanische negative Schwankung trotz wachsender Häufung der Reize sich ihrer absoluten Grösse nach nicht weiter verändert, sobald die Zahl der Reize in der Zeiteinheit ein gewisses, ziemlich niedriges Maass überschritten hat, ein Verhältniss was oft schon bei einer Geschwindigkeit von 40 Reizen in der Secunde eintritt.

Unter der Voraussetzung, dass die einzelnen Schwankungen im Tetanus gleich gross sind, ergiebt sich, dass dieselben mit abnehmendem Reiz-Intervall sich verkleinern miissen, und ferner, dass die erste Schwankung im Beginn des Tetanus grösser sein muss als alle ubrigen, da Mangels eines vorangegangenen Reizes für sie die Bedingung fehlt, in Folge deren sich die übrigen Schwankungen verkleinern. Die Voraussetzung absoluter Gleichheit der Schwankungen ist jedoch ebenso wenig bewiesen, wie ihre Isoperiodicität mit der Reizfolge. Die Resultate der Untersuchung des Muskeltones durch einfache Auscultation sowohl, als auch dieBeobachtung der Actionsströme mit dem Telephon schliessen die Möglichkeit eines periodischen Wechsels der Schwankungsgrösse nicht aus, wie vor allem die Beobachtung lehrt, dass bei Reizung mit dem akustischen Unterbrecher der Muskelton auch

1) Die Summation der negativen Schwankungen. Du Bois Archiv 1886, S. 251. 
die tiefere Quinte des erregenden Tones sein kann. Da hier Reizzahl und Schwankungszahl im Verbältniss von $2: 3$ stehen, lässt sich der Befund nicht wohl aus dem regelmässigen Ausfall eines der erregenden Stromstösse erklären. Eine genaue Analyse des tetanischen Schwankungsvorganges kann vielmehr mit den bisher zu Gebote stehenden Hilfsmitteln nur dadurch erreicht werden, dass man die tetanische Schwankung mit dem Rheotom in gleicher Weise untersucht, wie dies bis jetzt für die Einzelzuckung geschehen ist. Die vollständige Durchführung dieser Aufgabe wird sich nun freilich am iuberlebenden Muskel nicht bewerkstelligen lassen, da denn kein Muskel die hierzu nöthige grosse Zahl von Zuckungen liefern kann. Beschränkt man sich indessen darauf, zu untersuchen, wie sich die Schwankangscurve bei zwei oder drei auf einanderfolgenden Reizen verhält, so lassen sich einige positive Resultate gewinnen, welche ich im Nachfolgenden mittheilen will.

Untersuch ungsmethode.

In dem in Figur I beigezeichneten Schema bedeutet $R$ das Rheotom, dessen Rad, durch einen seiner Durchmesser $D$ vertreten, an seiner Peripherie einerseits den bekannten rotirenden Stift zur Erzeugung des Reizcontactes trägt, und den ich, um eine kurze Bezeichnung zu haben, den Contactstift nennen will. Ihm sitzt diametral gegentiber ein zweiter Stift, der die Zulassung des Muskelstroms zur Boussole in einer nachfolgends zu schildernden Weise zu besorgen hat, und der deshalb Boussolstift heissen möge. Von den drei horizontal and radial zur Rheotomtaxe aufgestellten ubrigens isolirten Contactdrähten $a, b, c$, tiber welche der Contactstift hinwegzugleiten hat, geht je eine metallische Verbindung zu den drei Vorreibern $\alpha, \beta, \gamma$, und von diesen zur rechten Seite eines Du Bois'schen Schlüssels. Von der rechten wie von der linken Seite dieses Schlüssels fübrt je ein Draht zu je einer Klemme des Stromumschalters $U$, von der linken Seite des Schlüssels ausserdem ein zweiter Draht nach Durchsetzung der primären Spirale $P$ zur Batterie des Reizkreises $E$. Der andere Pol der Batterie ist in der gewöhnlichen Weise durch die Axe des Instrumentes zum Contactstift geführt.

Den Contactdrähten, resp. ihrem Träger gegenüber, steht, unveränderlich fest auf der mit Gradeintheilung versehenen Grund- 


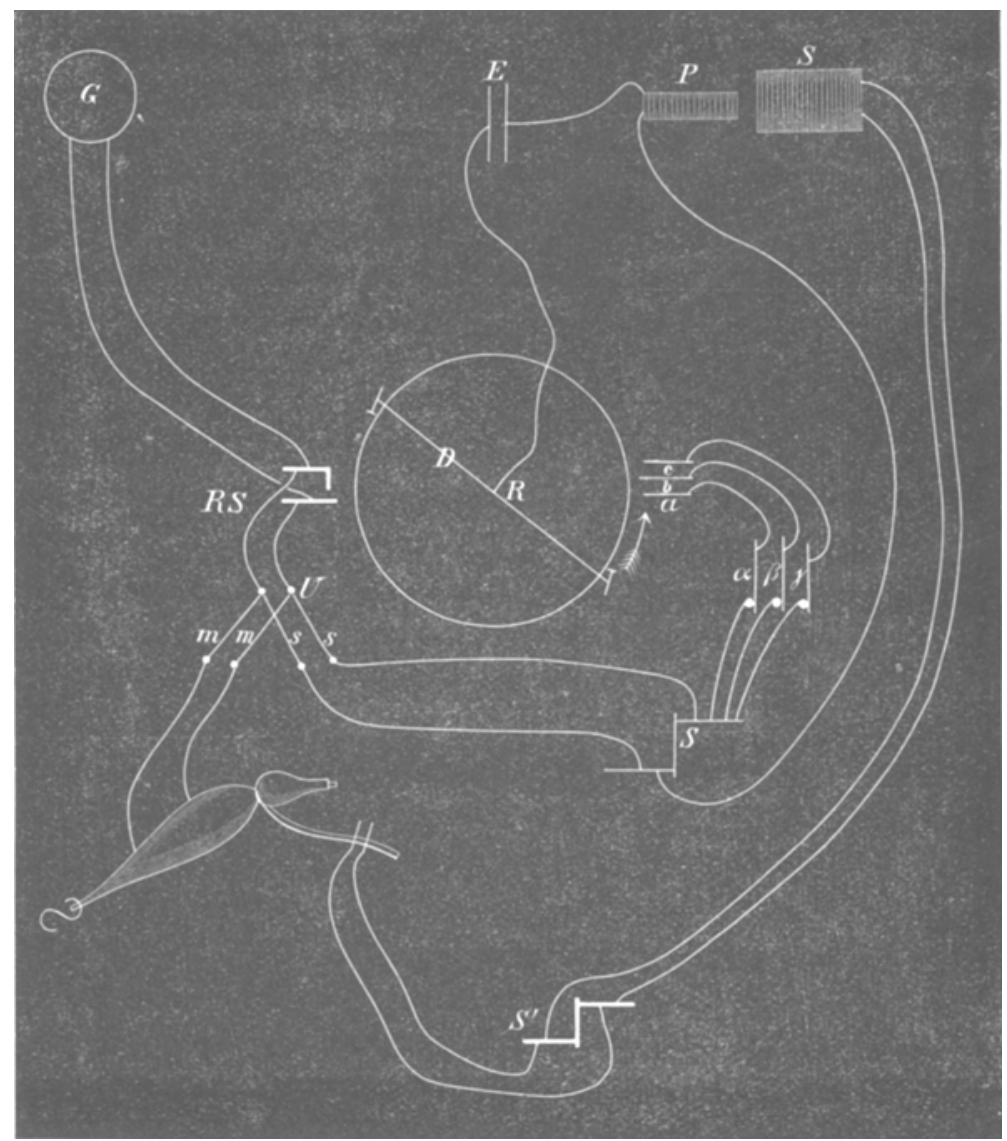

Fig. I.

platte des Instrumentes, die später zu beschreibende Ableitungsvorrichtung $R S$ für den Muskelstrom. Sie ist einerseits nit der Boussole $G$, andererseits mit einem Klemmenpaar des Umschalters $U$ verbunden. Die Electrodendrähte des Muskels endlich führen ebenfalls in ein drittes Klemmenpaar des Umschalters $U$.

Sind die Riegel des Umschalters, welche mit der Ableitevorrichtung $R S$ dauernd verbunden sind, in der Richtung $m m$ eingestellt, so geht der Muskelstrom durch $R S$ zur Bonssole. Der Reizstrom kann, solange der Schlüssel $S$ offen ist, iberhaupt nicht geschlossen werden, bei Schluss desselben kann er, je nachdem $\alpha, \beta$ oder $\gamma$ offen oder geschlossen ist, einen, zwei oder alle drei Reizcontacte durchsetzen. Ist der Umschalter $U$ in der Lage $s s$ 
eingestellt, so hat der Reizstrom beim Ablauf der Reizcontacte zwei Wege frei, den einen durch die Contactbahn, den andern durch die Ableitungsvớrichtung, zu welcher der Riegel des Schliissels $S$ die Nebenschliessung bildet. Nach Oeffnung des Schlüssels $S$ kann nur der Umweg durch die Boussolableitung rom Strom betreten werden, und man kann durch Verschiebung der Contacte längs der Peripherie der die Gradtheilung tragenden Scheibe die Zeit der Zufiihrung des Muskelstromes zur Boussole leicht in bekannter Weise ermitteln. Die Einzelheiten der Einrichtungen ergeben sich aus dem Folgenden. Es ist ersichtlich, dass das zur Construction der tetanisehen Schwankungscurve nöthige Material gewonnen wird aus der Grösse der einzelnen Phasen der negativen Schwankung, wenn erstens bei gegebener wechselseitiger Entfernung der Contacte und der Boussolableitung die Contacte $\mathbf{a}, \mathbf{b}$ und $\mathbf{c}$ jeder für sich, dann die Contacte a und b zusammen, und schliesslicb die Contacte $a, b$ und $c$ gemeinschaftlich zur Muskelreizung. benutzt werden, und zweitens, ohne dass in den gegenseitigen $A b$ ständen der Contacte etwas geändert wird, unter Aendernng ihrer Abstände von der Bonssolablcitung die ebengenanuten Reizungsserien wiederholt werden. Für die Vergleichbarkeit der erhaltenen Ausschlïge ist Vorbedingung, dass die Zeit wälurend welcher der Muskelstrom zur Boussole abgeleitet wird, sich nicht wesentlich ändere. Die Controle der Ableitungszeit könnte geschehen, indem man zwischen je zwei Versuchen dieselbe, nach Ausfïhrung der erforderlichen, in der Erläuterung der Versuchsanordnungen schon mitgetheilten Stromumschaltungen, unmittelbar misst, oder indem man die Ausschläge des Ruhestroms bei rotirendem Instrument selbst zum Controlobject macht. Dieselben werden, sobald die Ableitungszeit merklich sich ändert, ebenfalls wachsen oder abnehmen, und man wird, sobald die Scala im Fernrohr ihren Stand nicht verändert, annehmen können, dass die Ableitungszeit sich nicht verändert hat. Diese Bedingung wird von den bisher bekannten Ableitungsvorrichtungen in einer für unsere Versuchszwecke nur unzulänglichen Weise erfüllt.

Wer längere Zeit mit dem Bernste in'schen Quecksilbercontact gearbeitet hat, wird bald bemerkt haben, dass die Scala in einer den Versuch recht störenden Weise zu wandern beginnt, sobald derselbe eine Weile gedauert hat. Sie bewegt sich, in den einzelnen Lagen kürzere Zeit verharrend, ruckweis um eine mitt- 
lere Gleichgewichtslage hin und her. Die Abweichungen von letzterer gehen nach beiden Seiten häufig bis zu 10 Procent des Ausschlagsmittels, hin und wieder auch noch weiter. Ich hielt dieselben zunächst für den Ausdruck plötzlicher Schwankungen des Muskelstromes, die durch irgendwelche, an Querschnitt vor sich gehende Erregungen bervorgerufen seien. Ersetzte man jedoch den Muskelstrom durch den Zweigstrom eines Daniel'schen Elementes, so blieb die Erscheinung unverändert, konnte also auf Intensitäts-Schwankungen des Muskelstromes nicht beruhen. Die das Rheotom treibende electromotorische Maschine konnte Ursache der Ablenkung ebenfalls nicht sein, da die Ablenkungen ausblieben, wenn bei laufendem Instrument der zur Boussolleitung gehörende Du Bois'sche Schlüssel geschlossen war. Es konnte die Ursache der Erscheinung somit nur im Contact liegen, und in der That schwand sie anch jedesmal, wenn das Quecksilber der Contactnäpfe, durch frisehes, chemisch reines ersetzt wurde. Unreinigkeiten der Quecksilberoberfläche waren zur Zeit des Beginns der Störungen jedoch zumeist noch nicht zu bemerken.

Arbeitet man mit compensirtem Muskel oder Nervenstrom, so ist von derlei Unregelmässigkeiten nichts zu erkennen; da es, so lange der Muskel nicht gereizt wird, zu einer Ablenkung der Scala ja überhaupt nicht kommt. Da die bisherigen Rheotomversuche zumeist mit compensirtem Ruhestrom angestellt wurden, liegt hierin vielleicht auch der Grund, warum eine ausdrïckliche Beriicksichtigung dieses Punktes in den früheren Untersuchungen unterblieben ist. Für die allgemeine Feststellung der Schwankungscurve und der Fortpflanzungsgeschwindigkeit der Schwankung ist er auch ein Fehler von verhältnissmässig geringer Bedeutung.

Man hat daher bei der Arbeit ohne Compensation am Verhalten des Ausschlags eine sebr gute Controlle der Contactzeit, und ich habe mich desshalb bei den hier angestellten Versuchen der Compensationsmethode nicht bedient.

Da die frische Füllung der Contactnäpfe immer mit etwas Umständlichkeit verbunden ist, und insbesondere auch jedesmal eine neue Bestimmung der Contactzeit benöthigt, habe ich mich bemuiht, eine bequemere Methode der Stromzulassung ausfindig zu machen. Unter den bisher bekannten Methoden scheint mir die Bernstein'sche noch immer die beste za sein. Der Hermannsche Bürstencontact arbeitet keinesfalls regelmässiger, und die 
Bürsten erleiden im Verlaufe mehrerer Versuche die sonderbarsten Verbiegungen, theils durch die Wirkung der Centrifugalkraft, theils wohl auch durch die fortwährend ihnen von den Kupferbänkchen während ihrer Thätigkeit ertheilten Stösse ${ }^{1}$ ). Bezüglich des dem Hermann'schen im Principe gleichenden Head'schen Contactes giebt $\mathrm{Head}{ }^{2}$ ) electromotorische Wirkungen desselben an, die eine vorsichtige Behandlung der Contactflächen nöthig machen.

Ich habe desshalb versucht, den Muskelstrom dauernd geschlossen zu halten, indem ich ihn von der Boussole durch eine am Rheotom befestigte Nebenschliessung abblendete, und die periodische Oeffnung derselben dem bereits genannten, am Rheotomrade selbst befestigten Boussolstift ubertrug. Ich will den Apparat Rheotomschlüssel nennen. Seine Construction und Wirkungsweise ergiebt sich aus den auf Taf. III beigefügten Zeichnungen Fig. 1-3.

An dem Eförmig gebogenen Messingstück $A$, siehe Fig. 1, welche den Apparat von der Seite darstellt, mittelst dessen der Rheotomschliussel an die Theilscheibe des Rheotoms angeschraubt wird und welches an der oberen Seite der Scheibe, um einen festen Stand zu ermöglichen, derselben mit nur drei Punkten aufliegt, ist die Laufschiene $b$ für den Schlitten $c$ angebracht. Letzterer bildet den eigentlichen Träger des Schlüssels, und ist in seiner Bahn parallel der Rheotomaxe durch die Schraube $d$ mit feiner Einstellung zu verschieben. Für die gute Function des Apparates ist sorgfältige Herstellung der Gleitflächen Hauptbedingung. Da die gewöhnliche Schiebung in dreieckigen Prismen mit Federklemmung nicht genügt, um seitliche Verschiebungen des Gleitstiucks sicher zu verhindern, wurde die in der Mechanik anch sonst gebräuchliche Schwalbenschwanzführung mit Keilklemmung angewendet, welche seitliche Verschiebungen absolut ansschliesst. Der Sehlitten selbst trägt auf der, der Rheotomaxe zugewendeten Seite einen Ebonitwtirfel $E$. Die axiale Seite desselben bleibt frei, anf der rechten jedoch wie auf der linken Seite trägt er ein Schraubklemmenpaar $e$ u. $f$ (siehe Fig. 2 u. 3 ), welches die von der Boussole und von den unpolarisirbaren Electroden kommenden Drähte

1) Ich muss allerdings dazu bemerken, dass die Bürsten Producte meiner eigenen Hände waren. Vielleicht sind die von Hermanns Mechaniker bezogenen etwas widerstandsfähiger.

2) H. Head, Ueber die negativen and positiven Schwankungen des Nervenstromes. Pflüger's Archiv Bd. XXXX, S. 245. 
aufzunehmen bestimmt ist. Das eine von ihnen $(f)$ ist mit einem auf der oberen Fläche des Ebonitklotzes befestigtem Messingwtirfel $(f$, metallisch verbunden, das andere $(e)$ sitzt auf einer Messingplatte, deren axialer Rand bei $h$ iiber den Ebonitklotz vorsteht, und daselbst eine nach aufwärts strebende Messingsäule $(h)$ trägt. Diese ist in der Höhe der oberen Fläche des Messingwürfels borizontal und tangential zum Rheotomrade umgebogen, und trägt an ihrem Ende eine nach abwärts laufende, am nnteren Ende mit einem Platinstift versehene Contactschraube $(h$,$) . Die auf dem Messingwürfel$ verschraubte, an der Stelle ihrer Berührung mit der Contactschraube ebenfalls mit Platinblech versehene Blattfeder $i$ verbindet endlich metallisch das rechte und linke Klemmschraubenpaar. Das ganze stellt somit einen Dubois'schen Schliussel dar, welcher durch die Feder dauernd geschlossen ist, und nur geöffnet wird, wenn der am Rheotomrade isolirt befestigte Stift $k^{1}$ ) (Boussolstift) bei seinem Umlauf den iiber $h$, vorstehenden Rand der Feder nach abwärts bewegt.

Die Figuren 2 und 3 stellen den Schliissel von oben und von der der Axe des Rheotoms zugewendeten Seite dar, bei Fig. 3 ist Schlittenbahn und Schlitten weggelassen. Die Bezeichnungen sind die gleichen wie bei Figur 1. Da der Gebrauch des Rheotomschlïssels grössere Reibungswiderstände einfülurt, als der Quecksilbercontact, und die Benutzung dreier Contacte ebenfalls gewisse Hindernisse fiur die gleichförmige Bewegung des Rheotomrades bietet, wurde dasselbe durch eine massive $2 \mathrm{~mm}$ starke Messingscheibe von $12 \mathrm{~cm}$ Durchmesser ersetzt und aus später zu erwähnenden Gründen die Axe des Rades ebenfalls verstärkt, dazu unter die Scheibe noch ein starker Schwungkranz gelegt ${ }^{2}$ ). Die Controlle des gleichmässigen Umlaufs lieferte eine Stimmgabelschrift auf einer zu diesem Zweck auf der Axe dauernd befestigten, mit berusstem Papier bezogenen kleinen Messingtrommel von $52 \mathrm{~mm}$ Durchmesser und $18 \mathrm{~mm}$ Höhe. Ich lasse zunächst eine Copie der auf ihr gezeichneten Curven des Pfeil'schen Chronographen folgen, welcher zu diesem Zweck mit dem akustischen Stromunterbrecher in den-

1) Um letzteren in die richtige Lage zu Fig. I zu bringen, muss man ihn sich parallel zu sich selbst so verschoben denken, dass der Buchstabe $k$ iiber dem Buchstaben $h$ der Fig. I stèt.

2) Scheibe nebst Schwungkranz wiegen etwa $1100 \mathrm{gr}$. 
selben Stromkreis aufgenommen war. An derselben lassen sich Schwankungen der Geschwindigkeit von irgend welchem Belang nicht wahrnehmen. Die Umlaufszeit der Trommel betrug 0,2 Secunden, ihr Umfang $164 \mathrm{~mm}$, die Länge der einzelnen Schwingung rund $6,0 \mathrm{~mm}$, ihre Dauer also 1/135 Secunden. Die Trägheit des Rades war noch für einen etwa 16-18maligen Umlauf desselben genuigend, wenn der dasselbe treibende Motor durch Oeffnen des Strornkreises plötzlich ausser 'Th:itigkeit gesetzt wurde, nachdem er vorher die volle Umlaufsgeschwindigkeit erreicht hatte, und die Contacte nebst dem Rheotomschlissel in der richtigen beim Versuch nothwendigen Einstellung sich hefanden. Die Ableitungszeit betrug dam 0,0:12-0,003 Secunden, je nach der höheren oder tieferen Einstellung des Schlüssels.

Wiederholt man mit dem Rheotomschliussel den auf Seite 138 angegebenen Versuch, indem man statt des Muskelstroms den Strom eines Daniel'schen Elementes, jedoch unter Einschaltunig des Schliissels zur Boussole ableitet, so erhält man bei dem fiir die Darstellung der negativen Schwankung nöthigen Empfindlichkeitsgrade derselben zunächst schon $\mathrm{Ab}$ lenkungen bei stillstehendem Rheotom. Die Nebenschliessung hat für stärkere Ströme also keineswegs einen verschwindenden Widerstand. Sie reicht jedoch bei Strömen von der Ordnung des Muskelstromes vollständig bin, um keine Spur einer Ablenkung an der Boussole aufkommen zu lassen, so lange sie geschlossen ist. Bei rotirendem Instrument musste dann, wenn das Dan iel'sche Element als Stromquelle henutzt wurde, die Empfindlichkeit der Boussole selbstverständlich bedeutend herabgesetzt werden, indem nur der vierte 'Theil des Boussolgewindes, bei möglichst weitem Abstand von der Dämpfhälse benutzt wurde. Ich habe die Ablenkungsgrösse bei laufendem Rheotom nicht aufgeschrieben. Sie betrug jedoch mehr als 100 Scalentheile, und änderte sich 
nach Verlauf von zwei Stunden langsam mit der selbstverständlich eingetretenen Abnahme der electromotorischen Kraft des Elementes, jede irgendwie plötzliche Aenderung des Ausschlages war 'jedoch vollständig ausgeschlossen. Die Scala blieb oft mehrere Minuten hintereinander an derselben Stelle.

Zur Bestimmung der Ableitungsdauer werden die im Schema schon erwähnten Umschaltungen ${ }^{1}$ ) in der Stromleitung vorgenommen und die Stellungen des Reizcontactträgers aufgesucht, bei welchen die ersten und letzten Ablenkungen der Seala auftreten. Ist der Reizcontact so eingestellt, dass die Berührung zwischen Contactstift und dem auf dem Contactträger sich befindenden Theil des Contactes nur leicht ist, so bemerkt man zunächst, dass in den kritischen Stellungen des Contactträgers immer nur vereinzelte Ablenkungen auftreten, indem die Scala stossweise aus ihrer Ruhelage herausgeht, und nach kurzem Verweilen in der neuen Lage auf längere Zeit in die Ruhelage zurïckkehrt. Auch bei einer Einstellung des Contactträgers in dem zwischen den kritischen Stellungen liegenden Gebiete bemerkt man theils häufige Wiederkehr der Scala in ihre Rubelage, theils Ablenkungen von sehr weehselnder Grösse. Die Erscheinung ist bei Benutzung des leichten, ursprünglich zum Instrument gehörenden Rades noch viel ausgeprägter. Sie rührt offenbar von minimalen Schwingungen her, zu denen das Rad dureh die ihm rom Contact und vom Rheotomschliussel ertheilten Stösse angeregt wird. Verstärkt man den Contact, so bleibt die Scala dauernd abgelenkt, und die Unterschiede zwischen den einzelnen Ablenkungen werden kleiner, ohne jedoch vollständig zu verschwinden. Es ist klar, dass die Amplitude der Schwingungen um so kleiner werden muss, je nachgiebiger der auf dem Contactträger sich befindende Contacttheil, und je starrer das Rheotomrad ist. Möglichste Verkleinerung derselben war der zweite Grund, welcher zur Abänderung des Rheotomrades in der beschriebenen Weise Veranlassung gab.

Hat man den Contact stärker gemacht, während der Contactträger in der kritischen Stellung steben blieb, so tritt jetzt das Umgekehrte mit den Ablenkungen ein. Die Ablenkung wird dauernd, und die Scala geht nur in ganz einzelnen Momenten zur Ruhelage zurück. Nach einer ungefähren Zählung bleibt etwa

1) Der Umschalter liegt nach $S S$, der Schlüssel $S$ ist offen. 
der zwanzigste Contact ohne Erfolg, oft auch ist die Rückkehr zur Ruhelage seltener. Eine Verschiebung des Contactträgers um etwa den zwanzigsten Theil eines Rheotomgrades reicht dann hin, um auch dieses Ausbleiben zu beseitigen. Die Verschiebung: jedoch, deren es bedarf um denselben aus der Stellung ohne Ablenkung in die Stellung zu bringen, wo fast jeder Contact eine Ablenkung hervorbringt, ist noch viel geringer. Sie bleibt jedenfalls hinter dem dritten Theil dieser Grösse weit zurück.

Man kann sich nun die Bestimmung der Boussolsehlusszeit noch weit bequemer machen, wenn man anstatt der Boussolablenkungen das Telephon zum Aufsuchen der kritischen Stellungen des Contactträgers benutzt. Man braucht dazu nur das Telephon an Stelle der Boussole mit dem Rheotomschlüssel zu verbinden.

Ich hatte schon erwähnt, dass bei Benutzung eines Danielschen Elementes der Widerstand der Nebenschliessung im Rheotomschlüssel nicht gering genug ist, um jede Ablenkung der Scala bei dauerndem Stromschluss zu verhindern. Dieselbe bleibt bei den kurzen Stromstössen, welche das Galvanometer durchfahren, sobald demselben die Ströme durch den Reizcontact zugeführt werden, aus, so lange der Stromschluss nicht gerade zu der Zeit geschieht, wo die Nebenschliessung offen ist. Im Telephon jedoch nimmt man diesfalls immer ein schwaches Ticken wahr. Dasselbe verstäkt sich plötzlich, wenn diejenige Stellung des Contactträgers aufgesucht wird, bei welcher Stromschluss und Oeffunng des Rheotomschluissels zusammenfallen. Ehe diese Stellung erreicht ist und in derselben wechselt die Schallstärke, wenn der Contact nur auf eine leise Beriuhrung der Contactflächen eingestellt ist, zwischen bestimmten Grenzen hin und her. Macht man den Contact kräftiger, so wird die Schallstärke constant, und bleibt auch in der kritischen Schieberstellung sich gleich. Sobald dieselbe iiberschritten ist, wandelt sich das Ticken in einen scharfen Knall $\mathrm{um}$, der auch, natürlich bedeutend leiser, zu hören ist, wenn man das Telephon vom Ohr entfernt und neben sich auf den Tisch stellt. Ich schätze die Strecke, auf welcher sich diese Schallumwandlung vollziebt, auf etwa den vierzigsten Theil eines Rheotomgrades. Sie wurde bestimmt bei der in den meisten Versuchen innegehaltenen Umlaufszeit von 0,2 Secunden, und wïrde sich demnach vollziehen in etwa $1 / 20000$ Secunde. Das Ende der Boussolableitung markirt sich in gleicher Weise wie der Anfang. 
Anfang und Ende der Ableitungszeit sind also sehr genau zu bestimmen. Die dieselbe betreffenden Constanten des Instruments ändern sich auch nach vielstündigem Gebrauch nicht in merklicher Weise. Sie waren nach einer Zeit von zwanzig Stunden, während welcher das Instrument im Verlauf dreier Tage benutzt worden war, noch unverändert.

Ich bin von befreundeter Seite befragt worden, ob ein Klirren der Feder ausgeschlossen sei, wenn der Boussolstift dieselbe verlassen hat, und der Contact wieder sich schliesst. Dasselbe könnte nachträgliche Oeffnungen des Schlüssels bewirken, welche denselben zu andern Versuchen eventuell untauglich machen würden. Ich habe hierüber folgendes ermittelt.

Man löse die Verbindung, welche der Contactstift des Reizeontactes mit dem die Rheotomaxe umschliessenden Quecksilberring bat, und verbinde statt dessen Contactstift und Boussolstift miteinander. Man führe sodann einen Strom durch den feststehenden Theil des Reizcontactes, die ebengenannte Verbindung von Boussolstift und Contactstift, die Feder des Rheotomschlüssels, und nehme endlich in diesen Kreis das Telephon auf. Dieser Kreis wird nur geschlossen werden können innerhalb der Breite der Rheotomtheilung, welche der Contactstift durchläuft, während der Boussolstift auf der Schlüsselfeder schleift. Man führe sodann bei rotirendem Rheotom den Reizcontact langsam, unter Benutzung der an ibm. befestigten Micrometerschraube, dureh diesen Theil der Rheotomtheilung bindurch, und notire sich die Stellungen, in welcher das den Stromschluss signalisirende knackende Geräusch im Telephon zum ersten und letzten Male auftritt. . Dasselbe beginnt sebr leise, wird bei nur geringer Verschiebung des Reizcontactes maximal (etwa bei 0,025 eines Grades der Theilung) und verschwindet später in gleicher Weise. In den Zwischenstellungen des Contactträgers ist es in unveränderter Stärke $s t$ e $t s$ vorhanden, ohne je bei einer Umdrehung auszusetzen.

Bis hierher war der im Rheotomschliissel befestigte Theil der Stromleitung in die Klemmschraube eingeschraubt, welche mit der Contact feder in Verbindung war. Man löse nun diese Verbindung und stelle die Stromleitung wieder her, indem man den Draht jetzt in eine der Klemmen einlegt, welche mit der Contact schra ube des Schlussels in Verbindung stehen. Jetzt kann die Leitung nur bei denjenigen beiden gegenseitigen Stellungen 
von Rad und Contactträger geschlossen werden, bei welchem 1) der Boussolstift die Feder bereits berührt und der Contact zwischen Feder und Contactschraube noch nicht gelöst ist, oder 2) derselbe nachdem er eine zeitlang offen war, wieder hergestellt wird, während zugleich der Boussolstift noch auf der Feder schleift, ausserdem aber Contactstift und der auf dem Träger des Reizcontacts stehende Contacttheil des letzteren ( $P$ der Fig. 4 auf Taf. III) miteinander in Berührung sind. Der zweite der beiden Fälle kann nicht eintreten, sobald die Feder nach dem Abgleiten des Boussolstiftes in freier Schwingung noch ein Stück Weg zuriickzulegen hat, ehe sie den Schliusselcontact wieder schliesst. Man führe nun bei dieser Versuchsanordnung und rotirendem Rheotom ebenfalls den Reizcontactträger mittelst der Schraube durch die kritischen Contactbreiten hindurch, und notire sich die Stellungen desselben, bei welchen das bekannte, diesmal bedentend schwächere Geräusch im Telephon Anfang und Ende der Stromschliessungen angiebt. Drittens suche man sich, nachdem die gewöhnlichen Verbindungen der Drähte wieder hergestellt sind, in der gebräuchlichen früher beschriebenen Weise Anfang und Ende der Boussolableitung auf. Es ergiebt sich :

Boussolableitung, in der gewöhnlichen Weise bestimmt 77,20-76,2 $2^{\circ}$.

Contact bei Ableitung über Contactstift, Boussolstift, Schlüsselfeder 76,175-77,225

" " " Contactstift, Boussolstift,

Schlüsselfeder und zugehöriger Contactschraube 76,175-76,2 u. 77,2-77,25. Zwischen 76,2-77,2 kein Contact.

Boussolableitung, bestimmt wie oben. 77,2-76,2.

Aus diesen Zahlen, und dem sonst über diesen Versuch Mitgetheilten ergiebt sich folgendes.

1) Boussolstift und Schlüsselfeder bleiben während der Streifung stets mit einander in Berührung.

2) Zur Lösung und Neubildung des Contactes bedarf es einer merkbaren aber sehr kleinen Zeit.

3) Eine freie Schwingung der Feder findet nicht statt, wenn sich der Boussolstift von ihr loslöst. Sie liegt vielmehr in dem Augenblick der Lösung bereits wieder an der Contactschraube an. Nachschwingungen und nachträgliche Lösungen des Contactes sind somit unwahrscheinlich.

4) Ist der Zeitmoment, in welchem, bei der gewöhnlichen Bestimmung der Boussolableitungszeit mittelst des Telephons, die 
Schallstärke plötzlich zunimmt, identisch mit dem Augenblick der Oeffnung des Rheotomschliussels.

Der Gebrauch des Rheotomschlüssels erleichtert somit die Benutzung des Rheotoms in beträchtlichem Maasse. Die Bestimmung der Boussolableitungszeit ist genau, ebenso diejenige der zwischen Reiz und Ableitung liegenden Zeit, durch die Unveränderlichkeit der Ableitungszeit wird das lästige Wandern der Scala bei Ableitung des Ruhestromes vermieden, die Erneuerung des Quecksilbers in den Contactnäpfen fällt weg, die Controlle des Nullpuncts und der Ableitungszeit fällt ebenfalls weg. Wo sie erwünscht ist, gestaltet sie sich unter Benutzung des Telephons ebenfalls einfacher.

Bei der Construction der Contacte musste auf die bei den ersten Versuchen sofort gemachte Erfahrung Rücksicht genommen werden, dass der Contactstift den zweiten und dritten Contact bäufig tibersprang. Ursache hierfür waren Schwingungen des Rheotomrades, und dieselben waren auch mit der Grund, wesshalb das Rad durch eine massive Scheibe ersetzt wurde. Da diesfalls der an der Scheibe befestigte Contactstift der unnachgiebige Theil des Contactes wird, musste der auf dem Contactträger befindliche Contactheil zum Ausweichen eingerichtet werden. Zugleich mussten alle drei Contacte auf demselben Träger untergebracht werden, damit sie gleichzeitig, obne Aenderung ihres gegenseitigen Abstandes längs der Peripherie des Rheotomrades versehoben werden konnten. Ihre Construction veranschaulicht Fig. 4 der Tafel III, welche sie, von der Rheotomaxe aus gesehen, zeigt.

Auf einer horizontalen, tangential zum Rheotomrad angeordneten Laufschiene $A$ laufen drei Läufer, $L$, in welche bei $B$ in einer horizontalen, senkrecht zu $A$ gehenden Axe eine kleine Messingplatte eingelenkt ist. Eine Stellschraube, $C$, vermag dieselbe fein vertical einzustellen, während sie zugleich durch eine Gegenfeder, $D$, fest gegen den Läufer angedrückt wird. Auf dieser Platte, $E$, ist, durch eine (schraffirt gezeichnete) Hartgummischeibe isolirt, eine Blattfeder $G$ aus Stahl von 8 Millimeter Breite in dem Messingklötzchen $H$ befestigt, welche auf ibrem freien, nach oben umgebogenen Rand horizontal und senkrecht zur Längsrichtung des Läufers $A$ einen ein Millimeter starken Platindrath $P$ angelïthet trägt. Der Contactstift trifft bei seinem Umlauf diesen Draht, und stellt somit, da von dem Klötzchen $H$ eine Leitung nach dem Schlïssel $\alpha$, resp. $\beta, \gamma$ des auf Seite 136 
Versuche über den zeitlichen Verlauf des Muskelstroms im Tetanus. 147

gezeichneten Schemas führt, den Schluss des Reizkreises her. Nachschwingungen der Feder werden theils durch ein zwischen ihr und der Hartgummiplatte eingelegtes, von einem Gummischlauch abgeschnittenes Stïck Gummi, theils durch die auf die seitlichen Ränder der Feder von oben drückenden Köpfe der Dämpfschrauben $K$ verhindert. Damit der zweite und dritte Contact genügend einander genähert werden können, steht die Feder des dritten eine Strecke weit frei über ihren Läufer hinaus. Die Laufschiene $A$ ist endlich an einem in der Zeichnung weggelassenen in senkrechter Richtung fein verstellbaren Schlitten befestigt, und dieser an Stelle des am Rheotom sonst befindlichen Reizschiebers auf dem denselben tragenden Arm angeschraubt. Zwei von letzterem weit nach rechts und links ausgreifende Arme $N$ verhindern endlich seitliche Schwankungen des Contactträgers. Die Federn weichen dem Contactstift leicht aus, schwingen sehr schnell $a b^{1}$ ), und bereiten dem Umlauf des Rades kein merkliches Hinderniss.

Wenn die Wirkungen zweier sich schnell folgender Induetionsschläge in Nerv oder Muskel sich nicht summiren, wird man zunäcbst zu fragen haben, ob beide Schläge gleich stark gewesen sind. Ich habe es daber für zweckmässig gehalten, erst den Verlauf der Inductionsströme zu studiren, wenn alle drei Contacte hintereinander in engen Intervallen fungirten. $\mathrm{Zu}$ diesem $\mathrm{Z}$ weck schalte ich den Rheotomschliussel als Nebenschliessung zur Boussole ein, nachdem dieselbe mit den Polen der secundären Spirale ver. bunden sind. Hierzu brauchen nur die von den, an den Muskel angelegten, unpolarisirbaren Electroden kommenden Drähte mit den Drähten der secundären Spirale vertauscht zu werden. Im primären Kreise ist alles zugerichtet wie zum eigentlichen. Versuche am Muskel selbst. Der primäre Kreis wird von sechs zur Kette verbundenen Daniell'schen Elementen betrieben, aus der primären Spirale sind die Eisenkerne entfernt. Ihre Enden sind durch einen inductionsfrei gewundenen Kupferdraht von absichtlich nicht zu geringem Widerstand miteinander verbunden. Aus

1) Herr Mechanikus Rothe in Prag liefert die hier beschriebenen Apparate, genau nach den von mir selbst gefertigten Originalen gearbeitet, für $58 \mathrm{Mark}$, Rheotomschlüssel und Schwungrad allein für $30 \mathrm{Mark}$, die Contacteinrichtung ebenfalls für 30 Mark. Zur Anbringung der letzteren muss das Rheotom eingesendet werden, Schlüssel und Schwungrad sind ohne weiteres an dem von Zimmermann in Heidelberg gelieferten Bernstein'schen Rheotom anzubringen. 
dem Rheotomschlüssel ist jedoch die zur Ableitung der negativen Schwankung benutzte Feder entfernt, und durch eine andere mit schmaler Spitze ersetzt worden, welche der Boussolstift in einer Ausdehnung von höchstens einem halben Millimeter bestreicht. Die Ableitungszeit beträgt 0,0003 Secunden, im Uebrigen ist der Contact in der schon angegebenen Weise auf Nachschwingungen untersucht und von solchen frei befunden worden. Während alle drei Contacte functioniren, wird der Reizcontactträger längs der Peripherie des Rheotomrades verschoben und es ergeben sich folgende Ausschläge.

Intervalle zwischen den Contacten 0,003 Secunden.

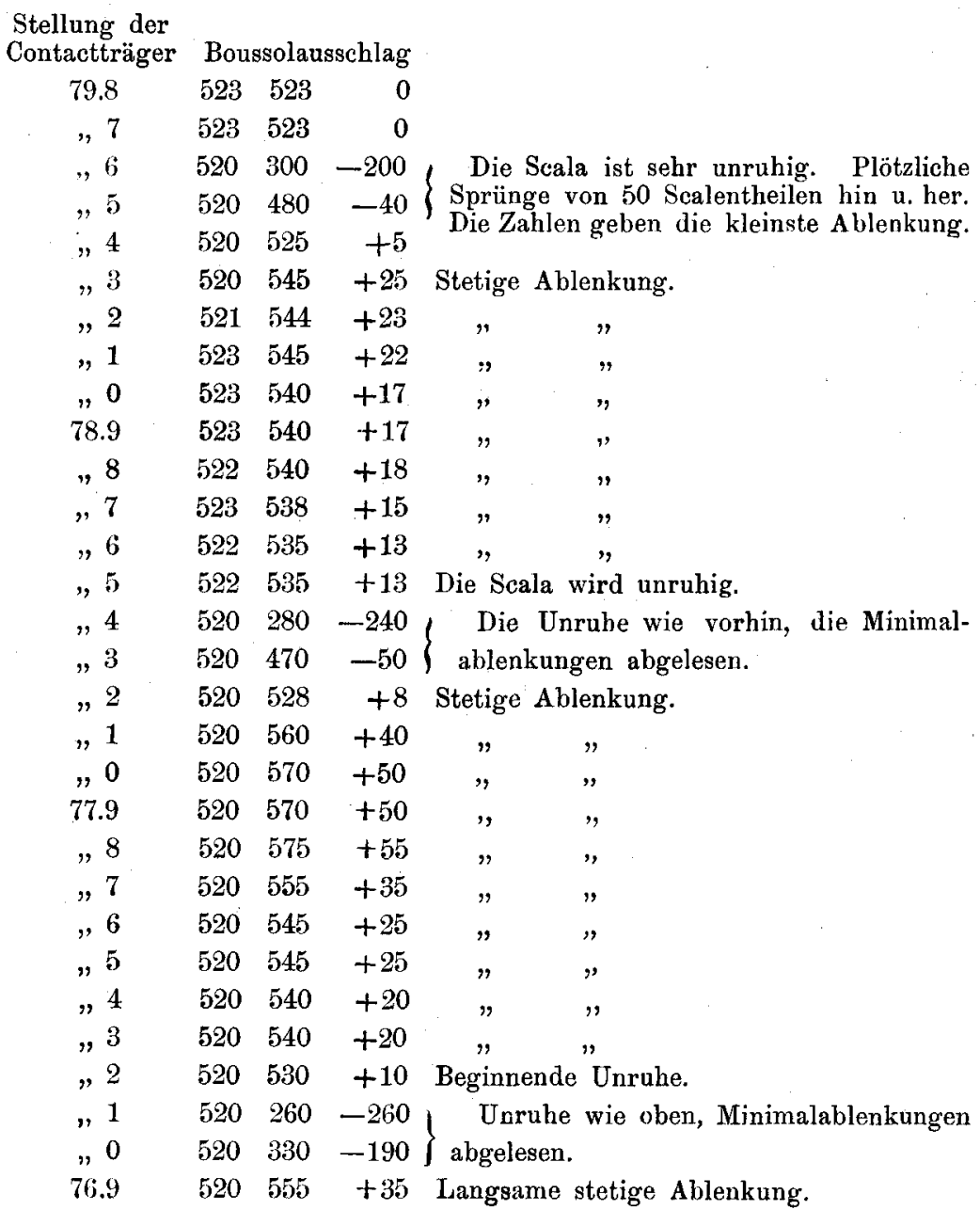


Versuche über den zeitlichen Verlauf des Muskelstroms im Tetanus. 149

Telephonische Maxima der Inductionsströme finden sich bei $77,05-77,2^{\circ}, 78,35-78,45^{\circ}, 79,55-79,675^{\circ}$. Die Stellen des Beginns und des Endes der Boussolableitung, mit dem constanten Strome bestimmt, fallen mit denen der telephonischen Maxima der Inductionsströme zusammen. Die Umlaufsdauer beträgt genau 0,25 Secunden, der Zeitwerth eines Grades der Eintheilung also 0,0025 Secunden. Innerhalb 0,2 Grad ist die maximale Erhebung der Inductionsschläge gelegen. Sie dauert also $0,0005=1 / 2000$ Secunde. Die Stärke der Schläge nimmt bei den beiden späteren Contacten zu, so dass man wird annehmen duirfen, dass etwaige Unwirksamkeit derselben in der Abnahme ihrer Intensität nicht begründet sei. Die beifolgende Curve stellt den Verlauf der Ströme dar. Ein Millimeter Ordinatenhöhe bedeutet zehn Scalentheile des Ausschlags. Kleinere Bruchtheile der Ordinaten als 0,5 Millimeter wurden nicht berïcksichtigt. Die Ordinaten sind über die Schieberstellungen als Abcisse aufgetragen.

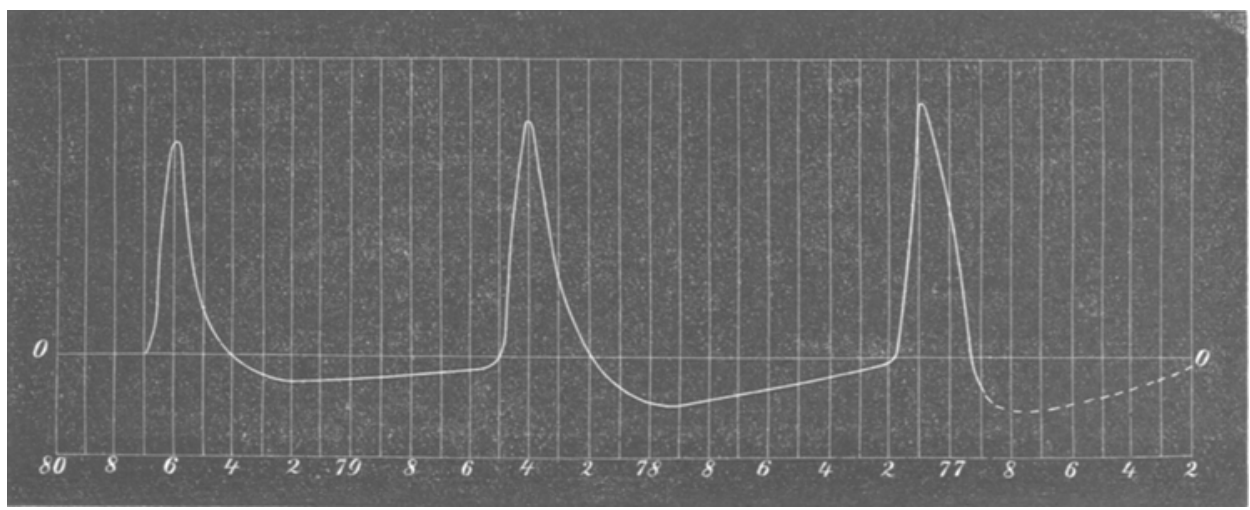

Fig. III.

Zum Versuch selbst habe ich mich leider des Gastrocnemius bedienen mutssen. Wenn man die Wirkung der Doppel- oder mehrfachen ${ }_{2}^{*}$ Reizung auch nur an einer einzigen Phase der negativen Schwankung bestimmen will, kann man nicht unter einer viermaligen Wiederholung der Ablesungen wegkommen. Drei derselben sind mindestens nöthig, um zu wissen, ob man sich im auf- oder absteigenden Theil der Schwankungscurve befindet, und um zugleich die Ablenkung kennen zu lernen, welche der zweite Reiz, allein angewendet, für sich hervorrufen würde. Die vierte Ablesung erst würde unter Anwendung der Doppelreizung vor- 
genommen werden können. Eine jede Ablesung aber erforderte, bei nur mässiger Empfindlichkeit der Boussole, zum mindesten zwanzig einzelne Zuckungen. Die den vier Ablesungen entsprechenden achtzig Zuckungen hat mir jedoch kein Sartorius mit künstlichem (thermischen oder Aetzungs-) Querschnitt ausgehalten, ohne die deutlichsten Kennzeichen der Ermüdung zu geben. Letztere aber ist im Stande, in Bezug auf die Wirkung der Doppelreize das am nicht ermideten Muskel erhaltene Resultat geradezu umzukehren. Ein Präparat von Semitendinosus und gracilis, wie ich es seinerzeit nach Ficks Angaben bei andern Versuchen benutzt habe, hält zwar etwas länger, aber doch nicht in genügendem Grade aus. Ich habe mich deshalb des genannten Muskels, wenn auch nur ungern bedienen müssen.

Gereizt wurde vom Nerven aus. Anf dem Muskel selbst wurden, nachdem die Mitte des Achillessehnenspiegels kräftig mit $5 \%$ iger Carbolsäure angeätzt worden war, Zuleitungsfäden aus Baumwolldocht, mit $0,6 \%$ iger Kochsalzlösung getränkt, aufgenäht. Wenn man feine Nadeln und feine Seidenfäden benutzt, können die vier hierzu benöthigten in der Faserrichtung laufenden (für jede Electrode zwei) Stiche sehr wohl ausgefuhrt werden, ohne dass auch nur, falls man die Eintrittsstelle der Nerven meidet, eine einzige Faser zuckt. Die aus dem Muskel hervorragenden Fadenenden werden tiber den Baumwollfäden zusammengekntipft und halten dieselben sicherer als jede andere Art der Befestigung in ihrer Lage fest. Das freie Ende der Dochtfäden wird in Kochsalzthon eingeknetet und letzterer zum Verschluss der die Zinksulfatlösung der unpolarisirbaren Electroden enthaltenden Glasröhren verwendet. Die Sehne des Muskels ist durch einen Glashaken mit dem Schreibhebel verbunden, der Femur wird, durch Gummischlauch isolirt, in seinen Halter geklemmt, Reizclectroden und unpolarisirbare Electroden sind sorgfältig isolirt, über das ganze wird eine mit feuchtem Fliespapier austapezirte Glasglocke als feuchte Kammer gestülpt.

Der Motor, eine electrische Rotationsmaschine älterer Construction, ist durch Schnurlauf mit einem Centrifugalpendel verbunden, dessen Schwanggewicht, nach einer von Helmholtz angegebenen Methode beim Ueberschreiten einer gewissen Umlaufsgeschwindigkeit einen Contact aufhebt, durch welchen die zum Motor führende Leitung unterbrochen wird. Die Berïhrung des 
Boussolstifts und der Feder des Rheotomschliussels, sowie der Anschlag des Contactstiftes an die Reizcontacte giebt bei jedem Umlanf ein gut wahrnehmbares Ticken. Nach letzterem wurde die Zahl der Umläufe in der Minute gezählt, und daraus die Umlaufsgeschwindigkeit für die Secunde berechnet.

Vor Beginn des Versuches wird das Reizintervall bestimmt, in dem ich für jeden einzelnen Contact nach dem oben geschilderten Verfahren die Stellungen aufsuche, welche mit Beginn und Ende der Boussolableitung zusammenfallen. Da die Contacte auf demselben, gemeinschaftlichen Träger stehen, muss sich für jeden Contact eine andere Stellung für das Zusammenfallen des Contactschlusses mit Anfang und Ende der Boussolableitung ergeben, und die Verschiebung des Contactträgers giebt das Reizintervall unmittelbar in Graden der Rheotomeintheilung an.

Versuchsergebnisse.

Zum Verständniss des Folgenden betrachte man nochmals das Versuchsschema, Seite 136. Der Umschalter $U$ ist in der Richtung $m m$ eingestellt, der Rheotomschlüssel dient also als Nebenschliessung zum Muskelstrom. Der Schltissel $S$ ist geschlossen. Das Rheotom rotirt in der Richtung des Pfeiles. Jetzt werden die Vorreiber $\alpha$ und $\gamma$ geöffnet, so dass der Strom des Reizkreises nur durch den Contact $b$ geschlossen werden kann, und diejenige Stellung des Contactträgers aufgesucht, bei welcher nach Reizung des Muskels durch Oeffnung des als Nebenschliessung zur secundären Spirale eingeschalteten Schlïssels $S^{\prime}$ die ersten Spuren der negativen Schwankung auftreten. Nach Notirung des Ausschlages wird der Vorreiber $\beta$ geöffnet, der Vorreiber $\alpha$ geschlossen, und die Reizung wiederholt. Die der Reizung rom Contact $a$ aus entsprechende Schwankung ist nun dem Reizintervall entsprechend schon mehr oder weniger stark entwickelt. Der Ausschlag wird ebenfalls notirt, und sodann, unter gleichzeitiger Schliessung von $\alpha$ und $\beta$ eine Doppelreizung vorgenommen. Nach Notirung des Ausschlags wird der ganze Versuchsturnus unter Verschiebung des Contactträgers um eine beliebige Strecke gegen die Richtung des Radumlaufs wiederholt. Die Betrachtung der an der rotirenden Trommel eines Balzar'schen Kymographions verzeichneten.Zuckun. gen giebt nach jeder Ablesung Aufschluss darïber, ob die Contacte gut functionirt haben. Etwaige Fehler in ihrer Einstellung, am 
Ausbleiben einzelner Zuckungen kenntlich, wurden, wenn nöthig, corrigirt, zugleich aber auch die dann als fehlerbaft betrachtete Ablesung erst wiederholt, bevor der neue Turnus begonnen wird. Ich werde im Folgenden die einzelnen Reizungen, resp. die zu ihnen gehörigen Ausschläge mit $a-, b-, c$-Reizungen, $a-, b-, c$-Ausschlag, die Doppel- und dreifachen Reizungen mit $a+b, a+b+c$ Reizung, resp. $a+b$-Ausschlag bezeichnen. Die Versuchsresultate wechseln nach dem Reizintervall und gestalten sich im Allgemeinen wie folgt. Vorbemerkt sei noch, dass sich aus den Versuchsergebnissen schliessen liess, dass jenseits eines engeren Reizintervalles als $1 / 500$ Secunde der zweite Reiz seine Wirksamkeit bald vollständig einbüssen würde. Ich habe daher kleinere Intervalle im Versuche nicht benutzt.

Hat man, bei einem Reizabstand von $1 / 500$ Secunde dem Contactträger die Stellung gegeben, in welcher die ersten Bruchtheile der, der $b$-Reizung entsprechenden Schwankung zur Boussole abgeleitet werden, so ist die $a$-Schwankung schon beträchtlich entwickelt. Der Ausschlag bei Doppelreizung ist dann grösser als der Ausschlag der a-Reizung allein, bleibt jedocb, wie überhaupt bei allen Doppelreizungen am unermadeten Präparat, hinter der Summe der $a$ - und $b$-Ausschläge zurück. Verschiebt man jetzt den Reizcontact gegen die Richtung des Umlaufs um einen, etwa $1 / 1000$ Secunde entsprechenden Winkelwerth, so ist damit zumeist schon die Einstellung erreicht, wo die Boussolableitung geschieht, wenn die $a$-Schwankung ihre grösste Höhe erreicht hat. Zugleich ist auch die $b$-Schwankung merklich gewachsen, etwa bis zur Hälfte, oder $2 / 3$ des Schwankungsmaximums ïberhaupt. Der $a+b$-Ausschlag ist dementsprechend auch weiter gewachsen, und der absolnte Betrag, mit welchem er über die Grösse der $a$-Schwankung hinausgeht, wird oft schon recht auffällig. In der dritten Schieberstellung fällt jetzt der $a$-Ausschlag, um anfangs schneller, dann langsamer abzunehmen, während die $b$-Schwankung zuerst noch wächst. Es findet sich dementsprechend unter den nächsten Contactträgerstellungen eine, zumeist die dritte, bei welcher der zwischen der $a$ - und $b$-Schwankung bestehende Unterschied am kleinsten ist. Bei dieser Einstellung hat die $a+b$-Schwankung ihr Maximum bereits ïberschritten und beginnt langsamer als die a.Schwankung zu fallen. Sie bleibt zunächst noch grösser, als die $b$-Schwankung. $\mathrm{Zu}$ der Zeit jedoch, zu welcher die $b$-Schwan- 
kung maximal geworden ist, fällt die $a+b$-Schwankung stets merklich kleiner aus, als jene. Am Ende der $b$-Schwankung werden schliesslich beide Schwankungen wieder nahezu gleich gross, wenn nicht die später noch $z \mathfrak{u}$ besprechenden Aenderungen im Erfolg der Reizung eintreten, welche die Curve der $a+b$ Schwankung weit ïber die der $b$-Schwankung hinaus in die Höhe treiben. Als Beleg für die eben geschilderten Verbältnisse mögen von den am Ende dieser Mittheilung beigefizgten Versuchen die Versuche No. 75, 76, 78, 81, 82, 84, 87, 88 dienen.

Wenn der Betrag der $a+b$-Schwankung zu der Zeit, wo die $b$-Schwankung im Zustand ihrer höehsten Entwickelung sich befindet, bereits unter den Betrag der $b$-Schwankung herabgesunken ist, so wird man zunächst versucht sein, den Grund hierfür in der Ermüdung des Muskels zu suchen. Ihr Einfluss wird zu ermitteln sein, indem man die $a+b$-Schwankung zwischen zwei $b$-Schwankungen einschaltet. - Ich babe, um mir den Verlauf der einzelnen Versuchsreihe nicht zu stören, von dieser Controlle nur selten Gebrauch gemacht. Wenn der Abstand der Contacte bekannt ist, hat man es vollkommen in der Hand, bei der nach einem Ablesungsturnus vorgenommenen Verschiebung des Contactträgers eine seiner Stellungen so zu wählen, dass der Contact $b$ in der vormaligen Stellung des Contactes $a$ sich befindet. Die Ausschläge miissen dann annähernd gleich sein. Absolute Gleichheit derselben darf man indessen nicht verlangen, da die Ermiidung ziemlich bald modificirend eingreift. Um mich jedoch der Richtigkeit der Beobachtung zu versichern, habe ich in einer Reihe von Versuchen mich darauf beschränkt, zwischen einfacher und Doppelreizung bei einer einzigen passenden Finstellung des Reizcontactes bis zur Ermïdung des Muskels abzuwechseln. Die $a+b$-Schwankung fällt auch hier kleiner aus, als die $b$-Schwankung. Ein Beispiel hierfïr bietet Versuch 45. Im Uebrigen wird man Gelegenheit haben, bei der dreifachen Reizung dem genannten Verhältniss bei der $b+c$-Reizung ebenfalls zu begegnen, und zwar in Versuchen am blutdurchströmten Muskel, wo die Ermüdung, wenn zwar nicht aufgehoben, so doch stark hinausgezogen werden konnte.

Für das Folgende, sowie für die bequemere Uebersicht der bis jetzt gewonnenen Resultate wird es gut sein, sich daran zu erinnern, dass man dieselben auch graphisch darstellen kann, wenn man die erbaltenen Ausschläge als Ordinaten iiber der Zeit als 
Abscisse aufträgt. Da die Umlaufsgeschwindigkeit des Rheotoms in dén bisher eitirten und den noch $\mathrm{zu}$ citirenden Versuchen im Wesentlichen dieselbe ist, und die Grade der Rheotomtheilung, um welche der Reizcontact von einem Ablesungsturnus bis zum andern verschoben wird, dementsprechend auch nahezu denselben Zeitwerth besitzen, habe ich es für bequemer gehalten, in den auf Tafel III u. IV beigegebenen Schwankungscurven unter Vernachlı̈ssigung des etwa vorhandenen kleinen Zeitfehlers die Ausschläge als Ordinaten auf die Schieberstellungen als Abseisse aufzutragen. Ein Scalentheil Ausschlag entspricht in den Curven 0,8 mm Ordinatenhöhe, ein Rheotomgrad einer Abscissenlänge von $8 \mathrm{~mm}$. $\mathrm{Zu}$ den Curven ist ausserdem noch folgendes zu bemerken. Für den Zweck dieser Versuche ist offenbar der bis zum Beginne der $b$-Schwankung abgelaufene Theil der $a$-Schwankung von minderem Interesse, dagegen ist es jedoch von Wichtigkeit, dass während der Messung der von Beginn der $b$-Schwankung an erfolgenden Vorgänge sich die Leistungsfähigkeit des Muskels so wenig wie möglich ändert. Hierfür aber ist es von gewissem Vortheil, sich die zwei oder drei behufs directer Bestimmung des ersten Theiles der $a$-Schwankung nothwendigen Ablesungen zu sparen. Ich babe dieselben desswegen auch unterlassen, zumal da man sich aus dem Verlauf der $b$-Schwankung den ersten Theil der $a$-Schwankung ganz gut reconstruiren kann, sobald man, wie dies hier immer der Fall ist, das Intervall der beiden Reize kennt. Man hat dann einfach den entsprechenden Theil der $b$-Schwankungseurve um das gegebene Intervall in der Richtung nach $a$ zu verschieben, um auch die Curve der $a$-Schwankung vollständig zu erhalten.

Auf diese Weise sind die zu den bisher mitgetheilten und demnächst noch mitzutheilenden Versuchsheispielen gehörigen Schwankungseurven construirt. Was bei ihnen am meisten auffällt, ist der ausserordentlich geringe Flächenzuwachs, welchen die $a$-Schwankung bei kurzem Intervall durch das Hinzukommen eines zweiten Reizes erbält, und der bei 0,002 Sec. Intervall nur selten mebr als etwa $1 / 10$ der Fläche der $a$, resp. $b$-Schwankung beträgt.

Von besonderem Interesse würde die Gestalt der Schwankungscurve sein zu der Zeit des Beginnes der zweiten Schwankung, sofern an dieser Stelle eine Unstetigkeit im Verlauf der $a+b$ Schwankungscurve eintreten müsste. Dass an dieser Stelle eine Knickung im Curvenzug vorhanden sein müsse, lässt sich a priori 
wohl annehmen. Es ist mir indessen bei dem in Rede stehenden engen Intervall nicht gelungen denselben mit dem Rheotom nachzuweisen. Begründet ist dies zum Theil in der Form der Curve, zum Theil in anderen Momenten. Bei engem Intervall fällt der Beginn der zweiten Schwankung entweder in den aufsteigenden Theil der ersten Schwankung, nahe dem Gipfel, oder entwickelt sich erst, wenn jene ihre grösste Höhe erreicht hat. Für den aufsteigenden Theil der $a$-Schwankung bedürfte es aber seiner Steilheit wegen eines ausserordentlich grossen plötzlichen Zuwachses der Ordinatenböhe, um eine solche Knickung erkennen zu lassen. In dieser Beziehung scheint jedoch auch für die Doppel- und mebrfachen Schwankungen dieselbe Grenze gesetzt zu sein, wie für die einfache Schwankung. Ihr Betrag geht nicht uiber die Grösse des Ruhestromes hinaus, und der Schwankungszuwachs kann desshalb, wenn die Ordinaten der a-Schwankung schon dieser Grenze sich genähert haben, nur klein werden. Können somit die Unterschiede in der Steilheit des Anstiegs, welche die Curve der Doppelschwankung vor und nach dem Einsetzen der zweiten Schwankung etwa zeigen würde, nur klein ausfallen; so bedürfte es ausserdem, um sie deutlich zu erkennen, der Bestimmung einer grösseren Zahl von Ordinaten während der Anstiegsdauer, und zwar bei möglichst kurzer Boussolzeit; in dieser Beziehung ist jedoch dem Versuche theils dureh die mit der Kürze der Boussolzeit bei gleichbleibendem absoluten Fehler wachsenden relativen Fehler derselben, theils auch durch die Ermiidung des Präparates bald ein Ziel gesetzt, und icb habe mich desshalb auf eine genauere Bestimmung dieses Theils der Curve bei einem so engen Reizintervalle nicht weiter eingelassen.

Mit der Vergrösserung des Intervalls nun erleidet die Gestalt der Curve sowohl, als auch der Schwankungszuwachs bei der Doppelreizung beträchtliche Veränderungen.

Wenn die zweite Schwankung erst einsetzt, nachdem die erste ihren Gipfelpunct geraume Zeit verlassen hat, also bei etwa 0,004 Sec. Intervall, beginnen die $a+b$-Ausschläge wieder $z u$ wachsen, je weiter man mit den Stellungen des Reizcontactes in das Gebiet der zweiten Schwankung hineinrückt. Sie erreichen dort ihr Maximum, wo die zweite Schwankung selbst am höchsten ist, und sinken wieder mit ibr. Die Schwankungscurve bekommt jetzt also bei der Doppelreizung einen zweiten Gipfel. Dieser bleibt an 
Höhe zunächst innerhalb einer ziemlichen Breite des Intervalles hinter dem der Einzelschwankung mehr oder weniger beträchtlich zurïck. Beispiele hierfür finden sich in den Versuchen 79 u. 80, dazu noch von den Versuchen mit dreifacher Reizung in Versuch No. 93, I. Von diesen giebt Versuch 80 ein Beispiel, dass die zweite Schwankung bei diesem Intervall nahezu die Höhe der ersten erreichen kann. Dies Verhalten ist jedoch bei einem Intervall von 0,004 Secunden nicht die Regel: Man findet selbst bei Intervallen bis zu 0,008 und 0,01 Secunde eine ausgesprochene Verkleinerung der zweiten Schwankung. Beispiele hierfür finden sich in den Versuchen mit dreifacher Reizung, insbesondere in Versuch Nr, 93, II.

Sieht man von der Höhe der Ordinaten der Schwankung ab, so findet sich im Allgemeinen mit Deutlichkeit noch das Verbalten ausgesprochen, dass der durch den zweiten Reiz erstehende Flächenzuwachs der Schwankung bei 0,004 secundlichem Intervall absolut und relativ bedeutend grösser ist, als bei einem Intervall von nur 0,002 Secunden. Man kann dic Fläche der zweiten Schwanknug' in Versuch Nr. 93 I ganz gut auf etwa den 4. bis 5. Theil der Einzelschwankung veranschlagen. Bei einem Intervall von 0,008 bis 0,01 Secunden werden nun hin und wieder die Verluste, welche die zweite Sehwankung durch das Vorangehen der ersten erleidet, so klein, dass sie an der einzelnen Curve und deren Flache unmittelbar nicht mehr erkannt werden können, wie dies z. B. Versuch 95 und 96 zeigen, wäbrend jetzt deutliche Aenderungen ihreszeitlichen Verlaufes in den Vordergrund treten. Es erreichtjetzt die zweite Schwankung früherihr Maximum, als dies nach dem Reizintervalleigentlich geschehen sollte. Dies Verhalten ist in den Versuchen $\mathrm{Nr}$. 94-98 deutlich zu erkennen. In den Versuchen 94 und 97 selbst beträgt diese Verschiebung etwa $1 / 250$ Secunde, in den andern ist sie kleiner. Eine eigentliche Verkürzung der Latenzzeit ist jedoch nicht damit verbunden, insofern das zweite Wachsthum der Ausschläge bei der Doppelreizung stets auch bei denjenigen Schieberstellungen seinen Anfang nimmt, in denen die $b$-Schwankung allein eben in das Bereich der Boussolableitung eintritt.

Aus den eitirten Versuchen tritt zunächst uns als allgemeinstes Resultat die Eigenthümlichkeit des Muskels entgegen, dass er seine volle Schwankungsfähigkeit erst einige Zeit nach Ablauf der ersten 
Schwankung wieder erlangt. Ist der Betrag der zweiten Schwankung, welcher sich zu der ersten als Schwankungszuwachs bei engerem Keizintervall zunächst einfach hinzuaddirt, sehr gering, so wächst er bei wachsendem Reizintervall allmählich beträchtlich an. Bei engerem Intervall ist es durch die Art des zeitlichen Verlaufs der ersten Schwankung bedingt, dass die dem zweiten Reiz zugehörige Schwankung als solche nicht sichtbar werden, sondern nur als Zuwachs zu der ersten Schwankung auftreten kann. Zieht man von dem Betrag der Doppelschwankung bei jeder einzelnen Messung den Betrag der ersten Schwankung ab, so kann man die Grösse und den Verlauf der zweiten, durch die vorausgegangene erste Erregung modificirten Schwankung in gleicher Weise graphisch darstellen, wie wir dies fur die einzelnen Schwanliungen und für die Doppelschwankung gethan haben, indem man die erbaltenen, stets positiven Differenzen als Ordinaten ïber der Zeit, resp.' den Schieberstellungen als Abscisse aufträgt. Die so erhaltenen Curven erheben sich zu derselben Zeit von der Abscisse, wie die durch den $b$-Contact erzeugte Schwankung allein, und erreichen ihre höchste Höhe bei engem Intervall gleichzeitig mit dieser, um ebenfalls gleichzeitig, erst convex, dann concav zur Abscisse weiter abzusinken. Aber die Geschwindigkeit ihres Anstieges ist zu gering, um, wenn ihre Ordinaten zu den an gleicber Stelle befindlichen Ordinaten der ersten Schwankung zuaddirt werden, an der so resultirenden Curve eine Unstätigkeit ihres Verlaufes erkennen zu lassen. Wächst dagegen mit zunehmendem Intervall die modificirte zweite Schwankung, so wird dieselbe sehr bald in der Curve der Doppelschwankung deutlich erkennbar.

Zur Ermittelung des Reizintervalls, welches nöthig ist, damit unter allen Umständen die zweite Schwankung bis zum Betrage der ersten sich wieder emporhebt, reichte die Winkelbreite, innerhalb deren die Contacte am Rheotom verstellt werden konnten, nicht aus. Bei dem grössten verfugbaren Intervall von 10 Rheotomgraden, welche bei einer Umlaufsgeschwindigkeit von 0,2 Secunden einem Intervall von $1 / 50$ Secunde entsprechen, kann der Flächenraum der zweiten Schwankung nach vorangegangenem ersten Reiz noch immer kleiner ausfallen, als die vom zweiten Contact aus allein, ohne Mitbenutzung des ersten Contactes erzengte Schwankung, wie dies Versuch Nro. 95 zeigt. Zwar möchte dies im ersten Augenblick nicht so scheinen, da die Ordinaten der $a+b$ Schwan- 
kung an Höhe die Ordinaten der vom $b$-Contact allein erzeugten Schwankung bedeutend ïbertreffen, construirt man sich indessen nach den auf der vorigen Seite erörterten Principien den wahren Betrag der zweiten Schwankung aus Ordinaten welche von der Differenz der Ausschläge der Doppelreizang und der $a$-Reizung dargestellt werden, so tritt die verkleinernde Wirkung des vorangegangenen $a$-Reizes deutlich in die Augen.

Für alle Fragen, welche die Natur des tetanischen Erregungsvorganges angehen, würde es offenbar von Wichtigkeit sein, zu wissen, bei welchem Reize einer tetanisirenden Reizreihe die beobachtete Verminderung der Schwankungen ibr Ende erreicht, und somit erhob sich im Verlaufe der Untersuchung die Forderung, die Beobachtungen auch über die später folgenden Schwankungen hin auszudehnen. Vorversuche lehrten bald, dass am ausgeschnittenen überlebenden Muskel die Untersuchung nicht durchzuführen sei. Im allgemeinen steigt bei den Boussolen mit gedämpft schwingenden Magneten die Schwingungszeit in dem Maasse, wie man das Instrument durch die Astasirung empfindlicher macht. Es erfordert desshalb' eine empfindlichere Einstellung desselben eine grössere Zuckungzahl zur Vollendung einer jeden einzelnen Ablesung, als eine weniger empfindliche, und da man aus leicht ersichtlichen Gründen mit den auf die einzelne Messung entfallenden Zuckungen möglichst sparen muss, ist es geboten, die Astasie so klein zu nehmen, als sich dies mit dem Versuche irgendwie verträgt. Bei dem mir zur Verfügung stehenden Instrument waren bei einem Ausschlage zwischen 10 und 15 Scalentheilen bereits gegen 40 Reizungen in dem gewählten Intervall von 0,2 Secunden - der Umlaufszeit des Rheotoms entsprechend - nöthig, und dies ergiebt bei etwa 20 Ablesungen für die Bestimmung des Schwankungsverlaufes bei nur zwei Reizen bereits 800 einzelne Reize, welche die verwendeten Muskeln in den seltensten Fällen ertrugen, ohne deutliche Ermüdung zu zeigen. In den fortgeschritteneren Stadien derselben aber ist ihre Einwirkung auf den Verlauf der Schwankung von gänzlich unberechenbarem Einfluss. Es wirkt bier derersteReiz inder a usgesprochensten Weise erregbarkeitssteigernd, so dass statt dersonst gebräuchlichen Schwankungsabnahme eine Schwan kungszunabme eintritt, welche den Ausschlag der Doppelreizungoft weit iiber diesummederbei- 
Versuche über den zeitlichen Verlauf des Muskelstroms im Tetanus. 159

den, bei Reizang jevom $a$ - und b-Contacteallein z u erhaltenden A ussehläge ansteigen lässt. Die Hubhöhe der Doppelzuckung wächst diesfalls dann auch beträchtlich über die der Einzelzuckungen hinaus, selbst bei einem Reizintervalle von 0,002 Secunden, bei welchem normaler Weise der Zuckungszuwachs im Ganzen gering zu sein pflegt; sic geht hierbei sogar häufig auch über die Summen der Hubhöhen der $a$ - und $b$-Zuckungen hinaus. Mit weiterer Ermüdung schwindet dann das Phänomen, sobald sämmtliche Muskel-Functionen bis zum Verschwinden abnehmen. Anderntheils ist deutlich erkennbar, dass die Ausschläge mit der Verschiebung des Reizcontactes von einer gewissen Schieberstellung an von 0 aus wachsen und dann wieder abnehmen. Da diese Schieberstellung mit derjenigen zusammenfällt, bei welcher die $a$-Schwankung beginnt, ist das unmittelbare Einbrechen der reizenden Inductionsströme in den Boussolkreis sowohl hiedurch, als auch durch den übrigen Verlauf der Vorgänge ausgeschlossen, da denn nicht wohl anzunehmen wäre, dass sich im Stadium der Muskelermiidung jedesmal irgendwelche Veränderungen im Untersuchungsapparat eingestellt haben sollten, die den Uebergang von Stromschleifen in den Muskel und die Boussole ermöglichten. Im übrigen schützt die Polvertauschung in der secundären Spirale vor Täuschung: sie ist ohne Einfluss auf den Gang der Erscheinung. Es betrugen in dem im übrigen nicht mitgetheilten Versuch Nro. 68 der Ausschlag bei Reizung vom Contact $a$ aus 6, vom Contact $b$ aus 3 Scalentheile, der Erfolg der Doppelreizung dagegen war vor und nach der Polvertauschung ein Ausschlag von 18 Scalentheilen. Da ferner alle Handgriffe, welche den Wechsel zwischen Einzelreizung und Doppelreizung und die Benutzung bald des einen, bald des andern Contactes zur Einzelreizung bezwecken, ausserhalb des Rheotoms, und ohne an demselben etwas zu ändern, vorgenommen werden, ist auch eine Aenderung der Umlaufsgeschwindigkeit ausgeschlossen, durch welche ein grösserer Theil der Schwankung abgeleitet, und so eine Vergrösserung derselben vorgetäuscht werden könnte. Im übrigen erhellt aus der Wirkungslosigkeit der Polvertauschung, dass polare Veränderungen der Erregbarkeit im Nerven nicht Ursache der Erscheinung sein können.

Es sei dem aber, wie es wolle, jedenfalls war durch die eben beschriebenen Vorgänge die Nothwendigkeit erwachsen, die dritte Schwankung unter Verhältnissen zu studiren, die die Er- 
müdung möglichst hinausschoben. Ich habe mich desshalb für die noch folgenden, übrigens schon theilweise eitirten Versuche des blutdurchströmten, im übrigen aber möglichst isolirten Gastroenemius zur weiteren Untersuchung bedient. Die zur Anfertigung des Präparates nöthigen Handgriffe sind ziemlich zahlreich.

Zwecks der Anästesirung, sowie um eine unbewegliche Lagerung des Muskels zu ermöglichen, werden beide Nervi ischiadici, möglichst hoch oben durchschnitten ${ }^{1}$ ), darauf der Ischiadicus selbst am Oberschenkel aufgesucht, und dicht unter dem Abgang der grösseren, für die Oberschenkelmusculatur bestimmten Nervenstämme durchtrennt. Dort, wo er in der Kniekehle in zwei Aeste sich theilt, wird er abermals aufgesucht, und nach Unterfübrung eines feinen Häkchens durch einfachen Zug mit leichter Mühe aus seiner Scheide von der oberen Schnittstelle an herausgeholt. Blutungen lassen sich so bequemer vermeiden, als bei dem Versuche, den Stamm in seinem Verlauf zu isoliren, und zwischen die Muskeln versenkte Elektroden unter ihn zu schieben.

Zur Isolirung nun des Gastrocnemius macht man zwischen erstem und zweiten Viertel des Unterschenkels in die Haut zwei längslaufende Einschnitte, gross genug, um eine schwächere Pincette durch den einen hindurch zwischen den Gastrocnemius und die übrigen Muskeln ein- und durch den anderen Einschnitt wieder herausschieben zu können. Man führt nun durch die Wunde mit

1) Die Ausführung der Operation wird durch die Resection des Kreuzbeins sehr erleichtert. Für diese aber ist folgender kleine Handgriff sehr nützlich. Wenn man Haut und darunterliegẹnde Fascie in der Länge des zu resecirenden Stückes durchtrennt hat, mache man, die Schneide der Kreuzbeinspitze zugewendet, am oberen Wundwinkel dicht am Knochen parallel demselben jederseits einen etwa $2 \mathrm{~mm}$ breiten Stich, so tief, dass die in die Stiche eingeschobenen beiden Branchen einer Pincette eben durch die Musculatur durchdringen können. Während man nun den Frosch fest fasst und namentlich die Kreuzbeinspitze gegen den Daumen der linken Hand stützt, gleitet man, die Pincettenbranchen stark zusammendrückend, mit diesen am Knochen bis zu seiner Spitze, wo er knorplich wird, herunter. Die Pincettenbranchen reissen hierbei alles, was Muskel ist, unblutig vom Knochen herunter, und alles, was in dem von den beiden Darmbeinen begrenzten Viereck liegt, wird auf diese Weise sofort vollkommen freigelegt, wenn man jetzt mit der Scheere das Kreuzbein an Basis und Spitze abschneidet und heraus nimmt. Verletzungen irgend welcher Gefässe sind so fast ausgeschlossen; die Fleischwunde lässt sich bequem wieder zunähen. 
Versuche über den zeitlichen Verlauf des Muskelstroms im Tetanus. 161

Hïlfe der Pincette einen kräftigen Seidenfaden und schnürt mit ihm alles was nach vorn von ihm liegt, mit einer Massenligatur zusammen. Dieselbe lässt den aus der Tibialis stammenden wichtigsten der den Gastrocnemius versorgenden Arterienäste unverletzt. Hierauf schlitzt man, von der Ferse beginnend, die Wadenhaut bis zur Kniekehle auf, den in derselben verlaufenden Arterienstämmen möglichst ausweichend, und hat nun noch nur zwei dicht an der Achillessehne in einem von der Haut ibergreifenden Fascienzug verlaufende Gefässe eventuell doppelt abzubinden, und zwischen Ligatur und Haut zu durchtrennen, um, nach Schlitzung der Achillessehne, Anätzung ibres Sehnenspiegels und dem Aufnähen der Electrodenfäden den Muskel nach oben umschlagen zu können. Darauf folgt die Abtrennung des Fusses im Sprunggelenk, und nachdem der restirende Hautlappen nach oben umgeschlagen ist, die Reinigung des Tibiastumpfes von der noch vorhandenen Musculatur. Kennzeichen für den gut erhaltenen Kreislauf des Muskels ist der Umstand, dass der Muskel bei Streckung durch starken Zug farblos wird, beim Nachlassen des Zuges seine rothe Farbe jedoch sofort wieder gewinnt. Durchschneidet man ihn ferner nach beendigtem Versuche, etwa in seiner Mitte, so rinnt aus der Schnittfläche Blutstropfen um Blutstropfen ab, bis zur Verblutung.

Nun wird der Frosch auf ein horizontales mit Glas belegtes Brettchen, an den Vorderextremitäten leicht gefesselt, so aufgelegt, dass die za benutzende hintere Extremität über die Kante des Brettchens gerade nach unten hängt. Dort fasst eine, dem Dubois schen Muskeltelegraphen entnommene Zange die ebenfalls nach abwärts hängende. Tibia, und hält sie, nur um das nöthige aus ihrer Berührungsfläche mit dem Muskel abgelenkt, fest. Dann wird der Nerv aus der Wunde herausgezogen, auf die Reizelectroden gelegt, die Kochsalzfäden der Muskelelectroden mit Dubois Thonstiefeln verbunden, der Muskelhebel eingehakt, über das ganze eine feuchte Kammer gestellt ${ }^{1}$ ) und der Versuch kann endlich beginnen.

Die ziemlich lange Mühe der Zurichtung lohnt sich, insofern man jedenfalls darauf rechnen kann, den Muskel über die zweite Schwankung hinaus frisch zu erhalten. Während der Ablesung

1) Ich habe es später einfacher gefunden, nur den Frosch feucht zuzudecken und den Nerven $a b$ und zu anzufeuchten.

E. Pfüger, Archiv f. Physiologie. Bd. XLV. 
der dritten Schwankung jedoch fängt in den weitaus meisten Fällen die Ermüdung an, sich durch die allgemeine 0 rdinatenabnahme der schwankungen anzuzeigen. Ich bin jedoch ohne diese Präparation überhaupt nicht bei der dritten Schwankung zu ablesbaren und verwendbaren Werthen gekommen, wenn nicht die oben citirten Veränderungen der Erregbarkeit eintraten, welche die letzte und die vorangehenden Schwankungen iuberbaupt unvergleichbar machten. Zur Charakteristik des Nutzeffektes möge dic Bemerkung dienen, dass in dem Versuch Nro. 96104 Ablesungen mit praeter propter $3500-4000$ einzelnen Reizungen erhalten wurden, und dies Nitte Dezember, zu einer Zeit, wo das Froschmaterial sich bereits nicht mehr in der besten Verfassung befindet.

Was bei Versuchen mit so zugerichteten Thieren zunächst auffällt, ist eine stetige, geringe Unruhe der Scala, die sich im allgemeinen jedoch weniger in den Versuchszahlen, als mehr der unmittelbaren Betrachtung offenbart. Das zuverlässige Hiulfsmittel, den Gang der Masehine zu controlliren, die Ersetzung des Muskelstromes durch den Stromzweig eines Daniells, weist unmittelbar nach, dass unregelmässige Funktion des Apparates nicht Ursache der Erscheinung ist. Sie ist übrigens nur in den seltensten Fällen so störend, dass der Versuch darunter leidet. Sie rührt möglicherweise von leichten Vertrocknungs-Erregungen am abgeschnittenen Nervenende her, sofern sie, nämlich wenn sie besonders stark wurde, dureh Abspülen der Nerven mit physiologischer Kochsalzlösung schnell auf ein geringeres Maass gebracht werden konnte.

Die erhaltenen Resultate selbst lassen sich dahin deuten, dass bereits mit dem zweiten Reiz ein für die fernere Reizung definitiver Zustand eingetreten ist. Fälle, bei denen dies unmittelbar sichtbar ist, geben freilich nur die Versuche Nro, 90, 92 und 93. In diesen weicht die Schwankung des $c$-Contactes nicht erheblich an Höhe von denen des $a$ - und $b$-Contactes $a b$, und der der $c$-Reizung zugehörende Antheil aus der Schwankung bei dreifachem Reiz verläuft, und dies gilt besonders für Versuch $93 \mathrm{I}$, nicht wesentlich anders als der auf die $b$-Reizung entfallende Theil der Schwankungscurve bei Doppelreizung. In den übrigen Versuchen fällt die Schwankung des $c$-Contactes der Ermtidung wegen meist erheblich kleiner aus, als die des $a$ - und $b$-Contactes, es ist aber trotzdem aus den Schwankungseurven ersichtlich, dass der 
$c$-Antheil der dreifachen Reizung zur Schwankung bei Reizung durch den isolirten $c$-Contact in ungefähr demselben Verhältniss steht, wie der dem $b$-Contact zugehörige Schwankungsantheil der zweifachen Reizung zu der durch alleinige Reizung vom $b$-Contakt aus erhaltenen Schwankung.

Abgesehen von der unmittelbar sinnlichen Darstellung des Schwankungsverlaufes gestatten die mitgetheilten Versuche, wie ich glaube, auch sonst einige bemerkenswerthe Schlussfolgerungen. Zunächst geht aus ihnen unmittelbar hervor, dass der Muskel nach der Auslösung einer Erregungswelle nicht sogleich im Stande ist, den Erregungsprocess in gleicher Stärke zu wiederlolen. Ja es scheint sogar, als ob in der der Auslösung des Schwankungsprocesses unmittelbar folgenden Zeit der Muskel überhaupt unfähig ist, einen neuen Erregungsanstoss von Seiten des Nerven anzunehmen, da denn aus dem Vergleich der Schwankungszuwüchse bei der zweiten Reizung in 0,002 und 0,004 secundlichem Intervall sich entnehmen lässt, dass der bei 0,002 secundlichem Intervall schon sehr kleine Schwankungs-Zuwachs bei noch engerem Intervall bis zur Unkenntlichkeit zusammenschrumpfen würde. Das mit dem Intervall zunehmende Wachsthum der zweiten Schwankung aber deutet unmittelbar darauf hin, dass von Anbeginn der ersten Schwankung an eine Neubildung des die Schwankung bestreitenden Materials anhebt, welche, eine messbare Zeit dauernd, ihr Ende erreicht, sobald die Menge der wieder angebildeten Substanz eine bestimmte Grösse erreicht hat. Die Grösse dieser Zeit lässt sich nach dem hier vorliegenden Material nicht oder nur annähernd bestimmen. Sie dauert mindestens 0,01 Secunden, ist aber, nach den Eingangs dieser Arbeit citirten Versuchen über die Summation der negativen Schwankungen jedesfalls bedeutend grösser, und wird unter Umständen bis zu 0,03 Secunden hinauf gehen können, da der maximale Grenzwerth der gesammten tetanischen Schwankung, auf Tetani gleicher Dauer bezogen, oft schon bei diesem Reizintervall erreicht wird. Ich will, um für diese Zeit einen kurzen Namen zu haben, dieselbe "Assimilationszeit" nennen, da doch offenbar in ihr Processe ablaufen müssen, durch welche unter Entnahme von Material aus dem Energievorrath des Muskels zunächst mindestens diejenigen Reconstructionen seiner Substanz geschehen, durch welche er zum Ablauf einer neuen Schwankung befähigt wird. 
Aus den Untersuchungen von Helmholz über die Summation zweier maximaler Zuckungen ergiebt sich, dass der Zuckungszuwachs bei einem Reizintervall von 1/600 Secunde unmerklich wird. Mit der Vergrösserung des Reizintervalls nimmt der Zuckungszuwachs zu, und erreicht nach Sewalli) sein Maximum bei einem Intervall von 0,048 Secunden. Summationen in einem engeren Intervall als $1 / 600$ Secunde, wie sie Sew all noch bis zu 0,001 Secunde Intervall angiebt, sind jedesfalls sehr gering. Der durch den zweiten Reiz bedingte Schwankungszuwachs wird bei einem kleineren Intervall als 0,002 Secunden wie oben bemerkt ebenfalls nur klein sein können, und jedenfalls rasch bis an die Grenze der rheotomischen Messbarkeit abnehmen.

Wenn es sich um nur zwei Reize in einem Intervall bandelt, das enger ist als die Latenzzeit des Muskels, so können die Contractionsprocesse nicht modificirend in die Schwankungsgrösse eingreifen, es muss also der geringe Betrag der während der Schwankung sich abspielenden Vorgänge Ursache des geringen Verkürzungszuwachses sein.

Dass die Grösse der zweiten Schwankung nicht beeinflusst wird durch den Grad der Verkürzung, in welcher sich der Mnskel als Folge des ersten Reizes befindet, ergiebt sich auch aus Versuchen wie die der Eingangs dieser Arbeit eitirten Versuchsreihe. Aus ihnen lässt sich schliessen, dass die Abnahme der einzelnen Schwankung schon beginnt bei einem Intervall, welches zur vollständigen Verschmelzung der einzelnen Zuckungen noch nicht genügt. Im maximalen Tetanus selber findet ausserdem jede folgende Schwankung bei gleichem Verkürzungsgrade statt, wie die vorhergehende und trotzdem fällt mit dem Intervall der absolute Werth des Antheils, mit welchem sie an der Gesammtschwankung theilnimmt. Die Uebereinstimmung, welche diese bei reiner Querschnittsableitung angestellten Versuche mit den Ergebnissen der gegenwärtigen Untersuchung bieten, giebt auch den aus der Benutzung des Gastrocnemius hergeleiteten Einwänden nur mindere Bedeutung.

Wenn man sich von dem allgemeinen Verlauf der electrischen Veränderungen während des Tetanus eine Vorstellung machen will,

1) H. Sewall, On the effect of two succeeding stimuli upon muscular contraction. Journal of physiologie II, S. 164-190. 
wird es bequemer sein statt von der Curve der negativen Schwankung von der der Actionsströme zu reden.

Von einem Intervall ausgehend, dessen Grösse unter Umständen mit der Zuckungsdauer identisch sein möchte, - worüber jedoch bis jetzt noch nichts feststeht, - in welchem aber alle Schwankungen gleich gross sind, werden die späteren Schwankungen mit Abnahme des Intervalls kleiner. Abgesehen von der ersten Schwankung behalten sie jedoch immer untereinander gleichen Flächeninhalt, die Höhe ihrer Gipfelpuncte braucht jedoch Anfangs wenigstens nicht immer gleich zu sein, und es kann der Gipfel der zweiten Curve über dem der ersten liegen. Mit der Verkleinerung des Intervalls von Versuch zu Versuch nimmt ihr Flächeninhalt nun ebenfalls ab. Die vom zweiten Reiz an erreichten Gipfel sind, obwohl untereinander gleich, so doch beträchtlich niedriger als der erste, und die Curven verflachen allmählich, um bei engstem Intervall so flach zu werden, dass die, die Gesammtcurve zusammensetzenden Einzeltheile rheotomisch nicht mehr von einander gesondert werden können.

Die Grenzen des Intervalls, bei denen das Rheotom versagt, sind dieselben, bei denen der stromprüfende Froschschenkel ebenfalls anfängt anzudeuten, dass die Unstätigkeiten oder periodischen Veränderungen der Stromescurven unter das den Nerven erregende Mass hinuntersinken. Der secuudäre Tetanus macht, obwohl am frischen Präparat vorhanden, an dem bereits benutzten Muskel bald der secundären Anfangszuckung Platz, in welche er, unter allmählicher Verkürzung seiner Dauer, bald tibergeht, ohne dass die Verktirzungsgrösse des primären Tetanus mit abnimmt. Bei Intervallen von 0,004 Secunden merklich, und bei 0,002 Secunden sehr deutlich tritt diese Erscheinung bei noch engerem Intervall in den Vordergrund. Auch das Telephon, beim Froschmuskel bei nur weitem Intervall anwendbar, versagt beim Warmblüter jenseits dieser Grenzen, das Capillarelectrometer noch viel früher. Für engere Intervalle fliessen also die periodisch mit den Reizen entstehenden Actionsströme zu einem einzigen Actionsstrom zusammen, der obwohl theoretisch an Intensität noch wechselnd, practisch doch, zum wenigsten für den angelegten secundären Nerven, als constanter Strom zu betrachten ist.

Trotzdem befindet der Muskel sich dabei noch auf der Höhe der mechanischen Leistungsfahigkeit. In dieser Thatsache scheint mir 
ein gewichtiges Bedenken gegen die Auffassung zu liegen, dass - zum wenigsten in der Muskelfaser - das Entstehen des Actionsstromes in einem Querschnittselemente der Faser Ursache der Erregung in einem benachbarten Elemente, und somit Ursache der Fortpflanzung der Erregung uberhaupt sei.

Ich babe nun noch einmal auf die Erscheinungen am ermüdeten - ausgeschnittenen - Muskel zurtickzukommen. Sie sind ganz aussergewöhnlich, und bilden vielleicht den Ausgangspunkt späterer Versuche für andere. Es wurde seinerzeit schon hervorgehoben, dass hier zunächst einmal die Summationen in ganz anderer Weise verlaufen, als gewöhnlich. Submaximale Zuckungen summiren sich nach bekannten Angaben in jedem Intervall. Die Zuckungen am ermüdeten Muskel verhielten sich in einer Anzahl von Fällen ähnlich wie erstere. Die summirten Zuckungen erreichten die doppelte Höhe der einfachen bei Intervallen von 0,002 bis 0,006 Secunden, und in nicht seltenen Fällen war die erreichte Hubhöhe beträchtlich mehr, als das doppelte der einfachen Zuckung, hin und wieder das 4-5fache derselben. Schleuderungen des Hebels meine ich ausschliessen zu dürfen, da das Hebelwerk gentigend leicht, und nahe der Axe belastet war. Dass Schleuderungen auszuschliessen seien, zeigte die analoge Zunahme der negativen Schwankung. Besondere Eigenthümlichkeiten bot jedoch die dreifache Reizung, wenn das Rheotom so eingestellt war, dass der Gipfel des Actionsstromes der $c$-Reizung gerade in den Moment der Boussolableitung fiel. Der der $c$-Reizung entsprechende Ausschlag ist dann, der Abnahme aller Muskelfunctionen entsprechend, ziemlich gering, und die Ausschläge, welche dem $a$ - oder $b$-Contact zugehören und dem Ende der $a$-, resp. $b$-Schwankung entsprechen, liegen dann, selbst bei nur 0,002 Secunden Intervall, oft schon in der Grenze der Versuchsfehler, indem sie sich zwischen 1,0 bis 0,5 Scalentheilen bewegen. Beobachtet man nun zunächst den $c$-Ausschlag, und geht dann, sobald er abgelesen ist, ohne Unterbrechung der $c$-Reizung sofort zur $a+b+c$-Reizung über, so wächst der Ausschlag meist sofort, manchmal auch erst nach mehreren Rheotomumläufen, zu der schon Seite 158 erwähnten paradoxen Höhe. Auf dieser Höhe bleibt er jedoch längstens $4-5$ Secunden, danach nimmt er wieder $a b$, etwa bis zu den Werthen der isolirten $c$-Reizung. Schaltet man jetzt - alles während derselben Ablesung - den $a$-Contact durch 
Oeffinung des Vorreibers $\alpha$ ans, so wächst der Ausschlag wieder, ebenso, wenn man statt des $a$-Contactes den $b$-Contact aussehaltet. Stellt man jetzt das Rheotom so ein, dass statt der $c$-Schwankung das Maximum der $b$-Schwankung abgeleitet wird, so wächst beim Einsetzen der $a+b+c$-Reizung der Ausschlag entweder sofort, oder auch erst nach mehreren Secunden zur früheren Höhe, und bleibt nun im Verlauf der Ablesung auf derselben stehen. Ob der $c$-Contact dabei mitarbeitet, oder nicht, ist gleichgiultig, die Ausschaltung des $a$-Contactes drückt den Ausschlag wieder auf die Höhe des bei alleiniger $b$-Reizung beobachteten Werthes herab.

Ich habe in dem Stadium der Ermuidung, wo die paradoxen Summationen auftraten, nicht bemerken können, dass die Schwankung bei Einzelreiz solches nachträgliches Wachsthum zeigte. Es war dasselbe vielmehr immer nur eine Eigenthümlichkeit der summirten Reizungen, und trat im allgemeinen häufiger auf, wenn mit der $a+b-$, resp. $a+b+c$-Reizung sofort begonnen wurde, seltener wenn aus der $a$-Reizung ohne Pause, also während derselben Ablesung, zur mehrfachen Reizung übergegangen wurde. Es wird also die Veränderung der Erregbarkeit, welche Ursache der paradoxen Summation ist, schon eingeleitet durch Reize, welche in einem Intervall von 0,2 Secunden, - gleich der Umlaufszeit des Rheotoms - einander folgen, und die Zeit, welche diese Modification der Erregbarkeit den ersten Reiz überdauert, wächst allmählich, bis sie das jeweilige Intervall der Doppelreizung erreicht hat, ohne jedoch den Zeitwerth einer Rheotomumdrehung zu erreichen. Beobachtet wurde die paradoxe Summation noch bei 0,02 Secunden Intervall. $\mathrm{Ob}$ sie über ein grösseres Intervall hinausreicht, habe ich nicht entscheiden können, da der Apparat, wie schon früher erwähnt, ein grösseres Intervall anzuwenden nicht gestattete.

Das Ermüdungsstadium, während dessen die in Rede stehenden Erscheinungen ablaufen, ist leider zu kurz, als dass sich über das wechselseitige Verhältniss der zweiten und dritten Schwankung etwas feststellen liesse. Man könnte zunächst daran denken, dass der grösste Werth der Schwankung erst beim dritten, vielleicht auch noch bei einem späteren Reiz erreicht würde. Ich habe an diese Möglichkeit jedoch erst nach Abschluss dieser Untersuchung gedacht, und muss die eventuelle Beantwortung dieser Frage auf eine spätere Zeit verschieben. Sicher geht jedoch aus der oben gegebenen Schilderung des Thatsächlichen hervor, dass das Maximum 
der Schwankung nicht immer bei derselben Ordnungszahl des Reizes erreicht wird, sondern dass, wenn während einer, etwa 20 bis $40 a+b+c$-Reizungen umfassenden Ablesung, bei Einstellung des Rheotoms auf das Maximum der c-Schwankung, die Schwankungswerthe beim Beginn der Ablesung noch gross sind, dieselben nach Ablanf etwa der 20. bis 40. Reizung abnehmen und die paradoxe Summation sich nur noch während der Dauer der $b$ Schwankung erhält.

Es ist begreiflich, dass diese etwaige Verschiebung des Schwankungsgipfels eine Verwendung der bei den Ablesungen erhaltenen Aussehläge zur Construction der Curve paradox summirter Schwankungen sehr erschwert, und ebenso, dass alle Schwankungswerthe, welche in dem Uebergangsstadium von dem normalen zum paradoxen Verhalten gewonnen wurden, zur Curvenconstruction überhaupt nicht verwendbar sind. Es würde zum Beispiel ein vollständig falsches Bild der summirten Schwankungen entstehen, wenn man zur Construction der Curve in Versuch Nr. 76 ausser den bei den Einstellungen des Reizcontactes Nr. 1-8 (vgl. das Protocoll) auch noch die Contacteinstellung Nr. 9 benutzen wollte. Ebenso hat wahrscheinlich die Curve I der summirten Schwankung des Versuches Nr. 85 auf dem beigegebenen Curvenblatt durch die allmähliche Entwickelung der paradoxen Summation starke Entstellungen erfahren.

Ich habe den Versuch gemacht, mit Hülfe der Versuchsdaten zu Ende des Versuches Nr. 85 und Nr. 88 eine Curve der paradoxen summirten Schwankungen zu zeichnen. Bei der Verwerthung der Versuchsziffern zur graphischen Darstellung war jedoch Folgendes zu berücksichtigen. Es wäre zunächst ganz leicht möglich, aus den durch den Versuch erhaltenen Ordinaten sich eine Curve von vollkommen stetigem Verlauf zu construiren. Dies wäre jedoch falsch. Die bei der Einstellung 77,5 und 77,0 des Versuches 85 erhaltenen Ausschläge der $a$ - $+b$-Reizung (Nr. 9 und 10) sind, wie aus den $a$ - und $b$-Reizungen der vorangehenden Ablesungsgruppen (Nr. 6 bis 8 ) und aus den vorangehenden Daten dieses Versuches ersichtlich ist, nur als Bruchtheile der $a$-Schwankung zu betrachten. Diese aber hat, ebenfalls nach Ausweis der genannten Ablesungen, bei der Einstellung 77,0 des Reizcontactes ihren böchsten Werth, und es müsste demnach ihre Curve bei dieser Einstellung der Abscisse naheza parallel laufen. Bei der 
Versuche übor den zeitlichen Verlauf des Muskelstroms im Tetanus. 169

Einstellung 77,0 aber beginnt die $b$-Schwankung mit einem, allerdings noch sehr geringen Werthe. Wir müssen daher in der graphischen Darstellung an dieser Stelle eine Unstätigkeit der Curve annehmen, da dieselbe einmal kurz vor der Einstellung 77,0 der Abcisse nabezu parallel verlaufen, andererseits aber von dieser Stelle selbst aus mit ziemlicher Steilheit bis zu dem bei der Einstellung 76,0 erreichten höchsten Werthe ansteigen muss.

Es liegt in der Natur des Repetitionsverfahrens, dass die bisher bekannten Erscheinungsweisen der Zuckungstreppe in den durch das Rheotom ermittelbaren Schwankungswerthen zum Ausdruck nicht gebracht werden können. Die rheotomische Untersuchung verlangt zur Ermittelung einer einzelnen Schwankungsordinate ja stets eine grössere Zahl von Reizungen und die Zuckungstreppe hat - maximale Reizung vorausgesetzt - bereits bei einer Ordnungszahl der Zuckungen ihren höchsten Werth erreicht, bei welcher die Ablenkung der Galvanometernadel ihren höchsten Stand noch nicht erreicht hat, so dass die Ablesung erst gemacht wird, nachdem die Treppe vollendet ist. Die beobachteten Schwankungswerthe können daher nur als solche betrachtet werden, die den Zuckungen am Ende der Treppe, oder bereits solchen angehören, die erst nach Erreichung des Grenzwerthes ausgelöst werden.

Untersuchungen über das Auftreten der Schwankungstreppe könnten also nur vorgenommen werden, wenn das Intervall zweier einander folgenden Schwankungen $a$ und $b$ bedeutend kleiner ist, als die Unlaufszeit des Rheotoms und die von der $b$ Reizung bis zum nächsten $a$-Reiz verfliessende Zeit so gross ist, dass die durch den $b$-Reiz hervorgebrachten Erregbarkeitsveränderungen bereits wieder verschwunden sind zur Zeit, wo der $a$-Reiz repetirt wird. Eine so grosse Umlaufszeit ist aber dem Repetitionsverfahren nicht zug:̈nglich, und bei den gegebenen Grenzen der Umlaufszeit ist das verwendbare Intervall zwischen der $a$ - und $b$-Reizung, das ja immer um ein vielfaches kleiner sein muss, als die Zeit von der $b$ - bis zur a-Reizung, bereits so klein, dass - maximale Reizung vorausgesetzt - die Situation durch die noch nicht vollendete Neubildung der schwankungsfähigen Substanz und dementsprechend durch die schwankungsvermindende Wirkung des Intervalls vollständig beherrscht wird.

Man könnte also am frischen Muskel bestenfalls unter Be- 
nutzung submaximaler Reize zur Darstellung der Schwankungstreppe gelangen, da man bei ihr voraussetzen darf, dass der $b$-Reiz aus dem vom $a$-Reiz noch übrig gelassenen Schwankungsvorrath plus dem neugebildeten schwankungsfähigen Material, eine zum mindesten gleich grosse submaximale Schwankung wird bestreiten können, wie der $a$-Reiz. Das Eintreten der Treppe innerhalb des Intervalls einer ganzen Rheotomumdrehung liesse sich vielleicht unterdrücken. Thatsächlich gelingt es auch, wenn man die Rollenabstände des Inductionsapparates möglichst an die Reizschwelle heran legt, die Zuckungen trotz des Auftretens der durch die Repetition der Zuckungen bewirkten Treppe annähernd untermaximal zu halten, aber sie werden jetzt sehr ungleich gross, werden hin und wieder maximal oder fallen auch ganz aus.

Die Ursache hierfür liegt in der Eigenthlumlichkeit der reizenden Contacte. Die Contactdauer muss unter allen Umständen merklich klein gegen das Reizintervall genommen werden und ist unter diesen Umständen, wie mir scheint, bereits kleiner als die vom Strom in der primären Spirale zu seiner Entwickelung benöthigte Zeit. Sobald dies der Fall ist, muss jedoch die Grösse der Inductionsschläge in der secundären Spirale mit der Dauer des Contactes im Reizkreise wechseln, und es liegt auf der Hand, dass bei submaximalem Rollenabstand auch sehr geringe Differenzen in der Dauer der Reizcontacte im primären Kreis erhebliche Unterschiede in den Zuckungen hervorbringen. Man müsste also versuchen, die Contactmethode zu ändern, oder die Grösse der bei maximaler Reizung im Nerven auslösbaren Erregnng vielleicht unter Zuhülfenahme des Anelectrotonus zu vermindern, Versuche, zu denen ich augenblicklich die Zeit nicht gehabt habe.

Die eben erwähnte Eigenthümlichkeit der Rheotomeontacte gewährt nun aber in dem Stadium der paradoxen Summation Bürgschaft dafür, dass die einzelnen Reize noch maximal waren, denn die Zuckungshöhen waren, wenngleich gering, so doch genau einander gleich. Dann aber ergiebt sich für den frischen und den ermildeten Muskel der Untersehied, dass jener die maximalen Contractions- und Schwankungsprocesse in einem kiirzeren Intervall in gleicher Grösse wiederholen kann, als dieser.

Sucht man die Ursache dieses scheinbar fundamentalen Unterschiedes, so findet man sie leicht in dem Umfang des Processes selbst. Die maximale Contraction des frischen Muskels 
Versuche über den zeitlichen Verlauf des Muskelstroms im Tetanus. 171

verläuft mit allen ihren Antecedentien und Adnexen, Schwankung, Wärmeentwickelung, virtueller, am Spannungszeiger messbarer Kraftentwickelung unter viel grösseren numerischen Werthen, als die des ermuldeten Muskels. Wenn nun innerhalb eines gegebenen engen Intervalles letzterer seine maximale Leistung in gleichem Umfang wiederholen kann, ersterer aber nicht, so liegt die Erklärung hierftir wohl wesentlich in der Verschiedenheit der absoluten Werthe beider Leistungen.

Der ermidete Muskel hat wenig Spannkraft verbraucht und daher auch nur wenig zu ersetzen, der frische Muskel hat viel verbraucht und bedarf daher eines reichlichen Ersatzes. Wenn sich die Assimilationsgeschwindigkeit, d. h. die Menge des in der Zeiteinheit ersetzten Materiales unter dem Einfluss der Ermtidung nicht ändert, muss der geringe Ersatz des ermüdeten Muskels in kürzerer Zeit geschafft werden, als der grössere des frischen Muskels. Die gesunkenen Leistungen des ermüdeten Muskels nun finden ihren Ausdruck bereits in den der Contraction vorangehen. den Processen. Die Schwankungen sind kJein geworden und der geringe Abgang an schwankungsfähigem Material kann, unveränderte Assimilationsgeschwindigkeit vorausgesetzt, schneller wieder ersetzt werden, als die relativ grosse Menge des vom frischen Muskel verbrauchten Stoffes. Die factisch beobachteten Schwankungen als Maasseinheit betrachtet, muss daher die zweite Schwankung beim frischen Muskel kleiner ausfallen, als beim ermïdeten.

Bei dieser Auffassung des Vorgangs verliert somit die paradoxe Summation ihre Paradoxie, und erklärt sich zugleich, weshalb beim ermüdeten Muskel die Schwankungstreppe unter den Bedingungen des Rheotomversuches sichtbar werden kann. Es ist in dieser Beziehung von Wichtigkeit hervorzuheben, dass beim ermideten Muskel der Schwankungsgipfel der zweiten Schwankung bei Doppelreizen zu ungefähr derselben Höhe emporsteigen kann, wie die erste Schwankung am unermideten. Der Vergleich der Einstellungen 76,5 und 76,0 in den Ablesungen 2 und 3 einerseits, 6 und 7 andererseits in Versuch Nr. 85 giebt hierfür Beispiele.

Eine Reibe von Arbeiten aus dem Leipziger physiologisehen Institut, und insbesondere die schönen Untersuchungen M. v. F r e y's ${ }^{1}$ ), haben uns als die drei Factoren, von welchen die Form der tetanischen Curve beeinflusst wird, erkennen lassen: die Selbstunterstützung, die Contractur und die Treppe. Das Verbalten der 
negativen Schwankung zeigt, dass der Einfluss der letzteren mit fortschreitender Ermüdung stark zunimmt. Auf die Wirkung der Treppe lässt sich nun vielleicht auch noch die Erscheinung der Anfangszuckung zurïckführen. Die Anfangszuckung entsteht nur bei submaximaler Reizung. Ich habe seinerzeit gezeigt ${ }^{2}$ ), dass zum Zustandekommen der Anfangszuckung immer mehrere Reize nöthig sind, von denen jeder einzelne zur Erzeugung einer Zuckung nicht hingereicht haben würde. Es geht schon hieraus hervor, dass dieselbe nicht, wie Kronecker meint, als ein Product der Ermudung in dem Sinne betrachtet werden kann, dass die Tetanuscurve, die eigentlich als Folge einer Reihe von Reizen auftreten mulsste, in aussergewöhnlich kurzer Zeit auf Null herabsinkt.

Wenn nun, der eben citirten Untersuchung entsprechend, die Anfangszucknng das unzweifelhafte Product mehrerer Reize ist, so mitssen sich in dem zeitlichen Verlaufe derselben zweifellos Unterschiede zwischen ibr und der durch einen electrischen Momentanreiz erzeugten Zuckung auffinden lassen. Ich habe im Anschluss an die eben erwähnte Arbeit bereits früher nach solchen gesucht und hatte zunächst Unterschiede in den Latenzen beider Vorgänge erwartet. Da die Untersuchung solche nicht ergab, wurde das erbaltene Curvenmaterial zunächst bei Seite gelegt. Die eigenthtimlichen Analogien zur Anfangszuckung, welche nun das hier mitgetheilte Verhalten der negativen Schwankung des ermüdeten Muskels bot, veranlassten mich nun, die Curven nochmals durchzusehen. Es stellten sich dabei allerdings einige bisher nicht beachtete Unterschiede zwischen beiden Zuckungsarten heraus.

Ich verweise zunächst beztiglich der einfachen Methodik des Versuchs auf aiie eben citirte Arbeit. Geändert wurde nur die Curvenschrift, indem Anfangszuckung und Zuckung durch Oeffnungsinductionsschlag auf dieselbe Zeile geschrieben wurden. Hervorzuheben ist zunächst als allgemeine Regel, dass, wenn es gelingt,

1) Versuche zur Auflösung der tetanischen Muskelcurve. Beiträge zur Physiologie, C. Ludwig zu seinem siebzigsten Geburtstag etc. S. 55 und: Reizungsversuche am unbelasteten Muskel, Du Bois Archiv 1887, S. 195.

2) Zur Frage nach der Natur der Anfangszuckung, Du Bois Archiv 1882, S. 357. 
Versuche über den zeitlichen Verlauf des Muskelstroms im Tetanus. 173

die Höhe der Anfangszuckung so abzustufen, dass sie der aufgeschriebenen Oeffnungsinductionsschlagzuckung gleich ist, die Daner der Anfangszuckung immer um ein weniges grösser ist. Es fallen dann oft, aber nicht immer, die aufsteigenden Theile beider Curven so vollkommen in einander, dass auch die sorg. fältigste Durchsuchung derselben mit dem Mikroskope Spuren einer zweimaligen Schrift in der Curve nicht nachweisen kann. Erst im Anfang etwa des zweiten Drittels des absteigenden Theiles wird die Curvenspur doppelt, und die der Anfangszuckung gehörige Curve verläuft langsamer zur Abscisse, als die der Inductionszuckung.

Neben diesen Fällen findet sich ein Reihe von Curven, in denen die Trennung beider Zuckungen bereits auf der Gipfelhöhe, oder auch etwas vor derselben beginnt. In beiden Fällen dauert die Anfangszuckung immer etwas länger, und im zweiten Falle wird der Zuckungsgipfel auch etwas später erreicht, als bei der durch den Inductionsschlag erzeugten Zuckung.

Weiterhin kann nun die Anfangszuckung sich so verlängern, dass ihre Dauer die der einfachen Zuckung um einen grösseren Bruchtheil derselben, oder auch um das mehrfache ihrer ganzen Länge ubertrifft, so dass man statt von Anfangszuckungen eigentlich von Anfangstetanis reden müssle. Gegenüber den gewöhnlichen Tetanis findet sich in diesen nun - von der Eigenthümkeit der Anfangszuckung, dass die Muskelthätigkeit während der Reizung aufhört, ganz abgesehen - eine ganz charakteristische $\mathrm{Ab}$ weichung von der gewöhnlichen Verlaufsweise sowohl des Tetanus, als der superponirten Zuckungen. Die Anfangstetani steigen stets langsamer an, als eine Inductionsschlagszuckung von gleicher Höhe, oder lösen sich bestenfalls von derselben auf ihrem Gipfelpunkte ab. Nie dagegen steigt ein Anfangstetanus schneller an, als eine gleich hohe Zuckung. Um etwaige Missverständnisse zu vermeiden, soll der Begriff des Anfangstetanus hier noch näher präcisirt werden. Es sollen unter Anfangstetanis immer nur solche Tetani verstanden werden, welche mit dem akustischen Stromunterbrecher erzengt wurden, bei denen die Reizstärke so bemessen war, dass bei einer nur geringen Schwächung der Inductionsschläge die Zusammenziehung ganz ausblieb, und welche endlich, bei fortdauernder Reizung spätestens nach 0,3 Secunden, also etwa dem dreifachen einer einfachen Zuekungsdauer, spontan endigten. 
Für das hier Mitgetheilte mögen die nachfolgenden Curven der Fig. IV Belege geben. Von diesen ist Curve 1 und 5 mit

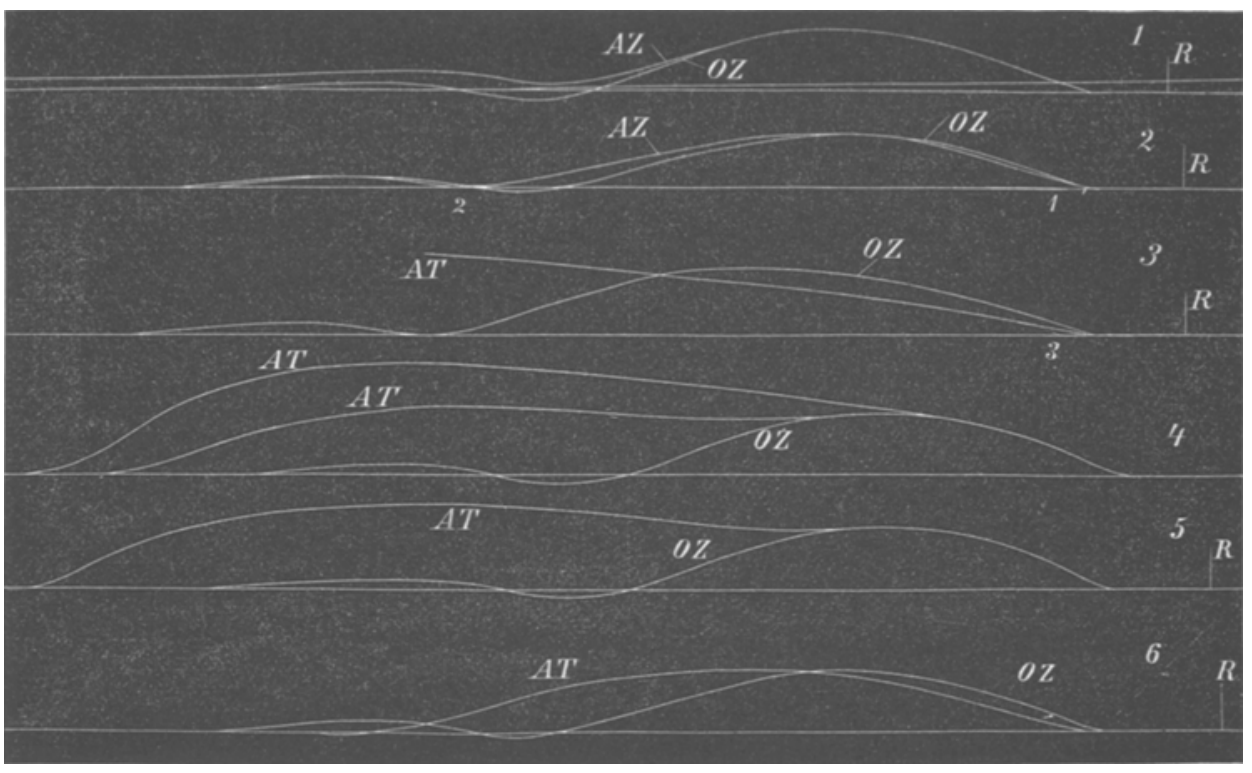

Fig. IV.

300 Reizen pro Secunde, Curve 2 und 3 mit 220, Curve 4 mit 480 Reizen pro Secunde gezeichuet worden. Die Abkürzungen $A Z, A T, O Z$ bedeuten Anfangszuckung, Anfangstetanus und Oeffnungszuckung. Zehn Millimeter Abscissenlänge entsprechen 0,014 Secunden. Die Curven 1 und 2 lassen die Unterschiede zwischen Anfangszuckung und Oeffnungsinductionsschlagszuckung deutlich erkennen, während die Curven 3,4 und 5 zeigen sollen, dass die Anfangstetani nur ebenso schnell (Nr. 4 und 5), oder langsamer (Nr. 3) ansteigen als die einfache Zuckung. Beziiglich des Standes der Inductionsrolle, welcher beim Uebergang von der einen zur andern Reizart jedesmal gewechselt werden muss, gilt das 1. c. bereits Angefübrte.

Wenn nun auch durch die eben citirte Untersuchung für die Ansicht Kroneckers, die er übrigens mit experimentellen Grinden zu belegen nicht vermocht hat, meinerseits der Richtigkeitsbeweis in soweit geführt wurde, dass die Nothwendigkeit mehrerer Reize zum Auftreten der Anfangzuckung dargethan wurde, so folgt doch noch nicht unmittelbar daraus, dass dieselbe als Tetanus betrachtet 
Versuche über den zeitlichen Verlauf des Muskelstroms im Tetanus. 175

werden müsse. Für den althergebrachten Begriff des Tetanus ist das wesentliche nicht sowohl die Vielheit der Reize, als vielmehr die Verschmelzung einzelner Zuckungsacte, und für diesen Fall ist die Voraussetzung, dass der einzelne Reiz über der Reizschwelle liege, nicht zu umgehen. Wenn aber bei der Anfangszuckung der einzelne Reiz der Reizreihe unter dem Schwellenwerth liegt, können Versuche mit Reizen über der Reizschwelle nur cum grano salis zum Vergleich herangezogen werden. Denn in letzterem Falle kommen stets Veränderungen zur Beobachtung, zu welchen alle Theile des Nervmuskelprïparates beigetragen haben, im ersteren muss dagegen erwogen werden, ob sich nicht an Orten, die zunächst mit der Contraction noch gar nichts zu thun haben, beispielsweise zwischen den Electroden, oder in den Nervenendigungen Vorgänge abspielen, welche, obwohl die Contraction von ibnen abluängig ist, doch ihrerseits von den Contractionen unabhängig sein können. Durch die Untersuchungen von J. v. Kries und Sewall1) waren zudem auch schon Andeutungen gegeben, dass die Summirung submaximaler, nahe am Schwellenwerth gelegener heize in den Intervallen der Anfangsszuckung unter Umständen andern Gcsetzen folgen kann, als den für die Summirung der Zuckungen geltenden. Obwohl die Bedingungen dieser Versuche mit denen, unter welchen die Anfangszuckung auftritt, noch am ehesten' zu vergleichen gewesen wären und obwohl in ibnen schon festgestellt war, dass ein an sich unwirksamer Reiz einen eben wirksamen kräftig unterstitzen kann, bat $\mathrm{K} \mathrm{r}$ one cker in den gegen die Anfangszuckung polemisirenden Arbeiten dieselben gar nicht berticksichtigt.

Ich habe bisher auf Kronecker's diesbezigliche Arbeiten nicht geantwortet, weil mir einestheils die Verwandtschaft zwischen Anfangszuckung, Anfangstetanus und derjenigen Erscheinung, die Kronecker mit dem "Zusammenschrumpfen des Tetanus auf eine einzige Ordinate ${ }^{* 2}$ ) bezeichnet, nicht ganz ansgeschlossen erschien, andererseits aber auch die bis über den Zuckungsgipfel hinausreichende Coincidenz des zeitlichen Verlaufs der gemeinen Zuckung und der Anfangszuckung einen gewichtigen Einwand gegen die Zusammensetzung der Anfangszuckung aus mehreren gewöhnlichen Zuckungen darbot.

1) Ueber die Summirung untermaximaler Reize in Muskeln und Nerven, Du Bois Archiv 1881, S. 66.

2) Du Bois Archiv 1883, S: 326. 
Die paradoxe Schwankung nun bietet ein Bindeglied zwischen den fraglichen Erscheinungen. Sie zeigt zunächst und zwar in Uebereinstimmung mit den gleichzeitig beobachteten Verkürzungswerthen, dass der ermuidete Muskel durch den ersten Reiz bochgradige Steigerung seiner Erregbarkeit erfahren kann, und dass diese Steigerung wechselnde Zeit, oft aber mehrere Reize hindurch anbält.

Daraufhin kann aber dem "Zusammenschrumpfen des Tetanus auf eine einzige Ordinate" auch noch eine andere Deutung gegeben werden, an welche zu denken bisher wohl wenig Grund vorlag. Es schrumpft der Tetanus bei engerem Reizintervall nicht sowohl auf eine einzige Ordinate zusammen, sondern erhebt sich durch Steigerung der Erregbarkeit so zu sagen auf die Dauer einer einzigen Ordinate über die eigentliche niedrige Tetanuscurve. Für diese selbst aber mag der Satz gelten, dass die Ermüdungscurve submaximaler Reize um so steiler abfällt, je enger das Intervall ist. Zieht man die anfängliche Steigerung der Hubhöhen von dem übrigen Verlauf der tetanischen, mit dem akustischen Unterbrecher gezeichneten Curven ab, nur den ibr nachfolgenden Theil derselben berücksichtigend, so bemerkt man allerdings leicht, dass dieser zweite Theil der Curve unter um so niedrigeren Werthen verläuft, je höher die Reizfrequenz ist. Andeutungen dieses Verhaltens gibt die zweite Hälfte der sub Fig. 3 Taf. XI in Du Bois Archiv 1886 gelegentlich einer Untersuchung über die Summation der negativen Schwankungen von mir mitgetheilten, mit dem akustischen Stromunterbrecher erzengten Tetanuscurven, bei denen ich dahingestellt sein lassen muss, ob die Reize bei den höheren Frequenzen noch maximal waren. Dass es sich bei den Anfangstheilen dieser Curve um Wurfhöhen nicht handelt, lässt sich leicht ersehen, wenn man berücksichtigt, wie sich der Anfangsgipfel immer mehr ausprägt, je höher die Reizfrequenz steigt.

Andererseits nun gewinnt die paradoxe Schwankung Beziehungen zur Anfangszuckung, weil sie zeigt, dass die Steigerung der Erregbarkeit nicht nothwendig durch eine ganze Reizreihe hindurch vorzuhalten braucht, sondern bald, sogar schon nach dem Ablauf des zweiten Reizes wieder erlöschen kann. Die Thatsache, dass das Wachsthum der $c$-Schwankung zunächst bei $a+b+c$-Reizung, später aber nur noch bei $b+c$ - 
Versuche über den zeitlichen Verlauf des Muskelstroms im Tetanus. 177

Reizung beobachtet werden kann, lässt sich nicht wohl anders deuten, als so, dass das in der $a+b+c$-Reihe zunächst uber die $c$-Schwankung reichende Schwankungswachsthum bei den späteren Reizungen nur noch bis zur $b$-Schwankung reicht. Man midsste allerdings auch daran denken, ob nicht der Abfall der $c$-Schwankung der Abnahme des Schwankungswerthes gleichzustellen sei, welche eine zweite Schwankung ïberhaupt erleidet, wenn sie im engen Intervalle der ersten maximalen nachfolgt. Es wäre hierbei zu berticksichtigen, dass in der That sehr oft durch paradoxe Summation Sehwankungswerthe erreicht werden, welche man sehr wohl noch als maximal betrachten kann. Aber dann wäre bei fortdauernd gesteigerter Erregbarkeit zu erwarten, dass der $c$-Antheil der $a+b+c$-Reizung sich auch innerhalb solcher absoluten Werthe bewege, wie man sie am $b$-Antheil der $a+b$-Schwankung des frischen Muskels beobachtet, dessen maximale Einzelschwankung ungefähr die Werthe der beobachteten durch paradoxe Summirung erreichten Schwankung hat. Dies ist aber nicht der Fall. Hat sich die paradoxe Summirung bei $a+b+c$-Reizung einmal von der $c$-Schwankung auf die $b$-Schwankung zurückgezogen, so bleiben die in das Stadium der $c$-Schwankung fallenden Reste der $a+b+c$-Schwankung eben so niedrig, wie bei der $c$-Reizung allein. Der beweisendste, allerdings nur selten zu beobachtende Fall ist der, dass die Werthe der Einzelschwankung so gering sind, dass sie gar nicht mehr zur Beobachtung kommen. Um an einen dieser Fälle anzuschliessen, so wurde in Versuch 69 beobachtet: Intervall $a, b 0,003$ Secunden, Intervall $b, c 0,00325$ Secunden.

1) Bei Einzelreizung von jedem der Contacte aus: keine Ablenkung.

2) Bei Reizung mit den Contacten $a$ u. $b$ zusammen: ebenso.

3) $", \quad n \quad$, $n$ u. $c \quad, \quad 7$ Scalentheile.

4) $", \quad " \quad, \quad, b$ u. $c \quad, \quad$ ebenfalls 7 Scalentheile.

Letzterer Ausschlag bestand ungfähr bis zur Mitte der ganzen ihn angehenden Reizungsperiode, schätzungsweise also bis zür zwanzigsten Zuckung, von da ab wurde er, während die Reizung noch iuber weitere 20 Zuckungen fortgesetzt wurde, kleiner, und endlich Null. Wie die beigegebenen Curven Fig. $V$ zeigen, blieben jedoch die erreichten Verkïrzungswerthe zu Ende der Reizung im wesentlichen dieselben, wie zu Anfang. Die $a+b \cdot$, sowie die $b+c$ Reizung gingen der $a+b+c$-Reizung dicht vorauf, die Werthe für

E. Pflūger, Archiv f. Physiologie. Bd. XLV. 


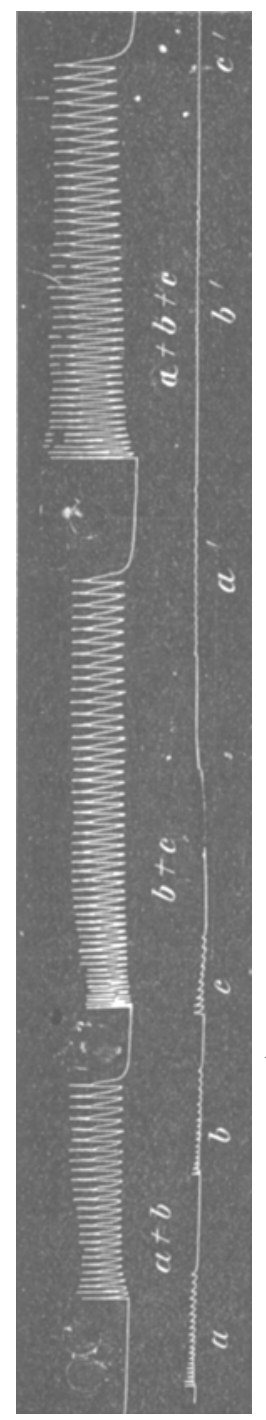

die Einzelzuckungen"entsprechen Einzelreizen aus bereits fruheren Versuchsstadien desselben Muskels, es liegen zwischen ihnen und den citirten mehrfachen Reizungen noch zwei $a+b$-, zwei $b+c$ - und eine $a+b+c$-Reizung, bei welch letzterer in währender Reizung ein Ritckgang von 10 auf 3 Scalentheile eingetreten war. Nach Beendigung der sub Nr. 4 oben angegebenen Ablesung wurden die Polenden der secundären Spirale vertauscht und die $a+b+c$-Reizung mit demselben Erfolg wiederholt, das Eintreten von Stromschleifen aus dem Reizkreis in's Galvanometer also ausgeschlossen. Die nun nachfolgenden Reizungen von den einzelnen $a-, b$-, resp. $c$ $\triangleright$ Contacten aus illustriren den Ermtidungsgrad $\therefore$ des Muskels wohl richtiger, als die sub Nr. 1 oben citirten, da letztere einem weit fruheren Versuchsstadium entsprechen. Ich habe die $\mathrm{zu}$ diesen gehörigen Zuckungscurven desshalb den beigesetzten Curven noch angeschlossen. Sie sind zum Unterschied von den sub $\mathrm{Nr} .1$ citirten $a-, b-;, c$-Reizungen mit $a^{\prime} b^{\prime} c^{\prime}$ bezeichnet.

Die Kurven stammen von einem Frosche grösster Art, und wurden mit höchstens zwei Gramm Belastung gezeichnet. Man wird sich bei Betrachtung der Einzelznckungen, namentlich der $a^{\prime} b^{\prime} \quad c^{\prime}$-Kurven des Eindrucks nicht erwehren können, dass hier nur wenige Fasern des Muskels gezuckt haben. Man wirde dann in dem Verhalten des grössten Theils der Fasern hier ein unmittelbares Analogon zur Anfangszuckung bezüglich des Punctes vor sich haben, dass der einzelne Reiz der Reihe unter dem Schwellenwerth der Reizung liegt. Somit lässt sich aus dem Schwankungsverlauf der Schluss ziehen, dass der anfänglich dreiactige Verlauf der Contractionen der $a+b+c$-Reizung sich nach und nach und zwar ohne Aenderung der erreichten Contractionswerthe in einen zweiactigen umgewandelt hat. Der erste dieser Acte, dem ersten Reize ententsprechend, würde nur in einer Aenderung der Erregbarkeit be- 
stehen, die den zweiten, an sich unwirksamen Reiz über die Reizschwelle emporhebt, so dass jetzt die resultirende Zuckungscurve als Doppelzuckung zu betrachten wäre, und zwar - nach Ausweis der gleichen Werthe der $b+c$ - und der $a+b+c$-Schwankung - als eine solche, bei der die sie zusammensetzenden, den zweiten und dritten Act darstellenden Einzelzuckungen etwa gleich hoch sind, während in den letzten Curven der Reihe die zweite der sie zusammensetzenden Zuckungen in dem Maasse kleiner wird, als die erste wächst. Graphisch also wäre eine Verschiebung des Zuckungsgipfels gegen den Anfang der Curve zu erwarten, ein Versuch, zu dessen Anstellung ich bisher indessen noch nicht die Gelegenheit gehabt habe.

Man übersieht leicht, dass die Reactionsweise des hochgradig ermudeten Muskels viel Aehnlichkeit mit der Anfangszuckung hat. $\dot{W}$ enn sich aber dort schliessen liess, dass die erregbarkeitssteigernde Wirkung des ersten Reizes sich gelegentlich bloss über das Intervall des zweiten Reizes erstrecken konnte, so verliert die Uebereinstimmung des zeitlichen Verlaufs der Anfangszuckung mit der durch einen Inductionsschlag erzeugten die Unerklärlichkeit, die ihr immer anhaften würde, wenn man die $\mathrm{Kr}$ onecker'sche Erklärung auf sie anwenden wollte. Letztere würde verlangen, dass die Anfangszuckung unter allen Umständen eine um das mehrfache des benutzten Intervalls längere Dauer besitze, als die Zuckung beim Momentanreiz.

Nun bleibt allerdings die Thatsache noch unerklärt, dass die Anfangszuckung eine merklich längere Latenzzeit nicht besitzt. Abgesehen davon, dass wirkliche, als solche deutlich zu erkennende Latenzverlängeiungen, wenngleich nur selten, in der Anfangszuckung und ihren Verwandten vorkommen, wofür noch der mit 480 Reizen pro Secunde erhaltene Anfangstetanus der Curve Nr: 6 (Fig. IV) ein Beispiel geben mag, und abgesehen davon, dass eine, wenngleich geringfïgige Latenz in solchen Anfangszuckungen versteckt sein mag, wie sie in Curve Nr. 2 gezeichnet sind, so braucht eine solche ausserdem nicht mit Nothwendigkeit erwartet zu werden. Denn der Beginn der Reizung fällt bei der angewendeten Reizmethode nicht nothwendig mit dem Anfang sei es des Schliesssungs, sei es des Oeffnungsinductionsschlages zusammen, sondern wird meistens bald dem Anfang, bald dem Ende näher; in den mittleren Theil desselben fallen. Betrachtet man diesen Bruchtheil des ersten Inductionssehlages als das erregbarkeits- 
erhöhende Moment, so würden schon bei 220 Reizen die zu erwartenden Latenzen im allgemeinen unter einem Werthe von $1 / 300$ Secunde liegen, und dies ausserdem bei jeder merklich höheren Reizfrequenz jedesmal der Fall sein.

Nach den Angaben Bernstein ${ }^{1}$ ) aber beträgt die Erregungszeit in den Nervenendorganen selbst $1 / 312$ Secunde und Erregungen von weniger als 0,003 Secunden Intervall müssten dort einander treffen. Es wäre nicht undenkbar, dass die Wirkung des ersten Reizes darin besteht, dass die von ihm gesetzte Erregung in den Nervenendorganen eine Art Bahnung vollzieht, zu Folge deren die 2weite Erregung, nachdem die Bahnung einmal geschehen, durch die Nervenendigung unverzögert bindurchtreten kann, obne sich in ihr zu erschöpfen, und man könnte zur Stuttze dieser Auffassung vielleicht die merkliche Verfrubung anführen, mit welcher die zweite Schwankung ibren Gipfel erreicht, wenn die Reizintervalle erst einmal so gross geworden sind, dass dieselbe wieder einen selbständigen Gipfel besitzt. Ich will indessen auf diese Erklärung ein besonderes Gewicht nicht legen, da die Voraussetzung, von der sie ausgeht, bis jetzt noch nicht bewiesen ist. Sie würde fordern, dass im Nerven Erregungen ablaufen können, ohne bis in den Muskel vorzudringen.

Fur die Anfangszuckung und die ihr verwandten Erscheinungen würde sich demnach folgende Reihe aufstellen lassen:

a) Die Reize liegen unter der Reizschwelle.

1) Die durch den ersten Reiz bewirkte Steigerung der Erregbarkeit dauert nur bis zum Eintritt des nächsten Reizes: Die resultirende Contraction ist dann, obwohl durch zwei Reize entstanden, nur als einfache Zuckung zu betrachten: reine Anfangszuckung.

2) Die Erregbarkeitssteigerung überdauert eine Reihe von Reizen: Anfangstetani.

b) Die Reize liegen uber der Reizschwelle, sind aber submaximal: Die Steigerung der Erregbarkeit überdauert mehrere Reize. Die Contraction des Muskels ist tetanisch, die Curve steigt zu Anfang schneller an, als es den von Bohr entwickelten Regeln entspricht, um ebenfalls schnell auf einen niederen Werth zu

1) J. Bernstein, Die Erregungszeit der Nervenendorgane in den Muskeln. Du Bois Archiv 1882, S. 329. 
Versuche über den zeitlichen Verlauf des Muskelstroms im Tetanus. 181

sinken. Der Muskel behält diesen niederen Contractionsgrad länger bei; Kroneckers "Zusammenschrumpfen des Tetanus auf eine einzige Ordinate".

c) Die Reize sind maximal, aber das Nervenmuskelpräparat ist in dem Zustand hochgradiger Ermüdung, eventuell am Absterben.

1) Der Einzelreiz ergiebt noch schwache Zuckungen. Die tetanische Reizung verläuft dann wie sub b.

2) Der Einzelreiz ist nabezu oder ganz unwirksam, und vermag die grosse Mehrzahl der Fasern nicht mehr zu erregen. Die Erregungen und die Contractionen verlaufen im Muskel wie sub a) 1 und a) 2 .

Ich lasse nun die Versuchsprotocolle zu den im Text angefuhrten Versuchen folgen und bemerke zur Orientirung folgendes.

In der ersten Colonne der Tabellen ist unter der Ueberschrift „Stellung der Reizcontacte" diejenige Stellung des gemeinschaftlichen Contactträgers zu verstehen, bei welcher der Index des letzteren auf den in dieser Rubrik angegebenen Theilstrich der - in hundert Theile eingetheilten - Rheotomscala einstand. Da nicht selten im Laufe des Versuches eine frühere schon benutzte Contacteinstellung wieder aufgesucht wurde, sind die einzelnen Einstellungen zur besseren Uebersicht mit laufenden Nummern versehen; anf diese ist bei der Citirung des Versuches und der einzelnen Schiebereinstellungen im Text verwiesen.

Ausser zu Versuch Nr. 45 gehört zu jedem der Versuche die in der angehängten Curventafel mit der Nummer des Versuchs versehene Curve ${ }^{1}$ ). Ueber die Bedeutung der Curven ist Seite 153 u. f. das nöthige gesagt.

Im Interesse der Darstellung eines möglichst stetigen Curvenverlaufes war es hin und wieder nöthig, die Curven nicht genau durch die Endpuncte der in den einzelnen Schieberstellungen aufgetragenen, den Ausschlägen entsprechenden Ordinaten zu ziehen. Es sind jedoch die Endpuncte der Ordinaten in der Curventafel stets mit eingezeichnet, so dass eine Abweichung des Curvenzuges von dem durch die Ordinate bestimmten Werth sofort in die Augen fällt.

1) Mit Ausnahme der Curve von Versuch Nr. 87, dessen Protocoll bei Abfertigung des Manuscriptes überschlagen wurde. Dasselbe ist Ende dieser Arbeit Seite 194 nachgetragen. 
Die den Reizungen unter Benützung nur eines der drei Contacte entsprechenden Ordinatenendpuncte sind mit einem dinneren Puncte, solehe, die einer Doppelreizung entsprechen, mit einem kräftiger gezeichneten Punet, solche endlich, die einer dreifachen Reizung entsprechen, mit einem Kreuzchen bezeichnet, wobei der Durchschnittspunct der sich kreuzenden Linien den Endpunct der Ordinate darstellt.

An den meisten Stellen der Curven kann über die Beziehung der Zeichen zu ihren Curven ein Zweifel nicht eintreten; wo solcher entstehen kann, weil die Curve der $a$-Schwankung sich mit der der $b$-Schwankung, der $a+b$-Schwankung u. s. w. kreuzt, ist durch die beigesetzten Buchstaben $a, b, c, a+b, a+b+c$ angegeben, dass das Zeichen sich auf die bei Reizung vom $a$-Contact, beziehentlich $b$-, oder $c$-Contact, oder bei Doppel-, resp. dreifacher Reizung erhaltenen Ausschläge bezieht.

Punctirt sind die nach dem Seite 154 angegebenen Princip ergänzten Theile der Curven.

Der Verlauf der Doppelschwankungen, sowie derjenige der bei dreifacher Reizung erhaltenen Schwankungen, ist von dem Punct an, wo er vom Verlauf der $a$-Schwankung abweicht, durch eine stärker ausgezogene Linie angedeutet.

Die Rubriken Ablesung und Ausschlag endlich bedürfen keiner besonderen Erklärung.

Versuch Nr. 45.

Reizintervall 0,0025 Sec. Ablenkung durch den Ruhestrom nach den kleinen Zahlen, Abstand der Contacte $1 \mathrm{Grad}$ der Rheotomtheilung. Umlaufzeit 0,25 Sec.

\begin{tabular}{|c|c|c|c|c|c|c|c|c|c|}
\hline 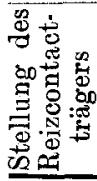 & 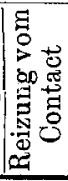 & \multicolumn{2}{|c|}{ Ablesung } & 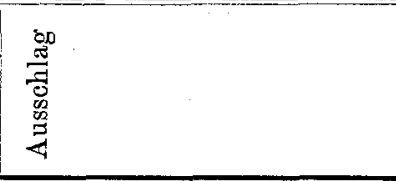 & 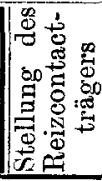 & 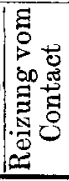 & \multicolumn{3}{|c|}{ Ablesung } \\
\hline $\begin{array}{l}90 \\
89.5\end{array}$ & & 365 & 381 & $\begin{array}{c}0-1 \\
16 \\
0\end{array}$ & 87.0 & $\begin{array}{r}b \\
a+b\end{array}$ & $\begin{array}{l}363 \\
363 \\
357\end{array}$ & $\begin{array}{l}384 \\
372 \\
365\end{array}$ & 9 \\
\hline 88.5 & & 361 & 389 & 28 & & & 358 & 378 & 20 \\
\hline & & $\begin{array}{l}362 \\
361\end{array}$ & $\begin{array}{l}377 \\
391\end{array}$ & $\begin{array}{l}15 \\
30\end{array}$ & & $a+b$ & $\begin{array}{l}358 \\
358\end{array}$ & 367 & 9 \\
\hline & & 362 & 390 & 28 & & $a+b$ & $\begin{array}{l}0,0 \\
358\end{array}$ & $\begin{array}{l}000 \\
366\end{array}$ & 8 \\
\hline 87.5 & & 354 & $\begin{array}{l}368 \\
382\end{array}$ & 14 & & $b$ & 356 & 374 & 18 \\
\hline & & & 370 & $\begin{array}{l}28 \\
14\end{array}$ & & $\left|\begin{array}{r}a+b \\
a\end{array}\right|$ & $\begin{array}{l}354 \\
355\end{array}$ & $\begin{array}{l}362 \\
360\end{array}$ & \\
\hline 87.0 & & & 370 & 12 & & & 354 & 369 & 15 \\
\hline & & 1 & 378 & 20 & & $a+b$ & 354 & 361 & 7 \\
\hline & $a+b$ & & $\begin{array}{l}371 \\
369\end{array}$ & $\begin{array}{r}11 \\
9\end{array}$ & & & $\begin{array}{l}355 \\
355\end{array}$ & $\begin{array}{l}358 \\
367\end{array}$ & $\begin{array}{l}3 \\
12\end{array}$ \\
\hline
\end{tabular}


Versuche über den zeitlichen Verlauf des. Muskelstroms im Tetanus. 183

Versuch Nr. 75.

Boussolableitung von Contact $a$ aus 77.0-78.0, von Contact $b$ aus $77.975-78.975$.

Ableitungsdauer $=1$ Rheotomgrad $=0,002$ Sec.

Intervall $=0,975$ Rheotomgrad $=0,00195$ Sec.

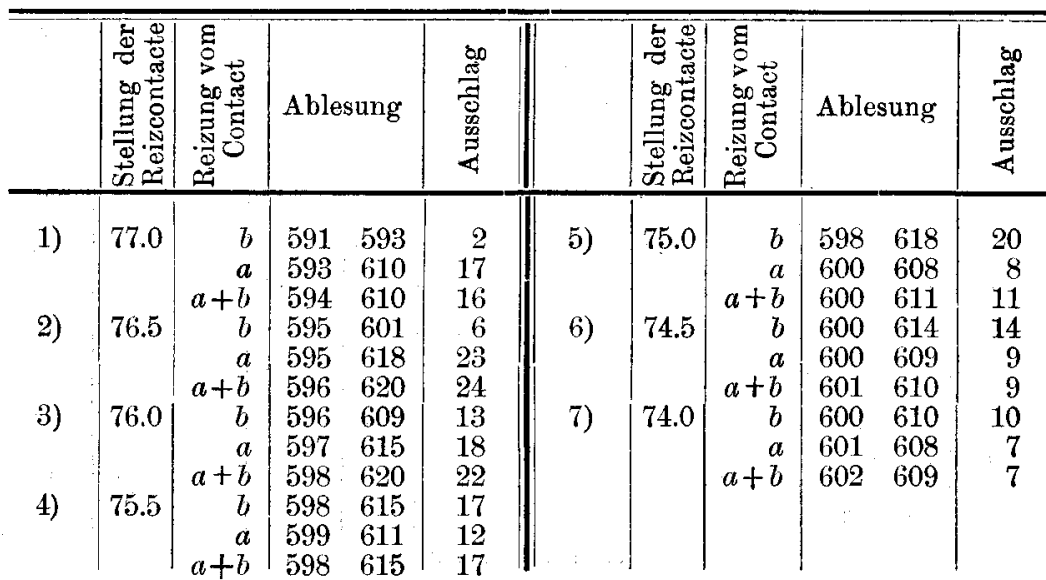

Hierzu Schwankungscurve Nr. 1 der beigegebenen Curventafel.

Versuch Nr. 76.

Die Versuchsconstanten wie bei Versuch Nr. 75.

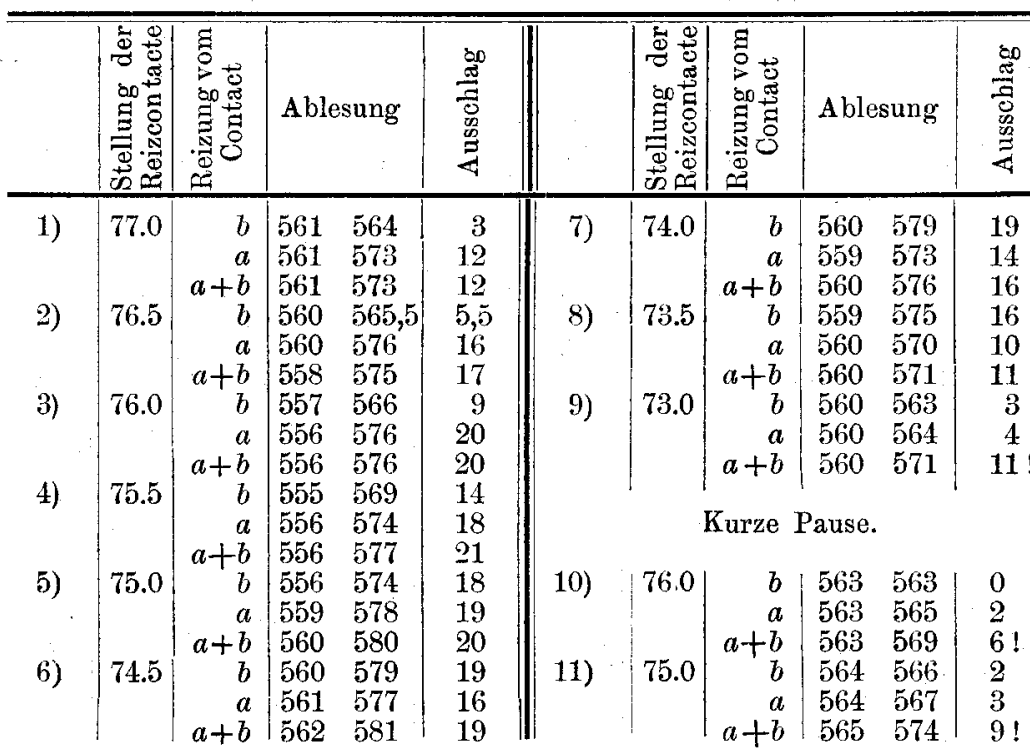

Von der Reizcontacteinstellung 73.0 an können die erhaltenen Aus* schläge zur graphischen Darstellung nicht mehr verwendet werden, da hier die auf Seite 158 beschriebenen Erregbarkeitsveränderungen eintreten. Hierzu Curve Nr. 2. 
Versuch Nr. 78.

Die Constanten wie bei Versuch $\mathrm{Nr}$. 75 .

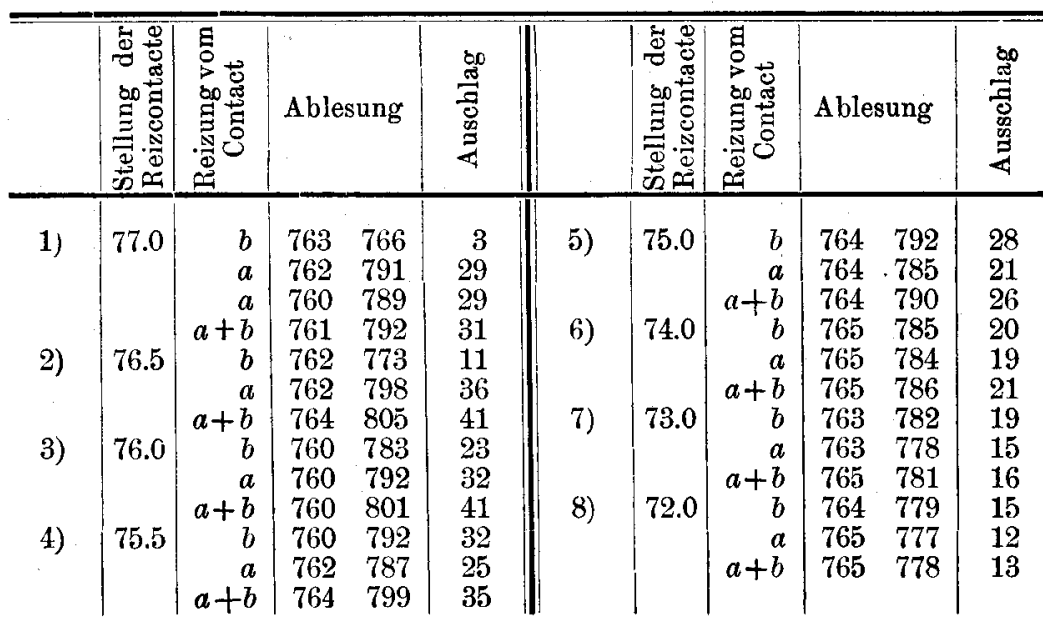

Hierzu Curve Nr. 3.

Versuch Nr. 79.

Intervall $=2$ Rheotomgrad $=0,004$ Sec.

Die übrigen Constanten wie sonst.

\begin{tabular}{|c|c|c|c|c|}
\hline & 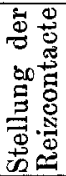 & 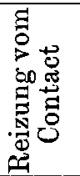 & Ablesung & 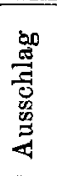 \\
\hline 1) & 76.5 & $b$ & $775 \quad 805$ & 30 \\
\hline \multirow[t]{3}{*}{ 2) } & 77.0 & $b$ & $775 \quad 787$ & 12 \\
\hline & & & $775 \quad 785$ & 10 \\
\hline & & $a+b$ & $775 \quad 791$ & 16 \\
\hline \multirow[t]{3}{*}{ 3) } & 76.0 & $b$ & $775 \quad 807$ & 32 \\
\hline & & & $778 \cdot 790$ & 12 \\
\hline & & $a+b$ & $\begin{array}{l}776 \quad 800 \\
76\end{array}$ & 24 \\
\hline \multirow[t]{3}{*}{ 4) } & 75.0 & $b$ & $778 \quad 792$ & 14 \\
\hline & & & $\begin{array}{ll}778 & 787\end{array}$ & 9 \\
\hline & & $a+b$ & $779 \quad 790$ & 11 \\
\hline \multirow[t]{2}{*}{ 5) } & 74.0 & $b$ & $780 \quad 790$ & 10 \\
\hline & & $a$ & $\begin{array}{ll}781 & 789 \\
782 & 709\end{array}$ & 8 \\
\hline \multirow{3}{*}{ 6) } & 73.0 & ${ }^{a \top}{ }_{b}$ & $\begin{array}{l}100 \\
784\end{array}$ & 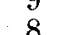 \\
\hline & & $a$ & $785 \quad 790$ & 5 \\
\hline & & $a+b$ & $786 \quad 795$ & 9 \\
\hline
\end{tabular}

\begin{tabular}{|c|c|c|c|}
\hline 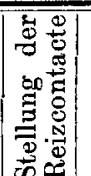 & 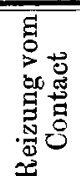 & Ablesung & 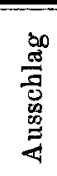 \\
\hline
\end{tabular}

Der Rest des Versuches lautet wie folgt:

\begin{tabular}{lll|ll|l}
$7)$ & $\mid 77.0$ & $b$ & 786 & 792 & 6
\end{tabular}

8) $\quad 76.5 \mid$\begin{tabular}{r|rr|r}
$a$ & 789 & 794 & 5 \\
$a+b$ & 792 & 804 & $12 !$
\end{tabular} 8) $\quad$\begin{tabular}{l|r|rr|r}
76.5 & $b$ & 794 & 802 & 8 \\
$a$ & 794 & 796 & 2 \\
$a+b$ & 796 & 810 & $14 !$
\end{tabular}

Pause.

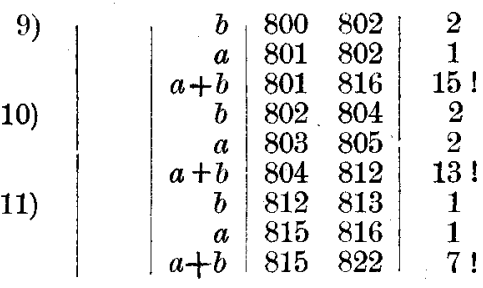

Vergleiche Seite 158. 
Versuche über den zeitlichen Verlauf des Muskeistroms im Tetanus. 185

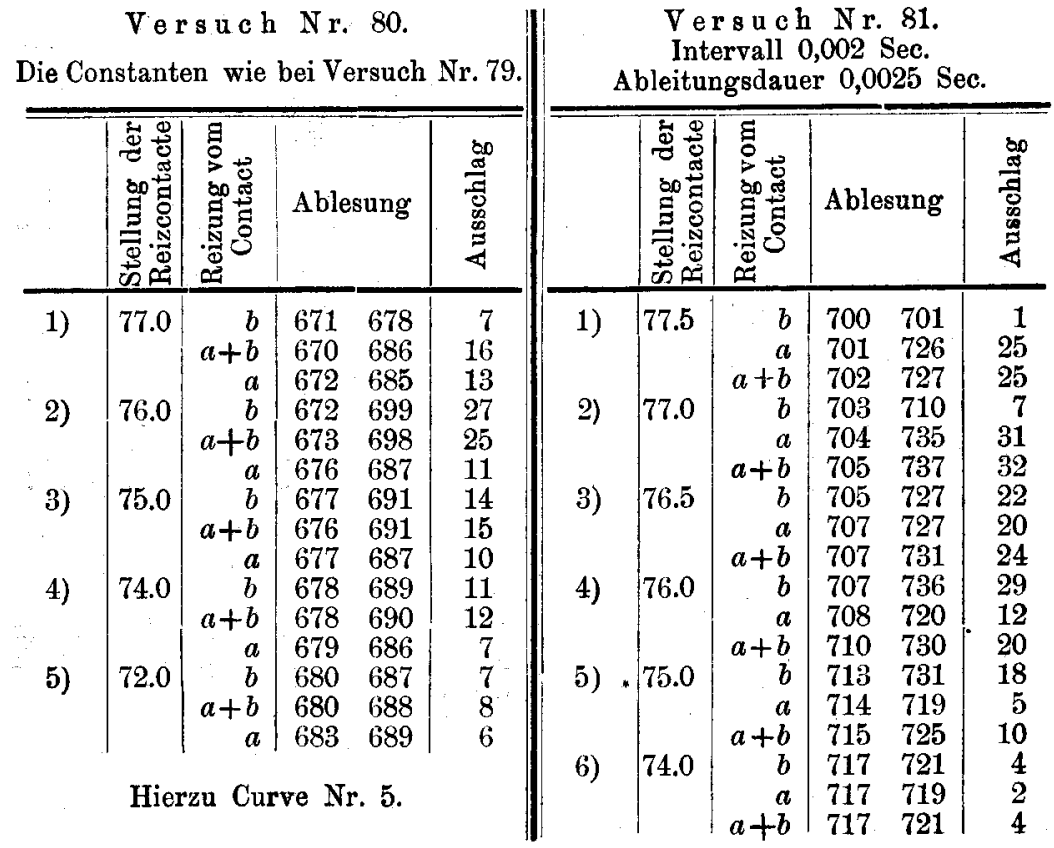

Hierzu Curve Nr. 6.

Versuch Nr. 82.

Die Constanten wie die des Versuches Nr. 81 .

Die Boussole war sehr empfindlich gemacht.

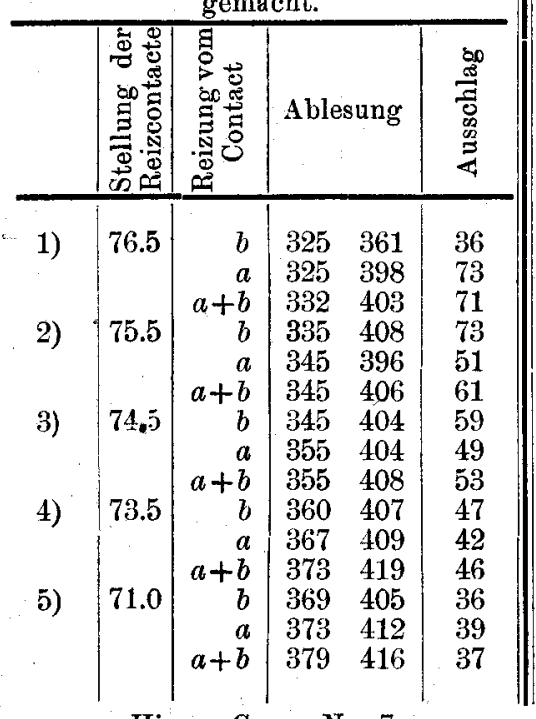

Hierza Curve Nr. 7.

Die Constanten wie bei Versuch 81 .

\begin{tabular}{|c|c|c|c|c|c|}
\hline \multicolumn{2}{|c|}{ 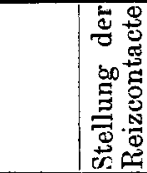 } & 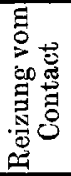 & \multicolumn{2}{|c|}{ Ablesung } & 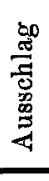 \\
\hline 1) & 77.0 & $b$ & 381 & 385 & 4 \\
\hline & & & & 410 & 30 \\
\hline & & $a+b$ & 382 & 413 & 31 \\
\hline 2) & 76.5 & $b$ & 382 & 393 & 11 \\
\hline & & & 384 & 417 & 33 \\
\hline 3) & 76.0 & & 390 & 414 & 24 \\
\hline & & & 393 & 424 & 31 \\
\hline & & $a+b$ & 395 & 427 & 32 \\
\hline 4) & 75.0 & & 393 & 422 & 29 \\
\hline & & $a+h$ & 394 & 412 & 18 \\
\hline 5) & 74.0 & $b$ & 398 & 418 & 20 \\
\hline & & & 400 & 411 & 11 \\
\hline & & $\begin{array}{r}a \\
a+b\end{array}$ & & $\begin{array}{l}412 \\
417\end{array}$ & $\begin{array}{l}10 \\
16\end{array}$ \\
\hline
\end{tabular}

Hierzu Curve Nr. 8. 
Versueh N r. 85. Die Versuchsconstanten wie bei Versuch 81.

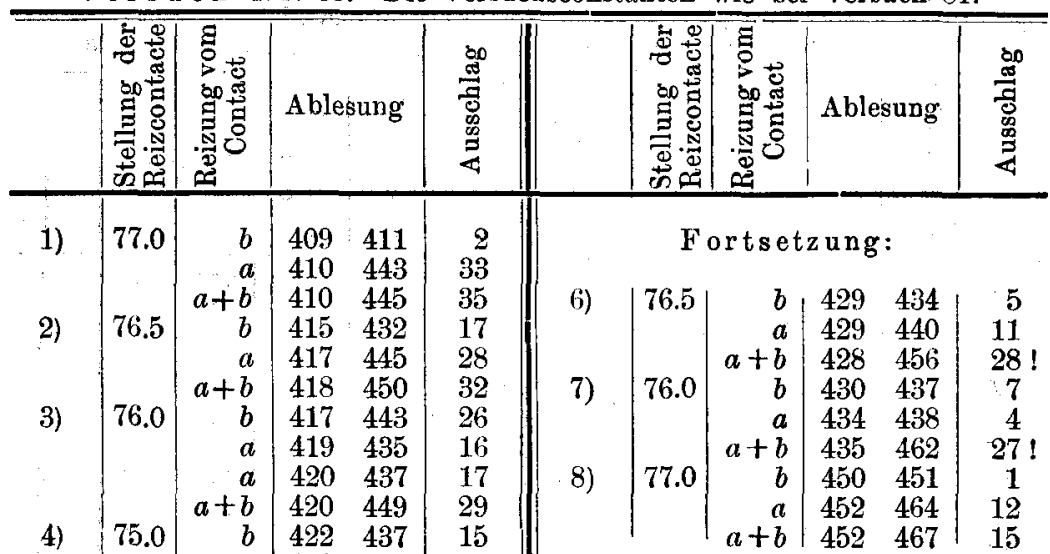

5)

5) $\quad 74.0 \mid$\begin{tabular}{r|rr|r}
$a$ & 422 & 429 & 7 \\
$a+b$ & 422 & 439 & 17 \\
$b$ & 422 & 431 & 9 \\
$a$ & 423 & 428 & 5 \\
$a+b$ & 424 & 437 & 13
\end{tabular}

Aus den nachfolgenden Ablesungen Nr. 9-14 inclusive ist die Curve Nr. II dieses Versuches construirt.

Aus den vorstehenden Messungen ist die Curve I des Versuches Nr. 85 auf der beigegebenen Curventafel construirt. Im weiteren Versuchsverlauf stellen sich (vielleicht schon bei dem Ablesungsturnus $\mathrm{Nr} .5$ beginnend) die characteristischen Ermüdungsveränderungen eiv. Die nächsten drei $\mathrm{Ab}$ lesungsserien konnten daher nicht zur Curvenconstruction verwendet werden.

\begin{tabular}{r|r|r|rr|r}
$9)$ & 77.5 & $a+b$ & 455 & 460 & 5 \\
$10)$ & 77.0 & $\#$ & 458 & 467 & 9 \\
$11)$ & 76.0 & $"$ & 460 & 481 & 21 \\
$12)$ & 75.0 & $"$ & 460 & 471 & 11 \\
$13)$ & 74.0 & $\#$ & 460 & 467 & 7 \\
$14)$ & 73.0 & $"$ & 464 & 468 & 4 \\
$15)$ & 76.0 & $"$ & 468 & 487 & 19 \\
$16)$ & 77.5 & $\#$ & 468 & 469 & 1 \\
$17)$ & 77.0 & $"$ & 463 & 465 & 2 \\
$18)$ & 76.5 & $"$ & 460 & 466 & 6
\end{tabular}

Versuch Nr. 88. Die Versuchsconstanten wie bei Versuch 81.

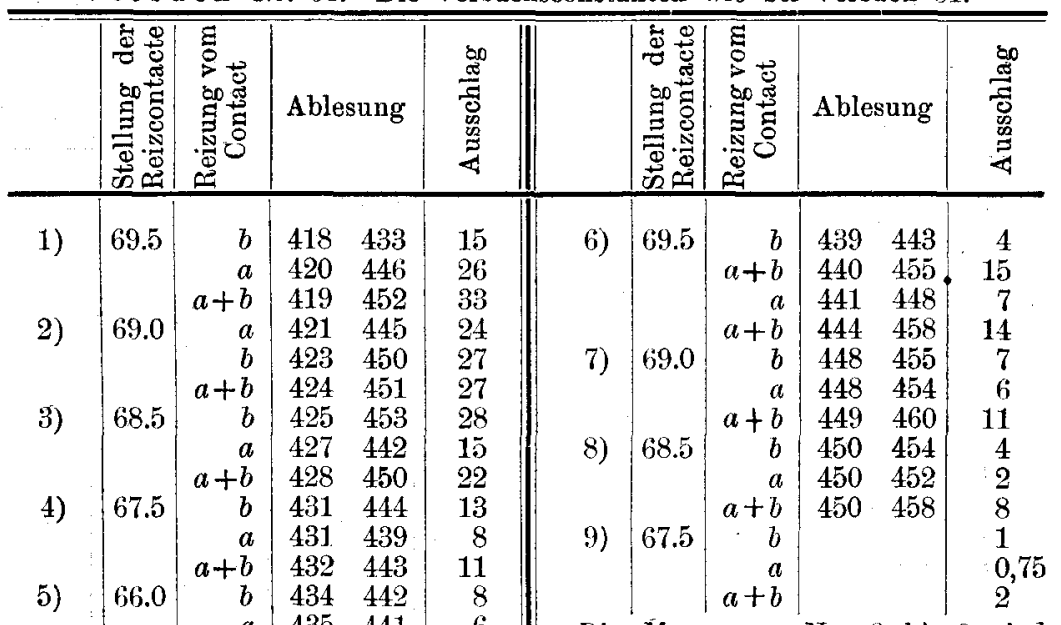

Die Messungen Nr. 6 bis 9 sind \begin{tabular}{r|rr}
$a$ & 435 & 441 \\
$a+b$ & 436 & 444
\end{tabular}

Hierzu Curve I dieses Versuches gehörig. verwendet zur Construction der Curve II dieses Versuches. 
Versuche über den zeitlichen .Verlauf des Muskelstroms im Tetanus. 187

Versuch Nr. 90.

Versuch am blutdurchströmten Muskel mit dreifacher Reizung.

Boussolableitung vom Contact a 73.8-72.75, vom Contact $b \quad 72.55-71.5$, vom Contact $c$ 71.1-71.0. Boussolschluss 1,050, Intervall $a b 1,25^{0}, a c 2,7^{\circ}$. $1^{0}=0,002$ Secunden.

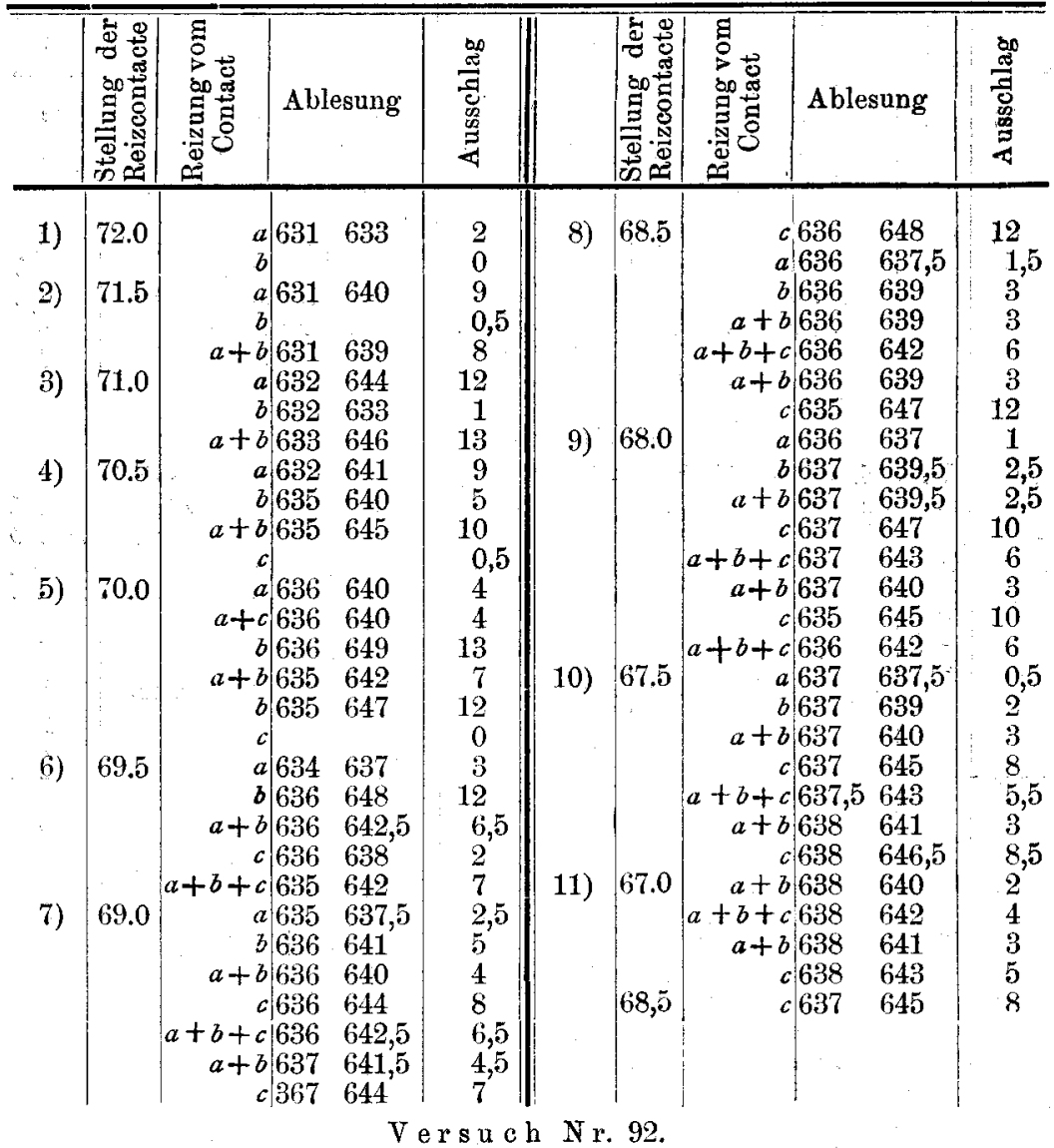

Versuch mit dreifacher Reizung am blutdurchströmten Muskel.

Boussolschluss von Contact $a 76.05-75.1=0,95^{\circ}$, von Contact $b 73.85-72.95$ $=0,9^{0}$, von Contact $c 71.75-70.70=0,95^{\circ}$. Intervall $a b=2,2^{0}, a c=4,3^{\circ}$. 10 der Theilung $=0,002$ Secunden.

Der Ruhestrom lenkt nach den grossen Zahlen ab.

\begin{tabular}{|c|c|c|c|c|c|c|c|c|c|}
\hline$\therefore$ & 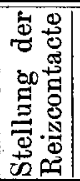 & 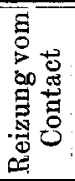 & Ablesung & 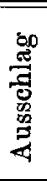 & & 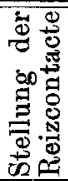 & 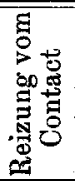 & Ablesung & 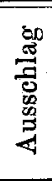 \\
\hline $\begin{array}{l}\text { 1) } \\
\text { 2) } \\
\text { 3) } \\
\text { 4) }\end{array}$ & \begin{tabular}{|l|}
73.5 \\
73.0 \\
72.5 \\
71.5
\end{tabular} & $\begin{array}{l}a \\
a \\
a \\
a\end{array}$ & $\begin{array}{ll}133 & 133 \\
130 & 122 \\
130 & 118 \\
128 & 121\end{array}$ & $\begin{array}{r}0 \\
8 \\
12 \\
7\end{array}$ & 5) & 70.5 & $\begin{array}{r}a \\
b \\
a+b \\
a\end{array}$ & $\begin{array}{rr}128 & 128 \\
128 & 118 \\
129 & 126 \\
129 & 129\end{array}$ & $\begin{array}{r}0 \\
10 \\
3 \\
0\end{array}$ \\
\hline
\end{tabular}


Versuch Nr. 92 (Fortsetzung).

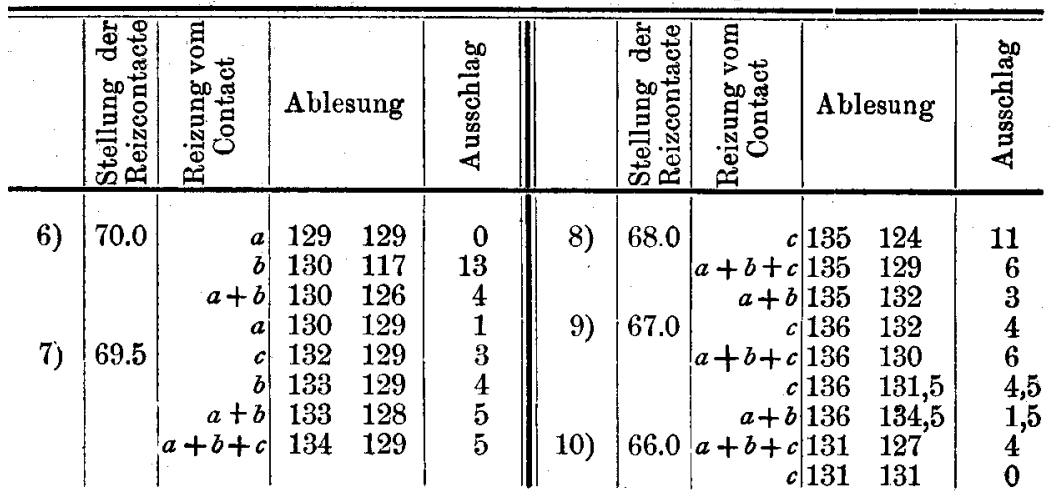

Versuch Nr. 93.

Versuch mit dreifacher Reizung am blutdurchströmten Muskel.

Boussolschluss von Contact $a 76.6-75.65=0,95^{0}$, von Contact $b 74.15-73.15$ $=1^{0}$, von Contact $c 72.0-71.05=0,95^{\circ} .1^{0}=0,002$ Sec. Intervalle $a b$ $2,45^{0}, a \subset 4,6^{\circ}$. Ablenkung durch den Ruhestrom nach den grossen Zahlen.

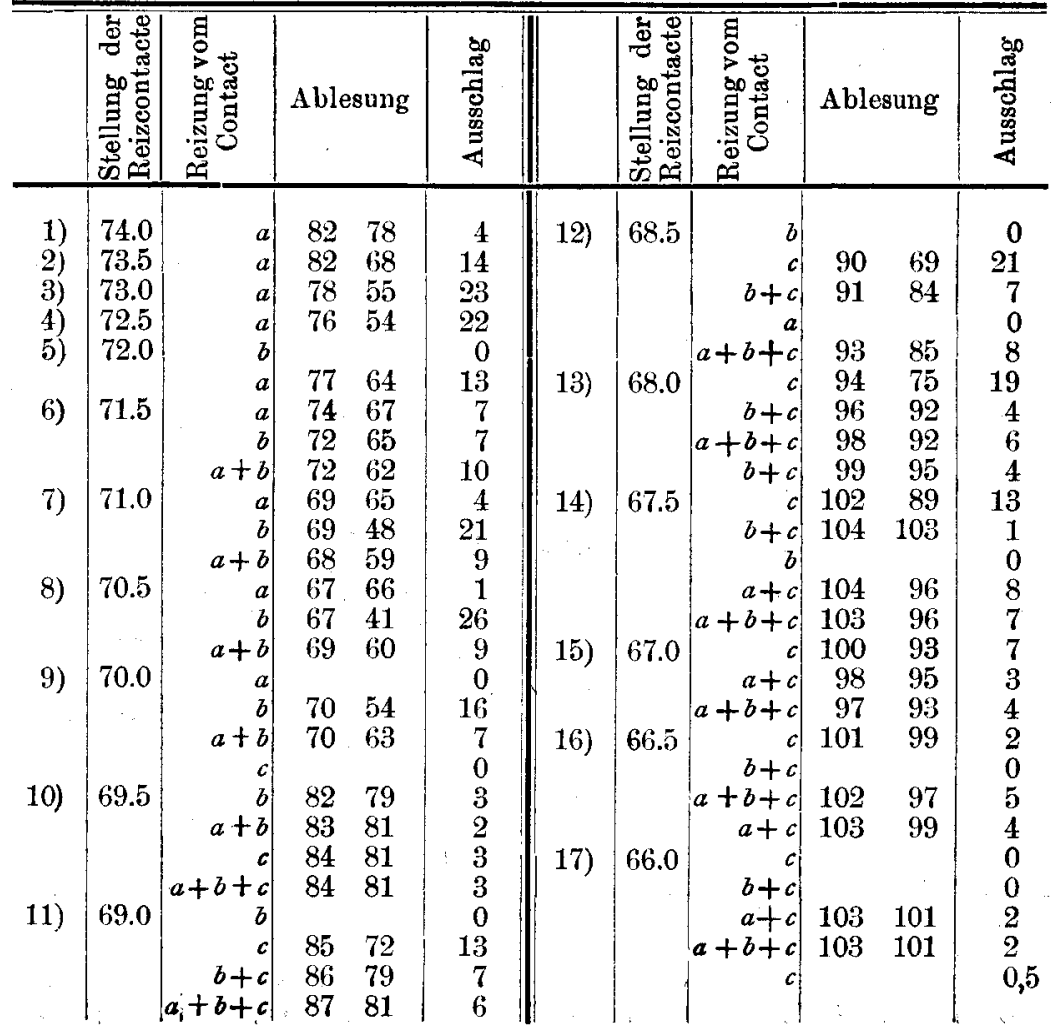


Versuche über den zeitlichen Verlauf dès Muskelstroms im Tetanus. 189

Versuch Nr. 93 (Fortsetzung).

Nach einer nicht systematischen Reihe von Ablesungen werden die Reizintervalle geändert. Intervall $a b$ von jetzt $\mathrm{ab} 3,8^{\circ}, a c 7,6^{\circ}$.

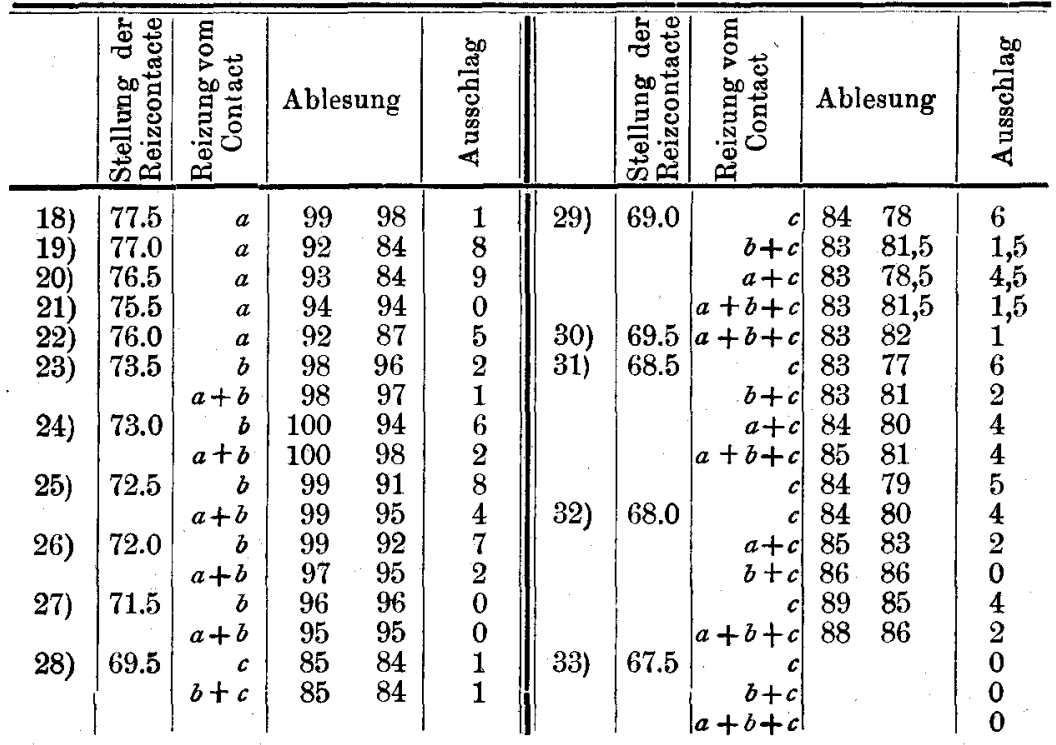

$\mathrm{Zu}$ den Ablesungsserien Nr. 1-17 gehört Curve I, zu den Serien 18-33 Curve II dieses Versuches.

Versuch Nr. 94.

Die Intervalle wie bei Versuch $\mathrm{Nr}$. 93, Ablesungen $\mathrm{Nr}$. 18 bis 33 .

Blutdurchströmter Muskel.

\begin{tabular}{|c|c|c|c|c|c|c|c|c|c|}
\hline & 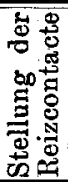 & 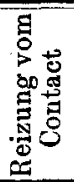 & Ablesung & 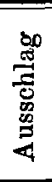 & & 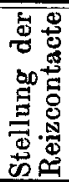 & 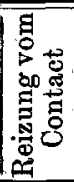 & Ablesung & 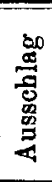 \\
\hline 1) & 77.0 & $a$ & $45 \quad 53$ & 8 & 10) & 720 & $a$ & $50 \quad 62$ & 12 \\
\hline 2) & 76.5 & $a$ & $38 \quad 54$ & 16 & & & $b$ & 5072 & 22 \\
\hline 3) & 76.0 & $a$ & $40 \quad 62$ & 22 & & & $a+b$ & $47 \quad 63$ & 16 \\
\hline 4) & 75.5 & $a$ & $35 \quad 61$ & 26 & 11) & 71.5 & $a$ & $45 \quad 57$ & 12 \\
\hline 5) & 75.0 & $a$ & $36 \quad 61$ & 25 & & & 6 & $47 \quad 70$ & 23 \\
\hline 6) & 74.5 & $a$ & $36 \quad 54$ & 18 & & & $a+b$ & $47 \quad 61$ & 14 \\
\hline & & & & 0 & 12) & 71.0 & $a$ & $47 \quad 58$ & 11 \\
\hline 7) & 73.5 & $a$ & $20 \quad 33$ & 13 & & & $b$ & $55 \quad 79$ & 24 \\
\hline & & & $56 \quad 61$ & 5 & & & $a+b$ & $54 \quad 68$ & 14 \\
\hline & & $a+b$ & $56 \quad 63$ & 7 & 13) & 70.5 & & $42 \quad 51$ & 9 \\
\hline 8) & 73.0 & & $55 \quad 68$ & 13 & & & & $34 \quad 54$ & 20 \\
\hline & & & $55 \quad 67$ & 12 & & & $a+b$ & $40 \quad 52$ & 12 \\
\hline 9) & 72.5 & $a+b$ & $\begin{array}{ll}54 & 72 \\
55 & 68\end{array}$ & 18 & 14) & 70.0 & $a$ & $47 \quad 55$ & 8 \\
\hline & & $\begin{array}{r}b \\
a+b\end{array}$ & $\begin{array}{ll}55 & 72 \\
53 & 68\end{array}$ & $\begin{array}{l}17 \\
15\end{array}$ & & & $a+b$ & $49 \quad 60$ & 11 \\
\hline
\end{tabular}


Versuch Nr. 94 (Fortsetzung).

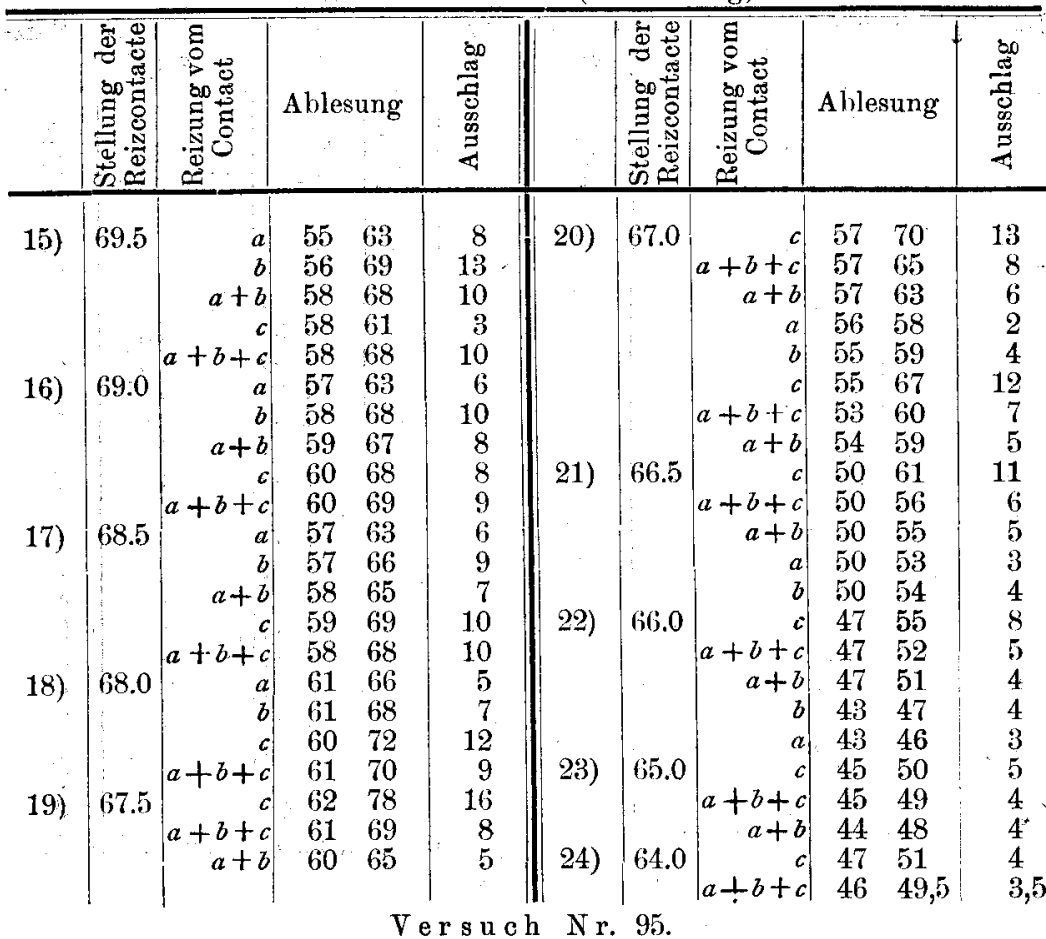

Boussolschluss $a 79.9-81.3, b \quad 73.5-74.9, c 68.6-70.0=1,4^{0}=0,0028$ Sec. Intervalle $a b=6,4^{0}=0,0128$ Sec., $a c=11,3^{0}=0,226 \mathrm{Sec}$

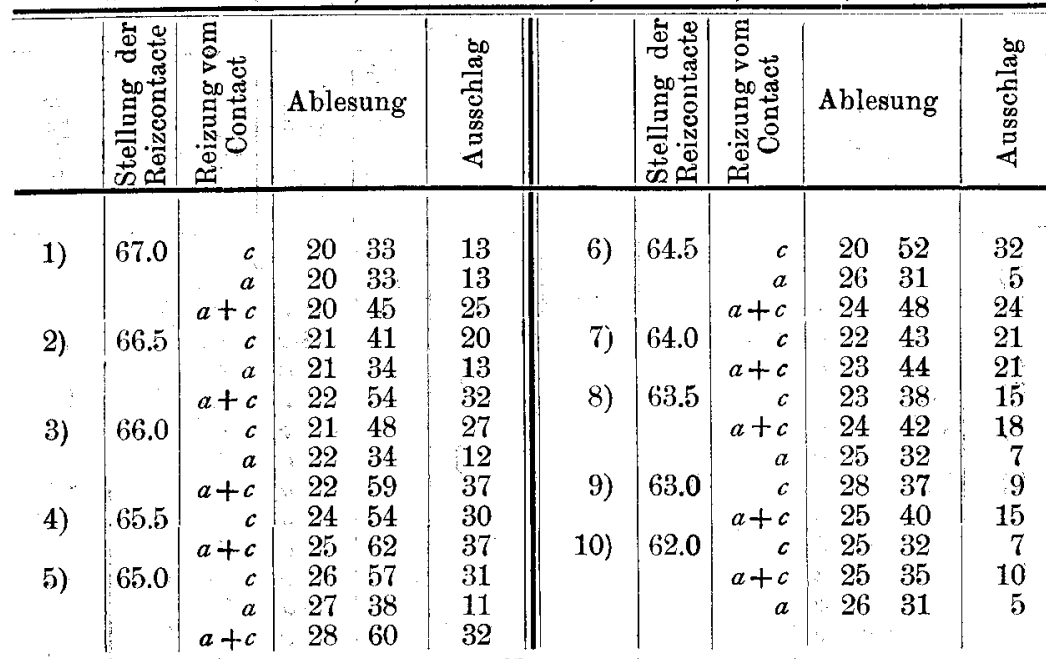

Nach den Ergebnissen der Messungen Nr. 1-10 ist Curve I dieses Versuches construirt. Die auf die Strecke $78,0^{\circ}-67,0^{\circ}$ des Rheotoms entfallenden Werthe der $a$ Schwankung sind nach den correspondirenden Messungen der $c$-Schwank. ergänzt. 
Versuche über den zeitlichen Verlauf des Muskelstroms im Tetanus. 191

Versuch Nr. 95 (Fortsetzung).

\begin{tabular}{|c|c|c|c|c|c|c|c|c|c|c|c|}
\hline & 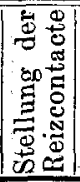 & 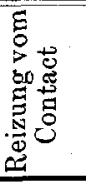 & \multicolumn{2}{|c|}{ Ablesung } & 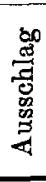 & & 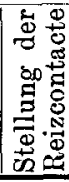 & 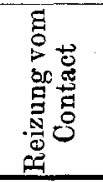 & \multicolumn{2}{|c|}{ Ablesung } & 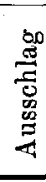 \\
\hline 11) & 77.5 & $a$ & 44 & 52 & 8 & 27) & 675 & & 50 & 52 & 2 \\
\hline 12) & 77.0 & $a$ & 45 & 57 & 12 & & & $b+c$ & 49 & 56 & 7 \\
\hline 13) & 76.5 & $a$ & 47 & 61 & 14 & & & $b$ & 48 & 50 & $\dot{2}$ \\
\hline 14) & 76.0 & $a$ & 46 & 61 & 15 & & & $a+b$ & 47 & 51 & $\overline{4}$ \\
\hline 15) & 75.0 & $a$ & 47 & 55 & 8 & & & $a+b+c$ & 45 & 51 & 6 \\
\hline 16) & 74.0 & & & 51 & 3 & 28) & 67.0 & & 43 & 47 & 4 \\
\hline 17) & 73.0 & " & & & $\begin{array}{l}0 \\
0\end{array}$ & & & $\begin{array}{l}b+c \\
a+b\end{array}$ & $\begin{array}{l}43 \\
45\end{array}$ & $\begin{array}{l}50 \\
49\end{array}$ & $\begin{array}{l}7 \\
4\end{array}$ \\
\hline 18) & 79.5 & & $\begin{array}{l}52 \\
53\end{array}$ & $\begin{array}{l}55 \\
56\end{array}$ & $\begin{array}{l}3 \\
3\end{array}$ & & & $a+b+c$ & 70 & 79 & $\begin{array}{l}\mathbf{4} \\
9\end{array}$ \\
\hline & & $a+b$ & 53 & 59 & 6 & 29) & 66.5 & $a+b$ & 71 & $\begin{array}{l}74 \\
78\end{array}$ & $\begin{array}{l}4 \\
7\end{array}$ \\
\hline 19) & 72.0 & & & & $\begin{array}{l}5 \\
3\end{array}$ & & & $\begin{array}{l}b+c \\
a+b\end{array}$ & $\begin{array}{l}72 \\
73\end{array}$ & $\begin{array}{l}80 \\
76\end{array}$ & $\begin{array}{l}8 \\
3\end{array}$ \\
\hline & & $a+b$ & 53 & 62 & 9 & & & $a+b+c$ & 74 & 81 & 7 \\
\hline 20) & 71.5 & $\begin{array}{r}b \\
a+b\end{array}$ & $\begin{array}{l}53 \\
53\end{array}$ & $\begin{array}{l}62 \\
65\end{array}$ & $\begin{array}{r}9 \\
12\end{array}$ & $30)$ & 66.0 & $a+b$ & $\begin{array}{l}74 \\
75\end{array}$ & $\begin{array}{l}77 \\
82\end{array}$ & $\begin{array}{l}3 \\
7\end{array}$ \\
\hline & & & 54 & 57 & 13 & & & 3 & 78 & 86 & 8 \\
\hline 21) & 71.0 & $b$ & 53 & 64 & 11 & $31)$ & 65.5 & & 101 & 106 & 5 \\
\hline & & 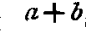 & 53. & 65 & 12 & & & $a+b$ & 101 & 104 & 3 \\
\hline & & & 64 & 57 & 3 & & & $a+b+c$ & 102 & 109 & 7 \\
\hline 22) & 70.0 & & 54 & 68 & 14 & 32) & 64.5 & & 102 & 104 & 2 \\
\hline 23) & 70.0 & & 58 & 68 & 10 & & & $\begin{array}{r}a+b \\
a+b+c\end{array}$ & $\begin{array}{l}101 \\
101\end{array}$ & $\begin{array}{l}103 \\
105 .\end{array}$ & 2 \\
\hline & & $a+b$ & 59 & 69 & 10 & 33) & 63.5 & & 100 & 101 & 1 \\
\hline & & & 60 & 62 & 2 & & & $a+b$ & 100 & 102 & 2 \\
\hline 24) & 69.5 & $b$ & 61 & 66 & 5 & & & $a+b+c$ & 100 & 100 & 2 \\
\hline
\end{tabular}

Nach den Messungen 11-33 ist die Curve II dieses Versuches construirt. Nach dem Verlauf der $a$-Schwankung muss angenommen werden; dass in der Angabe des Boussolsuhlusses $a$ ein Fehler von $1^{0}$ gemacht ist; das Intervall $a b$ wäre dann statt $6^{2}, 4^{0}$ nur $5,4^{0}$, und das Intervall $a c$ statt $11,3^{\circ}$ nur $10,3^{\circ}$, bez. 0,0108 und 0,0206 Sec.

Versuch Nr. 96

Boussolschluss $1,1^{0}=0,0022$ Sec. Die Intervalle wie bei Versuch Nr. 95. Man vergleiche jedoch die Bemerkung am Schluss des vorigen Versuches, welche ebenfalls für diesen Versuch gilt.

\begin{tabular}{|c|c|c|c|c|c|c|c|c|c|}
\hline & 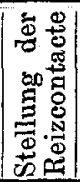 & 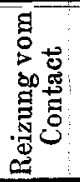 & Ablesung & 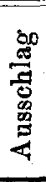 & & 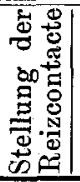 & 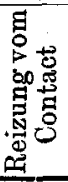 & Ablesung & 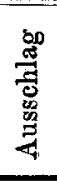 \\
\hline $\begin{array}{l}\text { 1) } \\
\text { 2) } \\
\text { 3) } \\
\text { 4) }\end{array}$ & $\mid \begin{array}{l}78.0 \\
77.5 \\
77.0 \\
76.0\end{array}$ & $\begin{array}{l}a \\
a \\
a \\
a\end{array}$ & $\begin{array}{ll}40 & 45 \\
42 & 56 \\
44 & 65 \\
45 & 73\end{array}$ & $\begin{array}{r}5 \\
14 \\
21 \\
28\end{array}$ & $\begin{array}{l}\text { 5) } \\
6)\end{array}$ & $\begin{array}{l}75.0 \\
\mathbf{7 4 . 0}\end{array}$ & $\begin{array}{l}a \\
a \\
b\end{array}$ & $\begin{array}{ll}45 & 60 \\
46 & 49\end{array}$ & $\begin{array}{r}15 \\
3 \\
0\end{array}$ \\
\hline
\end{tabular}


Versuch Nr. 96 (Fortsetzung).

\begin{tabular}{|c|c|c|c|c|c|}
\hline & 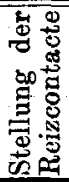 & 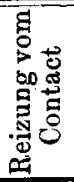 & \multicolumn{2}{|c|}{ Ablesung } & 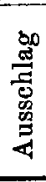 \\
\hline 7) & 73.5 & $a$ & 45 & 48 & 3 \\
\hline \multirow[t]{2}{*}{ 8) } & 73.0 & $a$ & 44 & 47 & 3 \\
\hline & & $b$ & 46 & 47 & 1 \\
\hline 9) & 72.5 & $b$ & 46 & 48 & 2 \\
\hline \multirow[t]{2}{*}{ 10) } & 72.0 & $b$ & $\begin{array}{l}49 \\
50\end{array}$ & $\begin{array}{l}56 \\
53\end{array}$ & $\begin{array}{l}7 \\
3\end{array}$ \\
\hline & & $a+b$ & 50 & 68 & 18 \\
\hline \multirow[t]{2}{*}{ 11) } & 71.5 & $b$ & 51 & 68 & 17 \\
\hline & 710 & $a+b$ & 52 & 81 & $\begin{array}{l}29 \\
99\end{array}$ \\
\hline \multirow{2}{*}{ 12) } & & & 56 & 59 & 3 \\
\hline & & $a+b$ & 55 & 85 & 30 \\
\hline \multirow[t]{3}{*}{ 13) } & 70.5 & $b$ & 58 & 79 & 21 \\
\hline & & $\begin{array}{l}a+b \\
a+b\end{array}$ & $\begin{array}{l}57 \\
60\end{array}$ & $\begin{array}{l}82 \\
84\end{array}$ & $\begin{array}{l}25 \\
24\end{array}$ \\
\hline & & $a+b$ & 61 & 84 & 23 \\
\hline
\end{tabular}

Von einer $a+b$-Reizung zur anderen Polwechsel in der secundären Spirale.

\begin{tabular}{|c|c|c|c|c|c|}
\hline 14) & 70.0 & $b$ & 63 & 79 & 16 \\
\hline 15) & 69.0 & & $\begin{array}{l}64 \\
64\end{array}$ & $\begin{array}{l}79 \\
67\end{array}$ & $\begin{array}{r}15 \\
3\end{array}$ \\
\hline & & $a+$ & 65 & 75 & 10 \\
\hline & $c 00$ & & 65 & 68 & $\begin{array}{l}3 \\
9\end{array}$ \\
\hline & 00.0 & $a+b$ & 68 & 76 & 8 \\
\hline & & 101 & $\begin{array}{l}69 \\
70\end{array}$ & $\begin{array}{l}72 \\
81\end{array}$ & $\begin{array}{r}3 \\
11\end{array}$ \\
\hline & 67.5 & & 73 & 81 & 8 \\
\hline & & $\begin{array}{r}a \\
a+b\end{array}$ & $\begin{array}{l}71 \\
71\end{array}$ & $\begin{array}{l}78 \\
84\end{array}$ & $\begin{array}{r}7 \\
13\end{array}$ \\
\hline & & & 70 & 72 & 2 \\
\hline & 67.0 & & 69 & 83 & 14 \\
\hline & & $a+$ & 68 & 73 & 5 \\
\hline & & & 68 & 70 & 2 \\
\hline & & & 68 & 70 & 2 \\
\hline a) & 66.5 & & 66 & 83 & 17 \\
\hline & & $a+b$ & 66 & 71 & 5 \\
\hline & & $\mid \begin{array}{r}a+b+c \\
b+c\end{array}$ & $\begin{array}{l}66 \\
67\end{array}$ & $\begin{array}{l}83 \\
82\end{array}$ & 17 \\
\hline & 65.5 & & 69 & 84 & 15 \\
\hline & & $a+b+c$ & 69 & 82 & 13 \\
\hline & & $a+c$ & 70 & 82 & 12 \\
\hline 1) & 64.5 & & 97 & 105 & 8 \\
\hline & & $a+b+c$ & 68 & 76 & 8 \\
\hline & & $b$ & 69 & 70 & 1 \\
\hline & & & 70 & 71 & 1 \\
\hline & 64.0 & $c$ & 96 & 97 & 1 \\
\hline
\end{tabular}

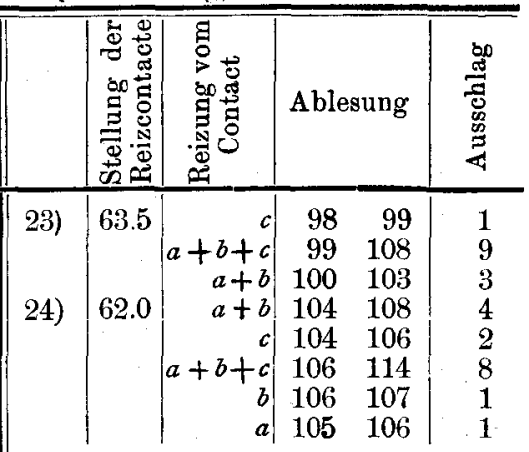

Aus den Messungen 1-24 ist die zu diesem Versuch gehörige Curve construirt. Nach beendeter Messung Nr. 24 wurde, um die klein gewordenen Schwankungen wieder in die Höhe zu treiben, dem Muskel $50 \mathrm{gr}$ directe Belastung angehangen. Wegen eines in der Ablesung $\mathrm{Nr}$. 30 vermuthlich gemachten Ablesungsfehlers habe ich jedoch aus diesen Messungen eine Curve nicht construirt. Die Versuche werden jedoch hier noch citirt, weil auch aus ihnen die Verfrühung des Schwankungsgipfels zu ersehen ist.

25) $|68.0|$\begin{tabular}{r|rl|l}
$c$ & 106 & 109 & 3 \\
$a+b$ & 108 & 110 & 2
\end{tabular}

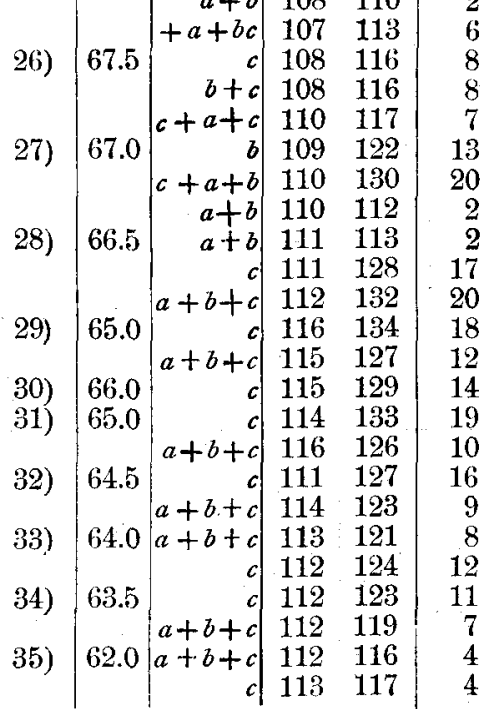


Versuche über den zeitlichen Verlauf des Muskelstroms im Tetanus. 193

Versuch Nr. 97.

Reizung am blutdurchströmten Muskel. Intervalle wie beim vorigen Versuch. Bei der Reizung Nr. 13 fing der Muskel stark an zu bluten, und es wurde desshalb der Versuch nicht bis zur dreifachen Reizung fortgesetzt, sondern vorher abgebrochen.

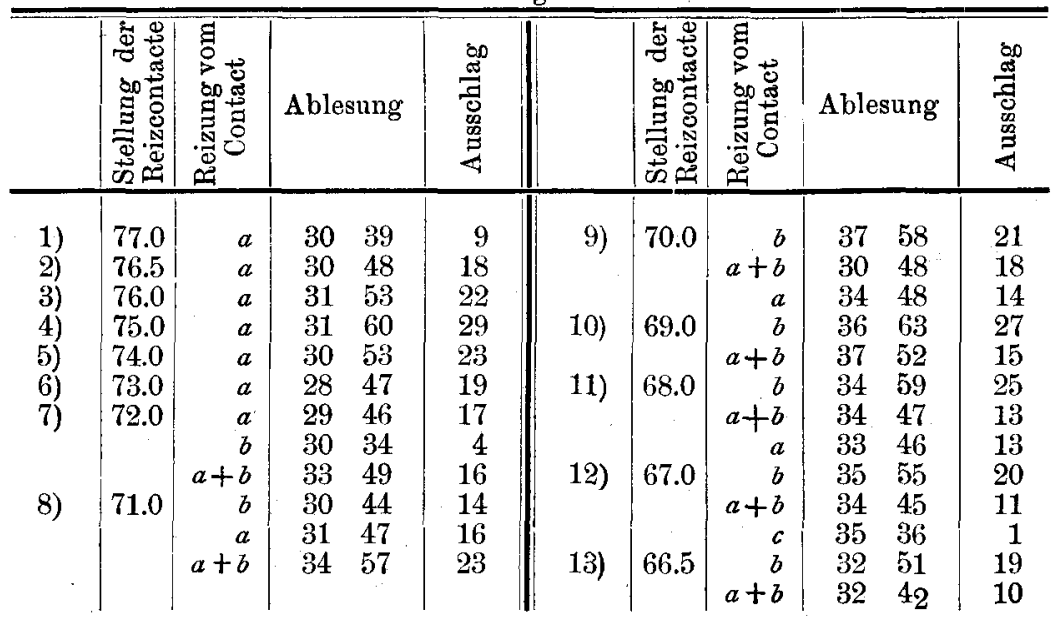

Versuch Nr. 98.

Die Versuchsconstanten wie bei Versuch 95.

\begin{tabular}{|c|c|c|c|c|c|c|c|c|c|c|c|}
\hline & 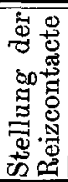 & 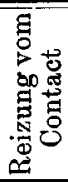 & \multicolumn{2}{|c|}{ Ablesung } & 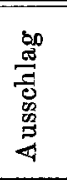 & & 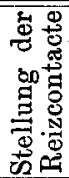 & 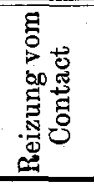 & \multicolumn{2}{|c|}{ Ablesung } & 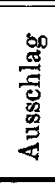 \\
\hline 1) & 78.0 & $a$ & 110 & 117 & 7 & 13) & 69.0 & 0 & 122 & 136 & 14 \\
\hline 2) & 77.5 & $a$ & 113 & 128 & 15 & & & $a+b$ & 122 & 132 & 10 \\
\hline 3) & 77.0 & $a$ & 112 & 136 & 24 & & & $a$ & 124 & 127 & 3 \\
\hline 4) & 76.0 & $a$ & 113 & 133 & 20 & 14) & 68.5 & 0 & 122 & 124 & 2 \\
\hline 5) & 75.0 & $a$ & 115 & 126 & 11 & & & $a+b$ & 120 & 126 & 6 \\
\hline 6) & 74.0 & $a$ & 116 & 123 & 7 & & & $a+b+c$ & 120 & 131 & 11 \\
\hline 7) & 73.0 & $a$ & 118 & 122 & 4 & & & & 122 & 128 & 6 \\
\hline & & $b$ & & & 0 & 15) & 68.0 & & 122 & 129 & 7 \\
\hline 8) & 72.5 & $b$ & 119 & 122 & 3 & & & $a+b+c$ & 123 & 135 & 12 \\
\hline & & & 119 & 122 & 3 & 16) & 67.5 & & 123 & 130 & 7 \\
\hline & & $a+b$ & 119 & 129 & 10 & & & $a+b+c$ & 122 & 135 & 13 \\
\hline 9) & 72.0 & & 121 & 130 & 9 & 17) & 66.5 & & 123 & 135 & 12 \\
\hline & & $a+b$ & 122 & 137 & 15 & & & $a+b+$ & 120 & 131 & 11 \\
\hline 10) & 71.5 & & 123 & 137 & 14 & 18) & 65.5 & & 115 & 127 & 12 \\
\hline & & $a+b$ & 120 & 142 & 22 & & & $a+b+c$ & 117 & 127 & 10 \\
\hline 11) & 71.0 & & 122 & 145 & 23 & 19) & 64.5 & & 119 & 130 & 11 \\
\hline & & $a+b$ & 123 & 144 & 21 & & & $a+b$ & 120 & 129 & 9 \\
\hline & & & 123 & 125,5 & 2,5 & & & $a+c$ & 118 & 123 & 5 \\
\hline 12) & 70.0 & & 123 & 143 & 20 & 20) & 63.5 & & 134 & 139 & 5 \\
\hline & & $a+b$ & 122 & 139 & 17 & & & $a+b$ & 134 & 140 & 6 \\
\hline & & & & & & 21) & 62.5 & & $\begin{array}{l}135 \\
136\end{array}$ & 138 & 3 \\
\hline
\end{tabular}


194 K. Schoenle in: Versuche üb. d. zeitlichen Verlauf d. Muskelstroms etc.

Nachtrag zur vorstehenden Arbeit.

(Vgl. die Fussnote S. 181.)

Versuch Nr. 87.

Die Versuchsconstanten wie bei Versuch 81.

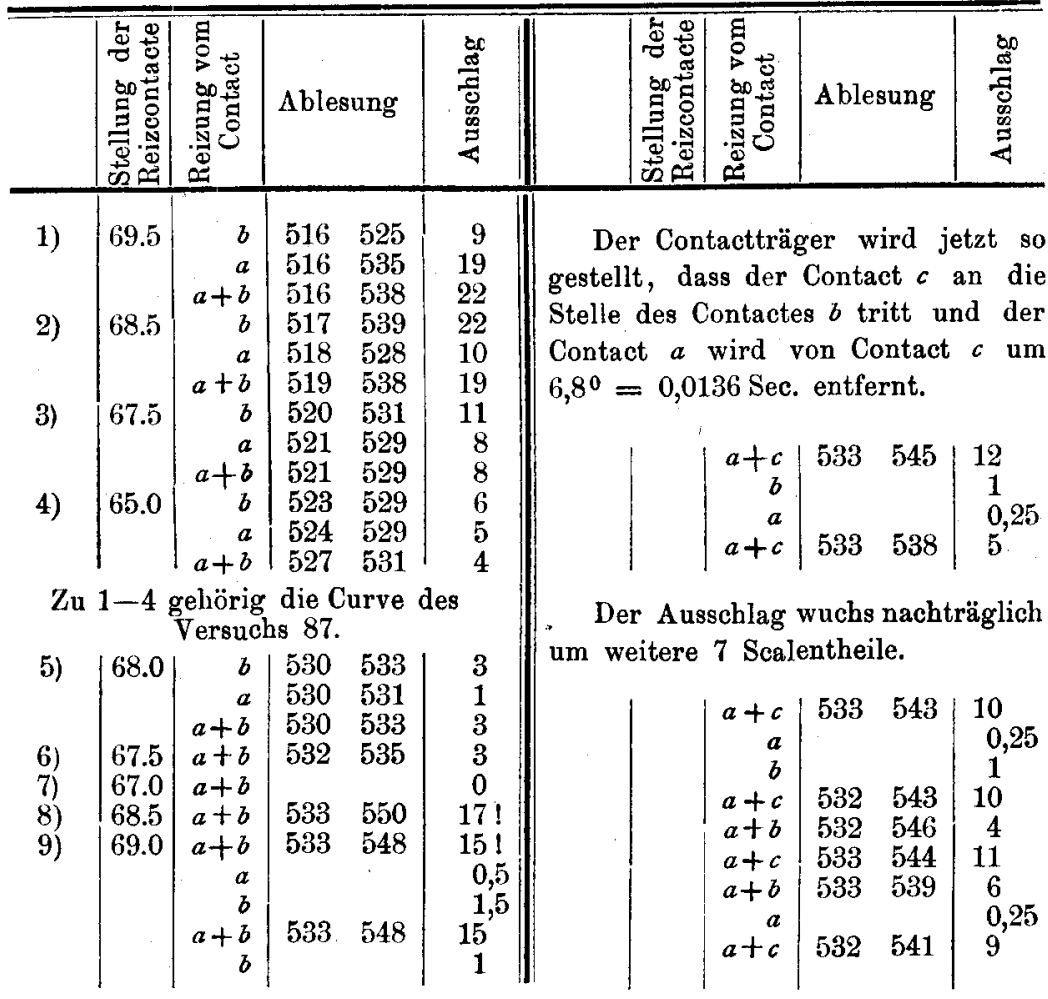



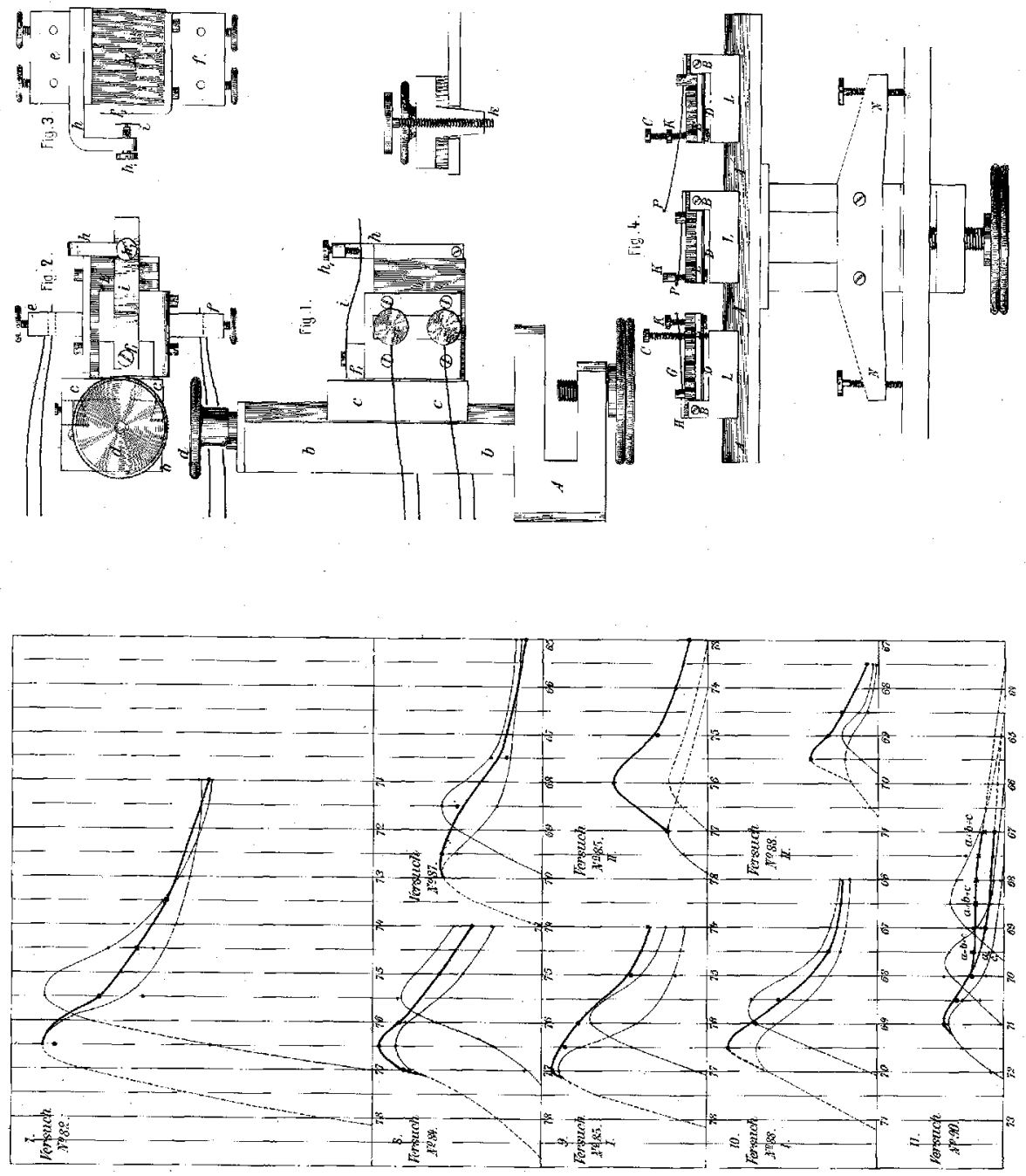

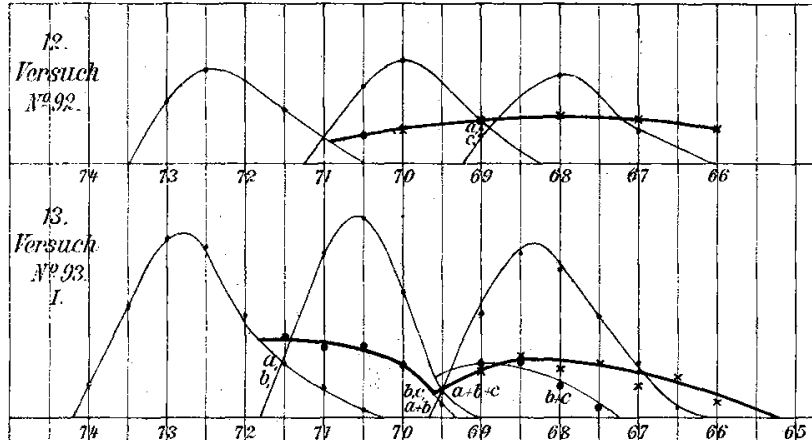

dy.

torstuch
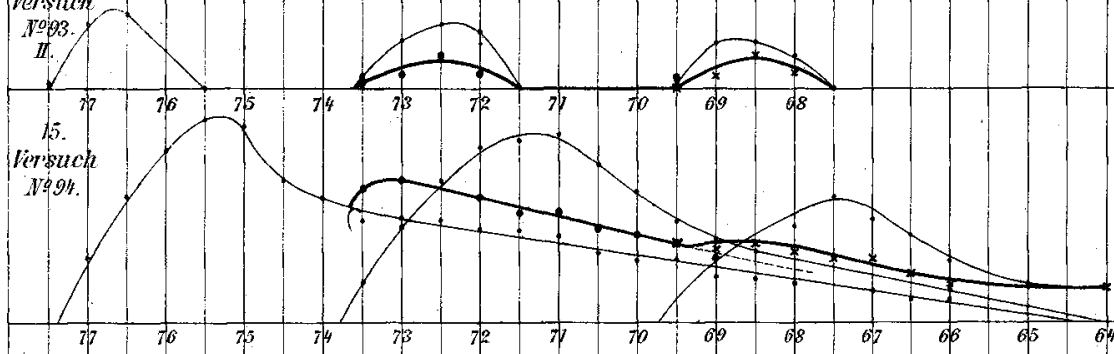

16

bensuch

vo 95

I.

Tersuct Wobs. I.
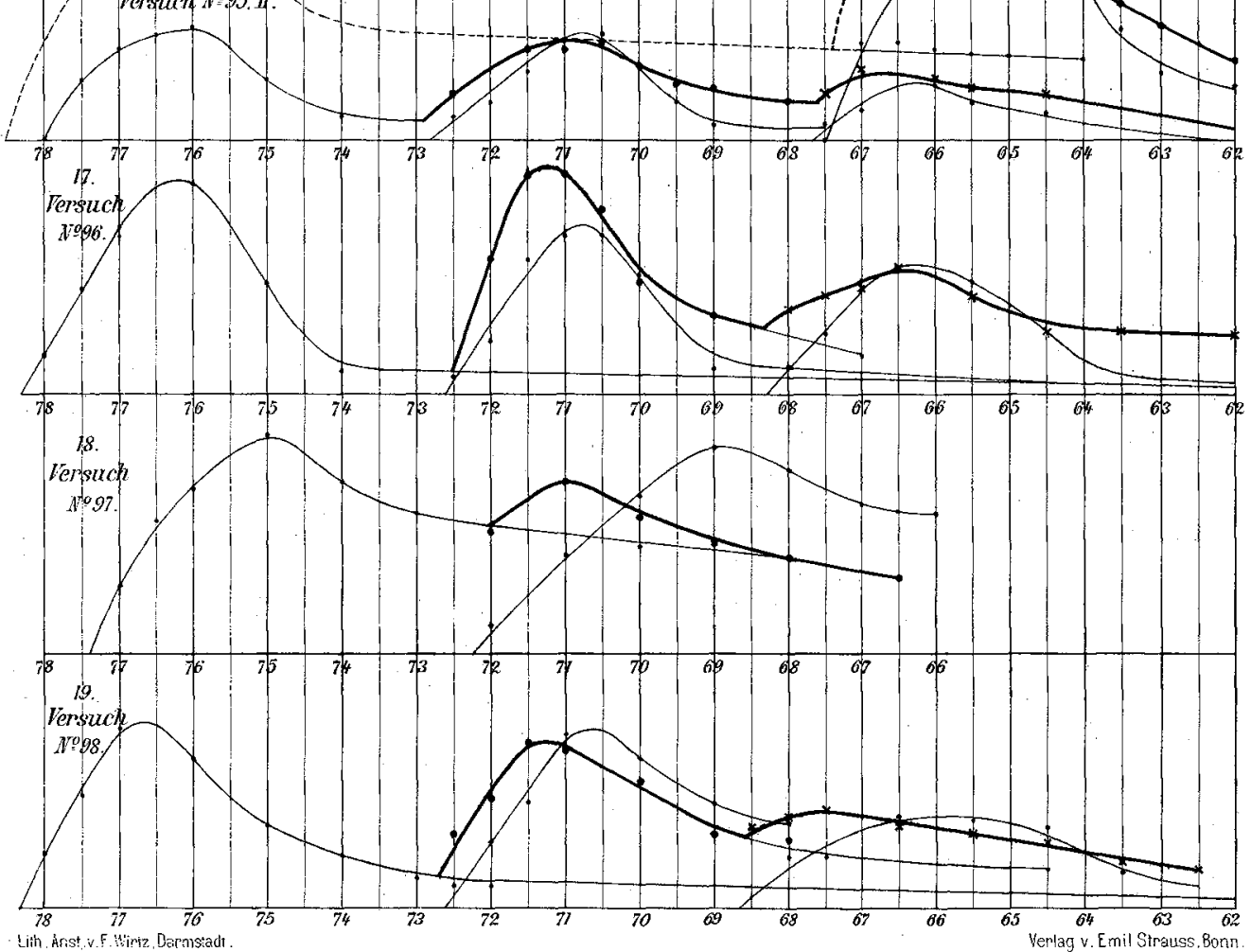